AUTARQUIA ASSOCIADA À UNIVERSIDADE DE SÃO PAULO

Características de amidos processados pela radiação ionizante

Bruna Saporito Teixeira

Dissertação apresentada como parte dos requisitos para obtenção do Grau de Mestre em Ciências na Área de Tecnologia Nuclear - Aplicações

Orientadora:

Profa. Dra. Nélida Lúcia del Mastro 


\section{INSTITUTO DE PESQUISAS ENERGÉTICAS E NUCLEARES \\ Autarquia associada à Universidade de São Paulo}

Características de amidos processados pela radiação ionizante

Bruna Saporito Teixeira

Dissertação apresentada como parte dos
requisitos para obtenção do Grau de
Mestre em Ciências na Área
de Tecnologia Nuclear-Aplicações

Orientadora:

Profa. Dra. Nélida Lúcia del Mastro

Versão Corrigida

Versão Original disponível no IPEN

São Paulo

2016 
Aos meus exemplos de vida, Angela e Luiz, por tornarem mais esta elapa possivel. 


\section{AGRADECIMENTOS}

À Prof ${ }^{a}$. Dr ${ }^{a}$. Nélida Lúcia del Mastro, pelos ensinamentos acadêmicos, pela confiança, incentivo, apoio e orientação.

À amiga Dra . Patrícia Yoko Inamura, pelo auxílio e incentivo no início deste trabalho. Pelos treinamentos na utilização dos equipamentos.

À $\operatorname{Dr}^{a}$. Vera Mahira e a Prof ${ }^{a}$. Dra . Mitiko Saiki, pelas sugestões na banca do Seminário de Área.

Ao Dr. Daniel Perez, pelo auxílio e colaboração nas análises de microscopia óptica.

À Dra ${ }^{a}$. Solange Kazumi Sakata e Dra . Luci Diva Brocardo Machado, pela disponibilidade da utilização do laboratório de análises térmicas.

À Dr $^{a}$. Ana Lúcia Exner Godoy e ao Técnico Nildemar, pelo treinamento e utilização do microscópio eletrônico de varredura.

Ao Doutorando Rafael H. L. Garcia, pela disponibilidade, ajuda e contribuição nas análises de difração de raios-X.

À $\mathrm{Dr}^{\mathrm{a}}$. Áurea Beatriz Geraldo, pela disponibilidade da utilização do equipamento de infravermelho FTIR.

Ao Dr. Eder de Carvalho Pincinato e a Dra . Marta Helena Fillet Spoto, por gentilmente terem aceitado o convite de participarem da banca examinadora.

Ao Dr. Leonardo Gondim de Andrade e Silva, pela atenção e apoio em diversos momentos.

Aos Engs. Elizabeth S. R. Somessari e Carlos Gaia da Silveira, pela realização da irradiação das amostras.

Aos colegas do Centro de Tecnologia das Radiações (CTR) e de todos os setores que percorri nesses anos, pelas conversas e troca de informações.

À Comissão Nacional de Energia Nuclear (CNEN) pela concessão da bolsa de mestrado. 
Ao IPEN-USP/SP, pela oportunidade da realização deste trabalho e estrutura disponibilizada.

Ao meu irmão, Cesar, pelo apoio, pela paciência, pela intensa troca de conhecimentos e principalmente pela fraternidade única e inabalável. Você sempre será meu orgulho.

A minha avó, Tilinha, pelos cuidados dispensados à mim todos esses anos me tratando com tanto zelo e carinho.

Ao meu afilhado, Bruno, com toda a sua inocência me faz acreditar em um mundo melhor.

Aos meus padrinhos, Fátima e Benedito (em memória), por sempre torcerem por mim e estarem presentes em todas as etapas da minha vida, quando possível.

Aos meus pais, pelo amor incondicional, por sempre estarem ao meu lado em todas as decisões da minha vida, por todos os esforços e sacrifícios realizados, pela educação e valores transmitidos. Se cheguei aonde estou, devo tudo ao apoio e alicerce que tive em toda a minha vida. 
"Os melhores resultados ha vida são normalmente atingidos por meios simples e o exercício de qualidades comuns. Estes podem, por sua maior parte, ser resumido em dois: bom senso e perseverança" 


\title{
CARACTERÍSTICAS DE AMIDOS PROCESSADOS PELA RADIAÇÃO IONIZANTE
}

\section{Bruna Saporito Teixeira}

\begin{abstract}
RESUMO
O amido é um polissacarídeo produzido pelos vegetais para reserva de energia e está disponível em abundância na natureza. Os amidos são preparados a partir de diferentes matérias primas, tais como trigo, cevada, milho, arroz, batata, batata doce ou mandioca. Na dieta humana o amido é utilizado como fonte de energia biológica. $\mathrm{Na}$ indústria de alimentos, o amido é utilizado para alterar ou controlar diversas características, como textura, aparência, umidade, consistência e estabilidade. Entretanto, há uma contínua procura por novas tecnologias para o desenvolvimento de novas propriedades funcionais para melhor adequação às necessidades do mercado. A radiação ionizante pode ser aplicada na modificação de macromoléculas como a do amido. O presente trabalho teve como objetivo estudar as características de amidos de batata, milho e mandioca (polvilho azedo) tratados com radiação ionizante e os correspondentes filmes comestíveis preparados com eles. Os amidos em pó foram submetidos à radiação em fonte de ${ }^{60}$ Co Gammacell 220 com doses de 0, 1, 5, 10 e 15 kGy, taxa de dose em torno de $1 \mathrm{kGy} \mathrm{h}{ }^{-1}$. Para o estudo dos amidos foram empregadas técnicas de microscopia, análises térmicas, espectroscopia no infravermelho, difração de raios-X e viscosimetria. Para os filmes foram avaliadas propriedades mecânicas, análise instrumental da cor, capacidade de absorção e índice de solubilidade. Constatou-se que a radiação não influenciou a morfologia dos grânulos, a termogravimetria e o padrão de difração de raios-X. A viscosidade dos hidrogéis dos amidos diminuiu com o aumento da dose de radiação e estes apresentaram características de fluidos não-Newtonianos e pseudoplásticos. Na avaliação instrumental da cor dos filmes houve um ligeiro aumento no parâmetro b*(cor amarela). A força de ruptura dos filmes decresceu conforme aumento da dose de radiação aplicada dependendo do tipo de amido empregado na sua fabricação. $A$ capacidade de absorção em água diminuiu e a solubilidade aumentou com a radiação.
\end{abstract}




\title{
FEATURES OF PROCESSED STARCHES BY IONIZING RADIATION
}

\author{
Bruna Saporito Teixeira
}

\begin{abstract}
Starch is a polysaccharide produced by plants for energy reserve and is available in abundance in nature. Starches are prepared from different raw materials such as wheat, barley, corn, rice, potatoes, sweet potatoes or cassava. In the human diet starch is used as a source of biological energy. In the food industry, starch is used to change or control various features, such as texture, appearance, moisture, consistency and stability. However, there is a continuous search for new technologies for the development of new functional properties to better adapt to market needs. Ionizing radiation can be applied to macromolecules such as starch modification. This work aimed to study the characteristics of potato, corn and modified manioc (cassava) starches treated with ionizing radiation and the corresponding edible films prepared with them. The starch powder underwent radiation treatment in a ${ }^{60} \mathrm{Co}$ source Gammacell 220 at doses of $0,1,5,10$ and 15 kGy with dose rate of approximately $1 \mathrm{kGy} \mathrm{h}^{-1}$. Starches were studied using microscopy techniques, thermal analysis, infrared spectroscopy, X-ray diffraction and viscometry. Films were evaluated by mechanical properties, instrumental color analysis, absorption capacity and water solubility. It was found that the radiation did not influence the morphology of the granules, the thermogravimetry and the diffraction pattern of X-rays. The viscosity of the starches hydrogels in general, decreased with increasing radiation dose, due to the degradation of the starch macromolecules, and it can be say that they presented characteristics as nonNewtonian pseudoplastic fluid. The instrumental evaluation of films color showed that there was a slight increase in parameter $b^{*}$ (yellow). The films of the breaking strength decreased as increasing the radiation dose depending on the type of starch used in its manufacture. The water absorption capacity decreased and solubility increased with radiation.
\end{abstract}




\section{SUMÁRIO}

Página

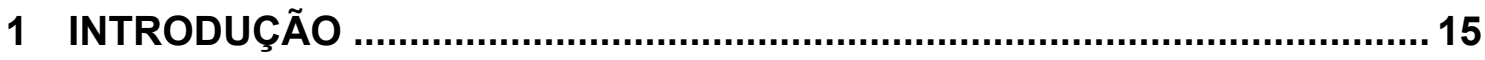

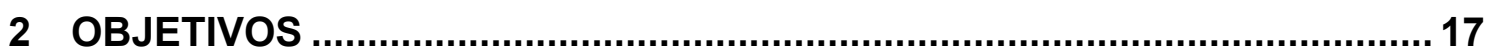

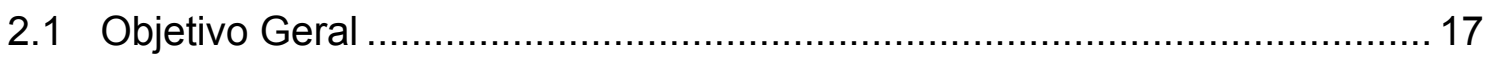

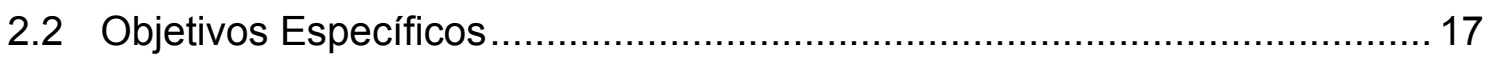

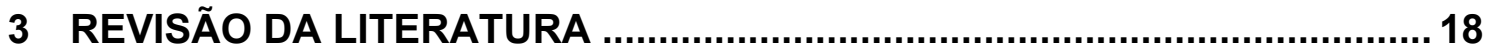

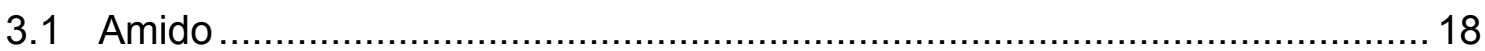

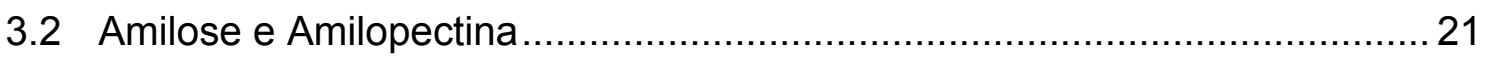

3.3 Solubilidade e poder de inchamento dos grânulos .................................... 28

3.4 Gelatinização do amido.................................................................. 29

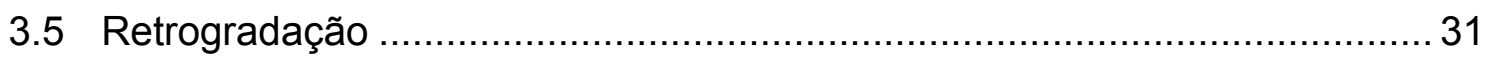

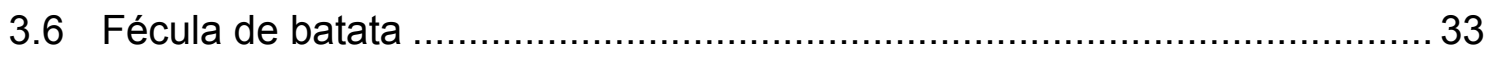

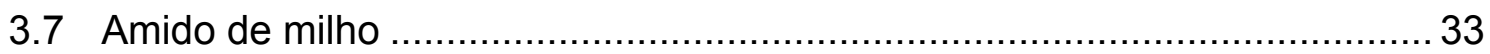

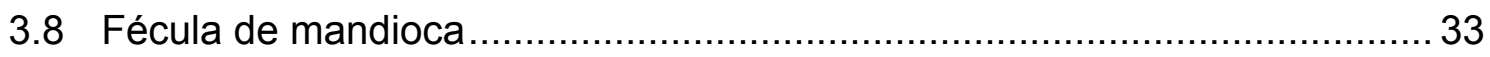

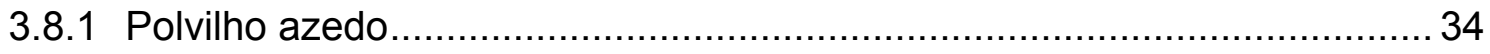

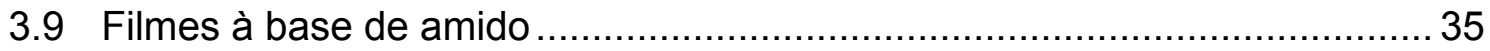

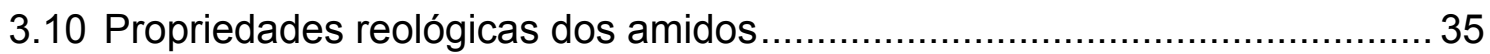

3.11 Análises Térmicas............................................................................. 45

3.12 Microscopia e Espectroscopia de amidos................................................. 46

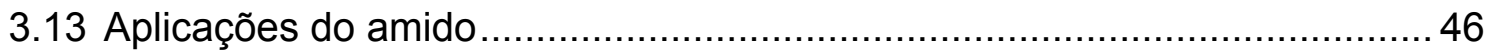

3.14 Processamento de produtos alimentícios pela radiação …..........................47

3.15 Efeito da irradiação sobre o amido .......................................................... 50

4 MATERIAL E MÉTODOS ............................................................................. 52

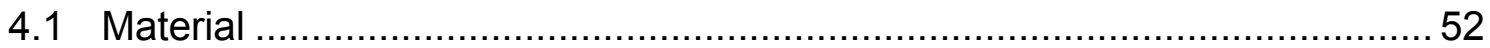

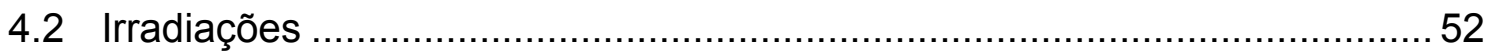

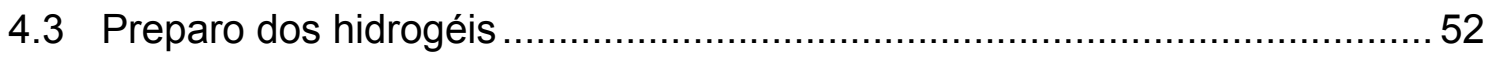

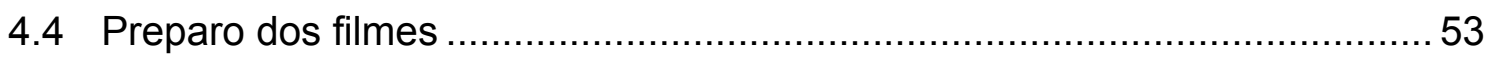

4.5 Análises realizadas nos pós de amidos .............................................. 53

4.5.1 Morfologia e tamanho dos grânulos................................................... 53

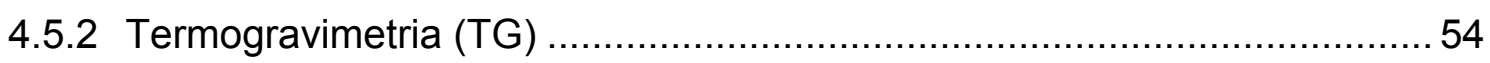

4.5.3 Espectroscopia no Infravermelho por Transformada de Fourier (FTIR) ..... 55 


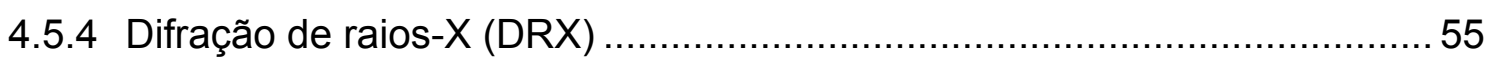

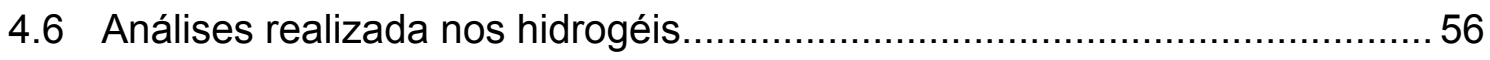

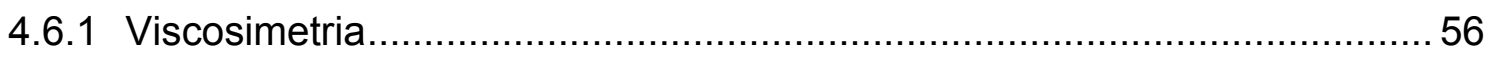

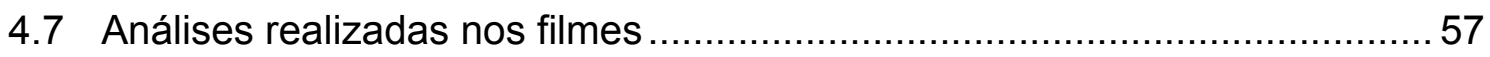

4.7.1 Análise instrumental de textura..................................................... 57

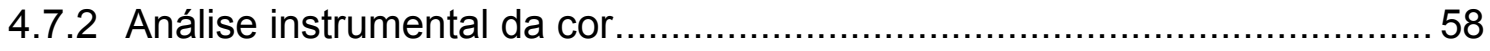

4.7.3 Capacidade de absorção de água (CAA) …........................................... 59

4.7.4 Índice de solubilidade em água (ISA) ........................................... 60

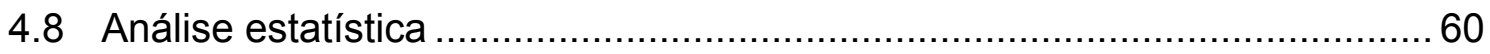

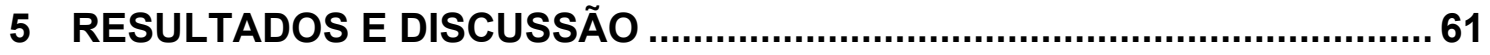

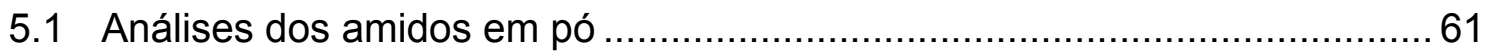

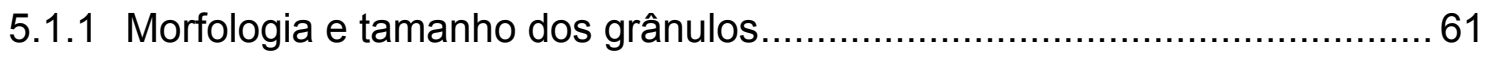

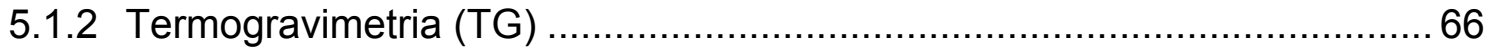

5.1.3 Espectroscopia de Infravermelho por Fourier ......................................69

5.1.4 Difração de raios-X e Cristalinidade relativa ............................................. 74

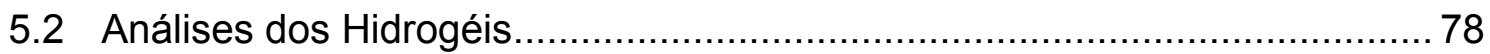

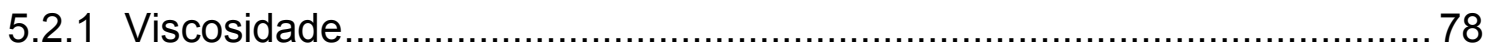

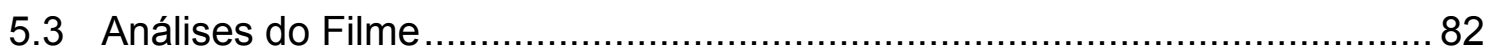

5.3.1 Ensaio Mecânico - Resistência à Tração............................................. 82

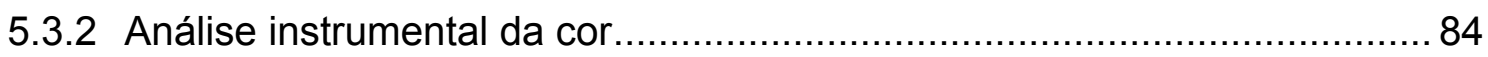

5.3.3 Capacidade de absorção de água e Índice de solubilidade ...................... 85

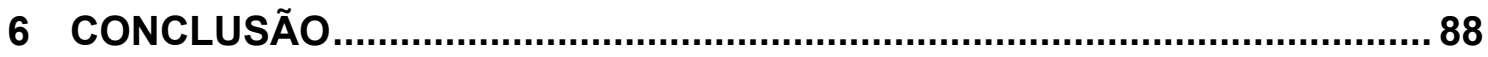

REFERÊNCIAS BIBLIOGRÁFICAS ............................................................. 90 


\section{LISTA DE TABELAS}

Página

TABELA 1 - Tipos de Cristalinidade de amidos obtidos de espectros de raios- X 26

TABELA 2 - Características comparativas entre as cadeias de amilose e de amilopectina

TABELA 3 - Teores de amilose e amilopectina de amidos de algumas espécies vegetais

TABELA 4 - Características do grânulo de amido de diferentes fontes botânicas 30

TABELA 5 - Propriedades dos amidos

TABELA 6 - Eventos Térmicos com os respectivos intervalos de temperatura e perda de massa (\%) das curvas de TG dos amidos.

TABELA 7 - Principais atribuições para as bandas de absorção no IV para o amido de batata

TABELA 8 - Principais atribuições para as bandas de absorção no IV para o amido de milho.

TABELA 9 - Principais atribuições para as bandas de absorção no IV para o polvilho azedo.

TABELA 10 - Cristalinidade relativa (\%) dos amidos em função das doses de radiação.

TABELA 11 - Equações das retas obtidas das aproximações dos gráficos de In (tensão) em função In (deformação).

TABELA 12 - Valores de índice de consistência $\left(\mathrm{K}_{\mathrm{c}}\right)$ e índice de comportamento $\left(\mathrm{n}_{\mathrm{c}}\right)$ de acordo com o modelo Lei da Potência para os três tipos de amidos.

TABELA 13 - Parâmetros de cor $\left(L^{*}, a^{*}, b^{*}, C\right.$ e ângulo Hue) dos amidos submetidos à diferentes doses de radiação.

TABELA 14 - Propriedades de absorção de água e solubilidade dos filmes dos amidos irradiados e não irradiados. 


\section{LISTA DE FIGURAS}

Página

FIGURA 1 - Modelo proposto para a síntese de amido em órgãos de armazenamento (Kossmann \& Lloyd, 2000)................................................... 19

FIGURA 2 - Seção da estrutura linear da amilose (Zamora, 2010). .................... 21

FIGURA 3 - Seção da estrutura ramificada da amilopectina (Zamora, 2010)....... 22

FIGURA 4 - Estrutura molecular da amilopectina em forma de cachos (clusters)

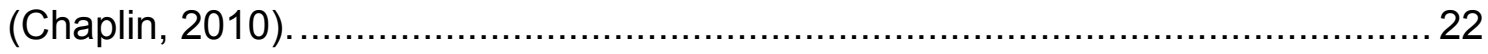

FIGURA 5 - Organização do grânulo de amilopectina (Chaplin, 2010). ............... 23

FIGURA 6 - Visão geral da estrutura dos grânulos de amido em diferentes níveis de organização (Gallant et al., 1997; Buleón, 1998).

FIGURA 7 - Alterações dos grânulos de amido em suspensões submetidos a processos térmicos (Pereira, 2004) . ........................................................ 30

FIGURA 8 - Retrogradação do amido (Palma et al., 2015)............................... 32

FIGURA 9 - Força de cisalhamento aplicada sobre um fluido (Brodkey, 1967) ... 37

FIGURA 10 - Comportamento de um fluido Newtoniano (Brodkey, 1967). 38

FIGURA 11 - Classificação dos fluidos segundo seu comportamento reológico (Brodkey, 1967).

FIGURA 12 - Curvas de (a) viscosidade e (b) de fluxo de fluidos pseudoplásticos (Brodkey, 1967).

FIGURA 13 - Curvas de (a) viscosidade e (b) de fluxo de fluidos dilatantes (Brodkey, 1967).

FIGURA 14 - Curvas de (a) viscosidade e (b) de fluxo de fluidos plásticos de Bingham (Skelland, 1967).

FIGURA 15 - Curvas de escoamento de fluidos não newtonianos de propriedades dependentes do tempo de cisalhamento (Skelland, 1967). 
FIGURA 16 - Curvas de (a) viscosidade e (b) de fluxo de fluidos tixotrópicos (Skelland, 1967).

FIGURA 17 - Curvas de viscosidade (a) e de fluxo (b) de fluidos reopéticos (Skelland, 1967).

FIGURA 18 - Diagrama ilustrativo dos comportamentos reais dos fluidos (Brodkey, 1967).

FIGURA 19 - Promoção da degradação [3] e Cross-linking [1] e [2] nas cadeias de amido pela irradiação gama (Bhat \& Karim, 2009 com adaptações).

FIGURA 20 - Microscópio Óptico Nikon Eclipse 80i.

FIGURA 21 - Microscópio Eletrônico de Varredura (IPEN-CCTM).

FIGURA 22 - Analisador Termogravimétrico modelo SDT Q600 (IPEN-CTR). .... 55

FIGURA 23 - Viscosímetro Brookfield com banho termostatizado Neslab. 57

FIGURA 24 - Texturômetro Stable Micro Systems TA-XT2 (Extralab).

FIGURA 25 - Colorímetro Chroma meter e a placa de calibração branco padrão.

FIGURA 26 - Representação esquemática da escala Cielab. 59

FIGURA 27 - Fotomicrografias de grânulos de fécula de batata não irradiada (aumento 500x e 1000x).

FIGURA 28 - Fotomicrografias de grânulos de fécula de batata 15 kGy (aumento 500x e 1000x).

FIGURA 29 - Distribuição do tamanho dos grânulos de batata em função da dose de radiação.

FIGURA 30 - Fotomicrografias de grânulos de amido de milho não irradiada (aumento 500x e 1000x).

FIGURA 31 - Fotomicrografias de grânulos de amido de milho 15 kGy (aumento 500x e 1000x). 64

FIGURA 32 - Distribuição do tamanho dos grânulos de milho em função da dose de radiação. 
FIGURA 33 - Fotomicrografias de grânulos de amido de mandioca não irradiado (aumento 500x e 1000x).

FIGURA 34 - Fotomicrografias de grânulos da fécula de mandioca 15 kGy (aumento 500x e 1000x).

FIGURA 35 - Distribuição do tamanho dos grânulos do polvilho azedo em função da dose de radiação.

FIGURA 36 - Termogravimetria de amido de batata 0 e 15 kGy.

FIGURA 37 - Termogravimetria de amido de milho 0 e 15 kGy.

FIGURA 38 - Termogravimetria do polvilho azedo 0 e 15 kGy.

FIGURA 39 - Espectroscopia de infravermelho por Fourier do amido de batata 0 e 15 kGy.

FIGURA 40 - Espectroscopia de infravermelho por Fourier do amido de milho 0 e $15 \mathrm{kGy}$.

FIGURA 41 - Espectroscopia de infravermelho por Fourier do polvilho azedo 0 e 15 kGy.

FIGURA 42 - Relação entre a intensidade e o ângulo de Bragg do amido de batata irradiado a 0 e $15 \mathrm{kGy}$.

FIGURA 43 - Relação entre a intensidade e o ângulo de Bragg do amido de milho irradiado a 0 e $15 \mathrm{kGy}$. 75

FIGURA 44 - Relação entre a intensidade e o ângulo de Bragg do polvilho azedo irradiado a 0 e $15 \mathrm{kGy}$. 76

FIGURA 45 - Relação entre a viscosidade dos hidrogéis e as doses de radiação dos três tipos de amidos estudados.

FIGURA 46 - Tensão em relação a taxa de cisalhamento da fécula de batata. ... 79

FIGURA 47 - Tensão em relação a taxa de cisalhamento do amido de milho. ....80 80

FIGURA 48 - Tensão em relação a taxa de cisalhamento do polvilho azedo. 80 FIGURA 49 - Força máxima de ruptura em função da dose de radiação do filme da fécula de batata 
FIGURA 50 - Força máxima de ruptura em função da dose de radiação do filme de amido de milho. 83 FIGURA 51 - Força máxima de ruptura em função da dose de radiação do filme de polvilho azedo. 83 


\section{INTRODUÇÃO}

O amido é uma importante fonte energética para a alimentação humana (Leonel \& Cereda, 2002), podendo ser extraído e utilizado para diversos fins (Matsuguma, 2006). O amido é o produto amiláceo extraído de partes comestíveis dos vegetais, sendo a fonte mais importante de carboidratos em todo o mundo, representando de 80 a $90 \%$ de todos os polissacarídeos da dieta. Matérias-primas ricas em amido estão disponíveis em abundância; assim o amido é extraído com elevado grau de pureza nos processos industriais. Formado por polímeros de glicose, o amido é organizado em uma estrutura macroscópica em que camadas de amilose e amilopectina são depositadas radialmente em torno de um ponto central, chamado hilo. A deposição continuada faz crescer a estrutura e dá origem ao grânulo semicristalino.

Os grânulos nas células podem apresentar formas e tamanhos variados dependendo da fonte botânica (Wurzburg, 1986). As principais fontes comerciais de amido no mundo são os órgãos de reserva de algumas plantas, dentre eles, os grãos de cereais (milho e arroz); algumas raízes (mandioca) e tubérculos (batata) e sementes de leguminosas (feijões e ervilhas), dentre outras. Países tropicais, como o Brasil, apresentam enorme variedade de culturas amiláceas ainda pouco exploradas quanto as suas características estruturais e propriedades físico-químicas.

O amido pode ser utilizado em várias indústrias, sendo as principais consumidoras as indústrias de papel, têxtil e de alimentos, onde é empregado como ingrediente em alimentos processados, sendo esta uma de suas principais áreas de aplicação. No entanto, essas aplicações apresentam limitações que dificultam sua utilização na forma nativa, em determinados produtos. Essas limitações podem ser solucionadas com modificações pelas vias: química, física, enzimática e/ou combinação de diferentes vias, conferindo ao amido propriedades funcionais peculiares. Portanto, as aplicações de amidos são dependentes de suas propriedades físicas e químicas, as quais variam de uma espécie para outra, 
ou são influenciadas por fatores ecológicos e agronômicos (Adebowale et al., 2005). Com isto, modificações químicas ou físicas de amido têm sido realizadas com o objetivo de aumentar seu potencial de uso e valor agregado.

A modificação do amido natural tem se mostrado importante fator no crescimento do mercado de produtos amiláceos devido à capacidade de espessamento, de ligação, formação de gel e textura (Nabeshima \& El-Dash, 2004). Para contornar os problemas de funcionalidade dos amidos nativos em uso, pode ser realizada a modificação da molécula do polissacarídeo, com fins de alteração das propriedades funcionais para melhor adequação às necessidades do mercado.

Torna-se necessário, portanto, realizar pesquisas sobre novos processos aplicados em amidos nativos e modificados que apresentam propriedades específicas capazes de conferir atributos desejados para elaboração de produtos de qualidade. Neste contexto, para incrementar as possibilidades e descobrir novas formas de uso, foi proposto o presente trabalho onde foram utilizados os amidos de batata, milho e mandioca (polvilho azedo) modificados através da radiação ionizante. 


\section{OBJETIVOS}

\subsection{Objetivo Geral}

O objetivo geral deste trabalho foi analisar as características dos efeitos do processamento por radiação ionizante em diferentes tipos de amidos comercializados para uso em alimentação humana e de interesse da indústria de alimentos, bem como, preparar e caracterizar filmes elaborados com esses amidos.

\subsection{Objetivos Específicos}

- Verificar a morfologia dos amidos estudados através da microscopia e calcular o tamanho dos grânulos.

- Avaliar o comportamento termogravimétrico dos amidos irradiados e não irradiados.

- Estabelecer se houve alteração dos grupos funcionais nas moléculas dos amidos irradiados por espectroscopia no infravermelho por Fourier.

- Avaliar possíveis mudanças na cristalinidade (difração de raios-X) dos amidos irradiados.

- Estudar o comportamento reológico dos hidrogéis dos amidos de milho, mandioca e batata de modo a estabelecer relação da viscosidade com a tensão e taxa de cisalhamento a diferentes doses de radiação.

- Investigar as propriedades mecânicas, através de testes de ruptura dos filmes preparados com os amidos irradiados, verificando se existe alteração da textura.

- Avaliar o padrão colorimétrico dos filmes preparados com os amidos irradiados.

- Determinar a solubilidade e absorção de água dos filmes. 


\section{REVISÃO DA LITERATURA}

\subsection{Amido}

O amido é considerado o principal polissacarídeo de armazenamento de plantas superiores que se apresenta na forma de grânulos com uma estrutura interna organizada e com formato e tamanho dependentes da espécie vegetal. Constitui fonte de energia essencial para muitos organismos, principalmente para o homem, apresentando-se como componente majoritário na dieta humana. As fontes mais importantes são os grãos de cereais (40-90\%), leguminosas (30$40 \%$ ), tubérculos (65-85\%) e frutas imaturas ou verdes (40-80\%) (Peroni, 2007; Guilbot \& Mercier, 1985).

A síntese do amido ocorre nas folhas das plantas através de resíduos de glicose formados durante o processo de fotossíntese, acumulando-se sob a forma de grânulos insolúveis nos cloroplastos. Este amido, é conhecido também como amido transitório, serve de reserva para auxiliar o metabolismo e crescimento da planta e também durante a noite quando a fotossíntese não é possível. Em tubérculos a síntese é feita pelo transporte da sacarose até os amiloplastos que catalisam este substrato para a síntese de amido, conhecido como amido de reserva (Niityla, 2004; Zeeman et al., 2004; Vieira, 2006).

As enzimas, ADP-glicose pirofosforilase (AGPase), amido sintase (SS), ramificadora do amido (SBE) e desramificadora do amido (SDBE), são encontradas dentro dos amiloplastos. Estas, na presença de adenosina trifosfato (ATP), são encarregadas de catalisar a biossíntese da amilose e amilopectina (Smith et al., 1997). A sacarose é hidrolisada no citosol e convertida em moléculas de hexose que atuam como precursoras da síntese do amido as quais são transportadas para o interior do amiloplasto (FIG.1).

Estes precursores são chamados de ADP-glicose, glicose 1-fosfato e glicose 6-fosfato, sendo estas duas últimas, também convertidas em ADP-glicose 
que servem como substrato para a síntese dos polímeros de amido. A enzima SS adiciona resíduos de D-glicose oriundos da ADP-glicose à extremidade não redutora de uma molécula precursora por meio de ligações $\alpha(1 \rightarrow 4)$. Uma das isoformas da SS, a amido sintase ligada ao grânulo (GBSS), é essencial para a síntese da amilose.

As outras isoformas da SS (SSI, SSIla, SSIlb e SSSIII) junto com a SBE, que introduz ligações $\alpha(1 \rightarrow 6)$, são responsáveis pela síntese e elongação das cadeias de amilopectina (Smith et al., 1997; Kossman \& Lloyd, 2000; James et al., 2003; Ball \& Morell, 2003; Denyer et al., 2001). Posteriormente a amilopectina é cristalizada dentro do amido através de ações coordenadas da SDBE e a 4-glicosil transferase (Firouzabadi, 2007).

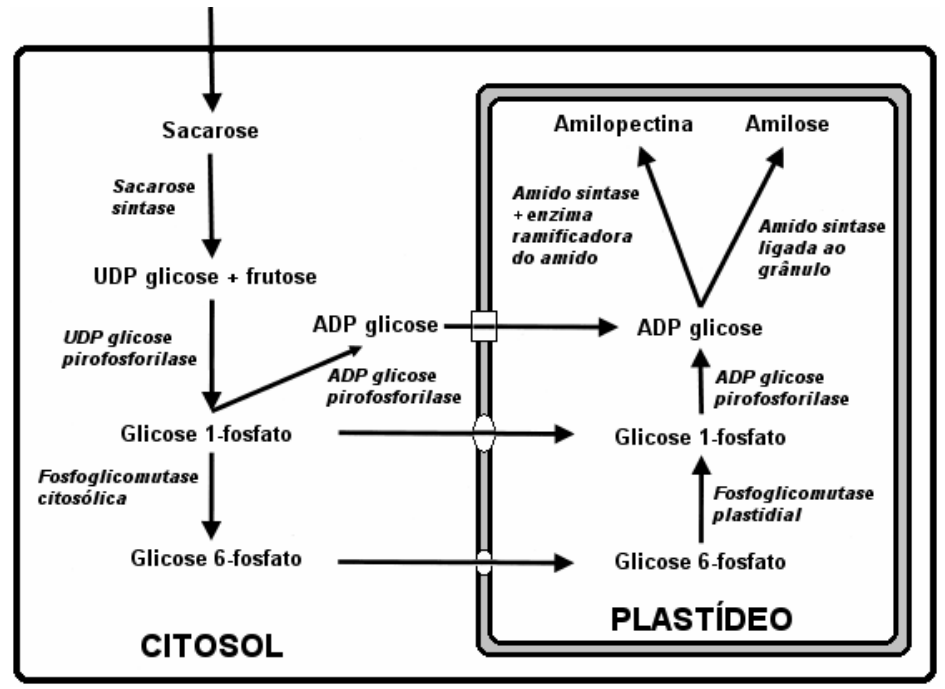

FIGURA 1 - Modelo proposto para a síntese de amido em órgãos de armazenamento (Kossmann \& Lloyd, 2000).

A formação das cadeias poliméricas do amido ocorre em uma matriz lipoproteica. Na membrana do envoltório e nas membranas da matriz interna do amiloplasto em desenvolvimento, encontram-se materiais lipídicos e proteicos que formam uma matriz lipoproteica limitante. No interior do amiloplasto a amilose e amilopectina são sintetizadas dando lugar à formação do grânulo de amido em uma proporção crescente até ser completamente ocupado pelo amido (Galliard \& Bowler, 1987). 
No vegetal, o amido é armazenado na forma de grânulos semicristalinos com um diâmetro entre 1-100 $\mu \mathrm{m}$ dependendo da fonte botânica. As características do amido dependem basicamente do tecido onde é armazenado podendo ser subdividido em: amidos de cereais (trigo - Triticum aestuvum, arroz - Oryza sativa, milho - Zea mays), frutos (banana - Musa cavendish, maçã - Malus domestica), raízes e tuberosas (batata, batata doce, mandioca - Manihot esculenta, mandioquinha-salsa), sementes de árvores (castanha européia - Castanea sativa, pinhão - Araucaria angustifolia), leguminosas (ervilha - Pisum sativum, lentilha - Lens culinaris, feijão - Phaseolus vulgaris) entre outros (Bicudo, 2008).

A RDC/263, de 22 de setembro de 2005, publicada no Diário Oficial da União, aprova o "Regulamento Técnico Para Produtos de Cereais, Amidos, Farinhas e Farelos", que tem por objetivo obedecer as características mínimas de qualidade.

As Normas Técnicas Especiais (Brasil, 1978), que normatizam produtos amiláceos no Brasil classificam os produtos em amidos ou féculas. Amido é o produto amiláceo extraído das partes aéreas comestíveis dos vegetais, como por exemplo, sementes, frutos, etc. Fécula é o produto amiláceo extraído das partes subterrâneas comestíveis dos vegetais (tubérculos, raízes e rizomas). O produto deverá ser designado amido ou fécula, seguido do nome do vegetal de origem, tais como amido de milho, fécula de batata (Cereda \& Vilpoux, 2003).

As técnicas de extração do amido, mencionadas na literatura são diversas e variam desde a simples extração com água pura até a utilização de diferentes reagentes químicos. A qualidade da extração do amido é avaliada em função de seu conteúdo de proteínas, lipídios, fibras e cinzas. Quanto menor o conteúdo destes componentes maior a qualidade do processo extrativo (Farro, 2008).

Amidos nativos apresentam características distintas quanto às propriedades físico-químicas e funcionais que devem ser consideradas na hora de determinar a aplicabilidade em alimentos e para outros usos industriais. Os amidos diferem em propriedades físico-químicas, estrutura, cristalinidade, aparência, conteúdo de amilose, amilopectina e outros constituintes que proporcionam características específicas de gelatinização e retrogradação; e 
entre as propriedades funcionais temos a solubilidade, inchamento, absorção de água, sinérese e comportamento reológico das pastas e géis (Wang \& White, 1994b).

O amido deve sua funcionalidade às duas macromoléculas que o compõem, amilose e amilopectina, assim como à organização física dentro da estrutura granular (Bello-Pérez et al., 2006). A seguir, uma descrição mais detalhada da amilose e da amilopectina.

\subsection{Amilose e Amilopectina}

O amido é um polissacarídeo formado por 2 tipos de polímeros: amilose e amilopectina. Todos os amidos são constituídos de uma ou de ambas moléculas, mas o percentual de cada uma varia de acordo com a fonte de amido.

A amilose é um homopolímero composto por unidades de D-glicose, ligadas entre si por ligações $\alpha(1 \rightarrow 4)$ (FIG. 2).

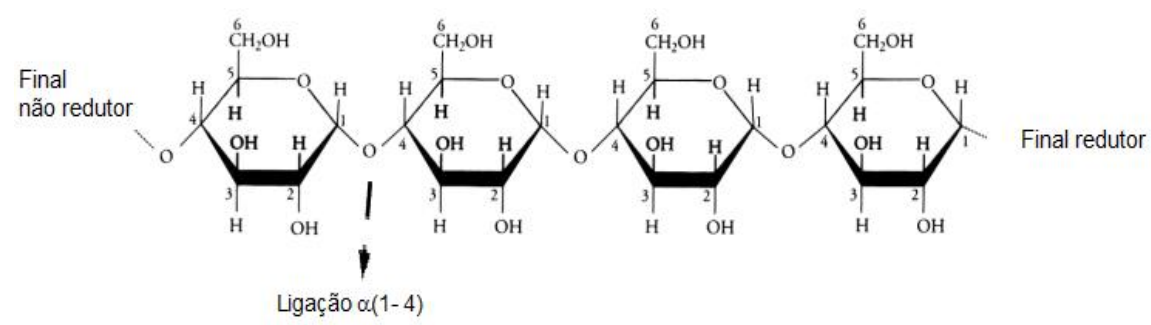

FIGURA 2 - Seção da estrutura linear da amilose (Zamora, 2010).

A molécula de amilose se apresenta na forma helicoidal cujo interior é lipofílico contendo predominantemente átomos de hidrogênio, enquanto as hidroxilas permanecem na parte externa da hélice. A amilose é considerada como sendo amorfa nos grânulos de amidos, porém amidos com alto teor de amilose podem desenvolver duplas hélices formando uma estrutura cristalina (Tester, 1997; Singh et al., 2003; Jane, 2006).

A amilopectina é uma molécula altamente ramificada formada por unidades de $D$-glicose ligadas em $\alpha(1 \rightarrow 4)$ e com 5 a $6 \%$ de ligações $\alpha(1 \rightarrow 6)$ nos 
pontos de ramificação (FIG. 3). A grande maioria dos amidos contém de 20 a $30 \%$ de amilose e 70 a $80 \%$ de amilopectina e essa razão se altera conforme a fonte botânica (Cordenunsi et al., 2006).

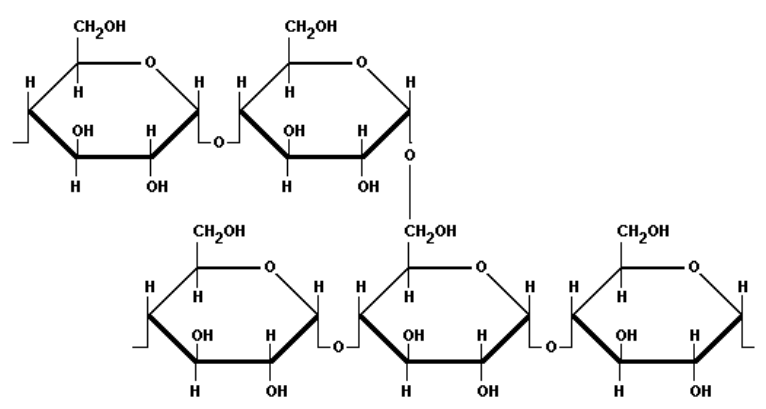

FIGURA 3 - Seção da estrutura ramificada da amilopectina (Zamora, 2010).

De acordo com a FIG.4, a molécula de amilopectina consiste de uma cadeia principal (representada pela letra $\mathrm{C}$ ), que carrega o único grupo redutor $\mathrm{e}$ numerosas cadeias ramificadas denominadas cadeias $A$ e $B$. As cadeias $A$ são aquelas que são conectadas a outras cadeias via ligações $\alpha(1 \rightarrow 6)$, mas não carregam qualquer ramificação. As cadeias $B$ (mais ramificadas) são aquelas conectadas a outras cadeias via ligações $\alpha(1 \rightarrow 6)$, que possuem uma ou mais cadeias A ou B (Chaplin, 2010).

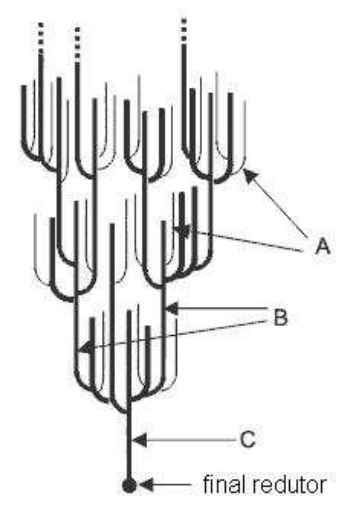

FIGURA 4 - Estrutura molecular da amilopectina em forma de cachos (clusters) (Chaplin, 2010). 
As moléculas de amilopectina são orientadas radialmente dentro do grânulo de amido e, à medida que o raio do grânulo de amido aumenta, aumentam o número de ramificações necessárias para preencher os espaços vazios, com a conseqüente formação de regiões concêntricas alternadas em amorfas e cristalinas (Bertoft, 2004).

A amilopectina é praticamente a única fonte da cristalinidade do amido, no entanto, verifica-se a existência de pontos de ramificação da amilopectina que são expulsos das cristalinidades para dentro das zonas amorfas (amilose e água). Desta forma, a amilopectina pode pertencer às camadas cristalinas e aos pontos de ramificação, tornando-se ainda, mecanismo de união entre as camadas concêntricas (Brouillet-Fourmam et al., 2003). A FIG. 5 mostra a organização das regiões amorfas e cristalinas na estrutura da amilopectina.

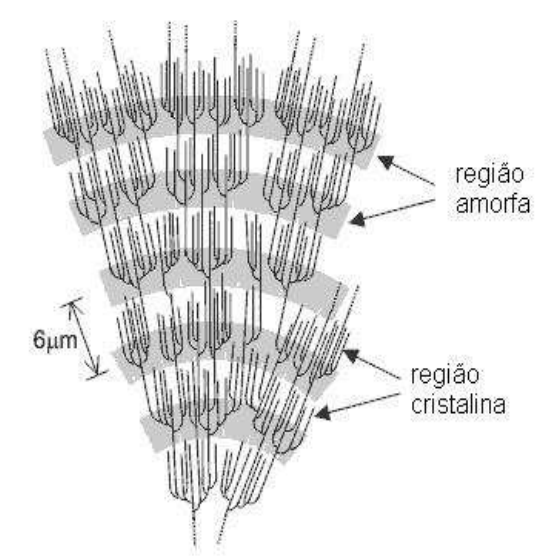

FIGURA 5 - Organização do grânulo de amilopectina (Chaplin, 2010).

O modelo proposto por French (1973) e Robin et al. (1974) tem sido largamente aceito para explicar a estrutura da amilopectina e em consequência a estrutura do grânulo de amido (FIG. 6). Neste modelo, os clusters ou cachos constituiriam uma camada cristalina com $60 \AA$ de espessura. Estes clusters formados de cadeias laterais da amilopectina constituiriam a fração dos grânulos de amido resistentes a hidrólise ácida, chamada de área cristalina (Kossmann \& Lloyd, 2000; Parker \& Ring, 2001).

A repetição das regiões amorfas e cristalinas formariam blocos (blocklets), ou seja, alterações de duas camadas organizadas dentro de 
estruturas maiores, mais ou menos esféricas (Cordenunsi et al., 2006). Os blocklets teriam formatos (redondos ou alongados) e tamanhos variados de acordo com a origem do amido e com a sua localização dentro do grânulo, de acordo com Gallant et al. (1997).
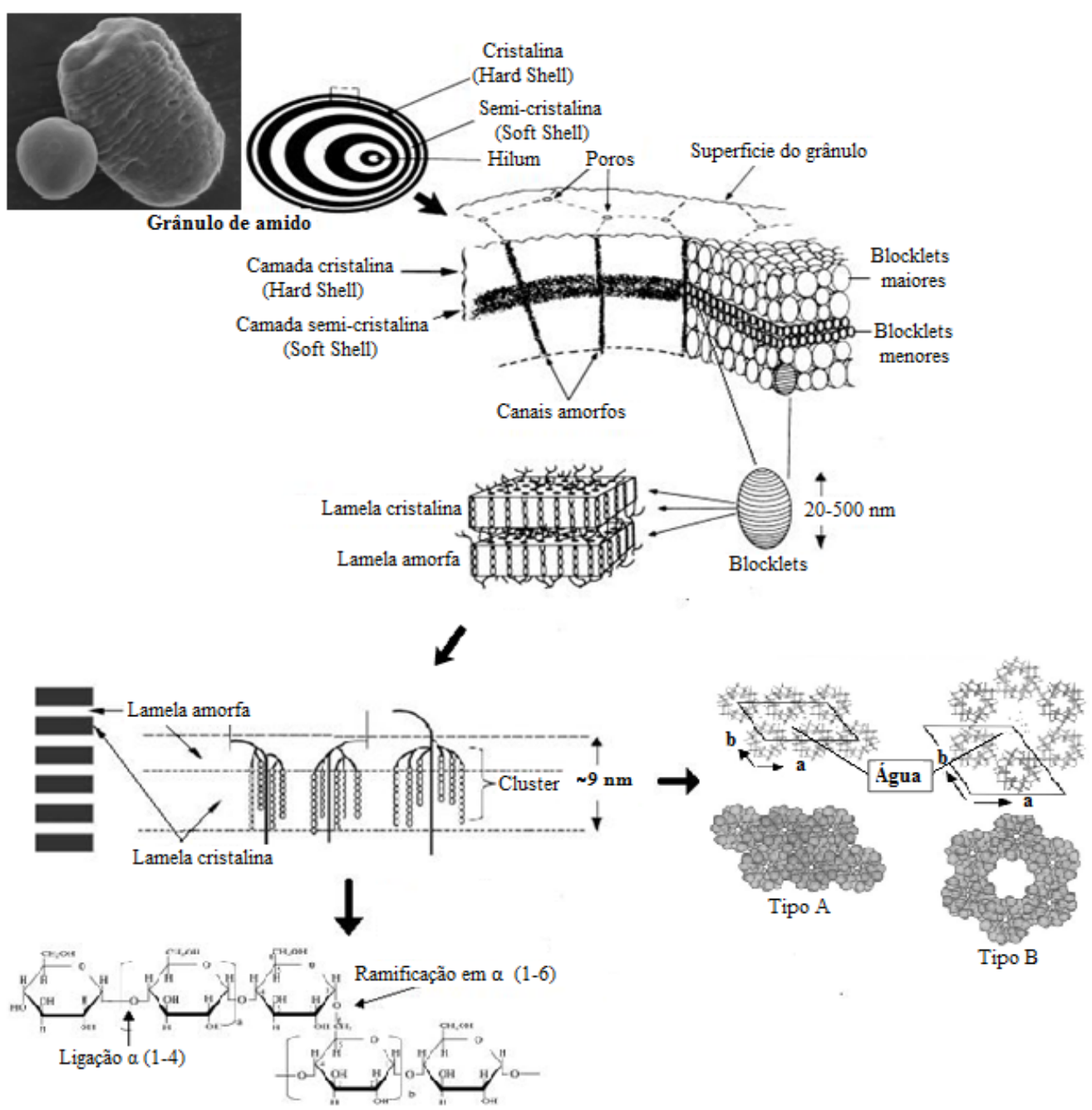

FIGURA 6 - Visão geral da estrutura dos grânulos de amido em diferentes níveis de organização (Gallant et al., 1997; Buleón, 1998).

No último nível de organização encontram-se as camadas alternadas de regiões cristalinas (sólidas) e semicristalinas (macias), conhecidas como camadas ou shells, onde as camadas cristalinas e semicristalinas estariam compostas por bloklets com tamanhos entre 50-500 nm e 20-50 nm, respectivamente. As repetições de camadas cristalinas e semicristalinas que se 
superpõem ao redor de um ponto denominado hilo ou hilum formam os anéis de crescimento (Kossmann \& Lloyd, 2000).

O hilo (hilum) é considerado o ponto original de crescimento do grânulo onde se encontra grande proporção de terminais redutores, sendo esta área menos organizada do que o resto do grânulo. As camadas ou anéis de crescimento que circundam o hilo são resultantes da deposição diária dos componentes do amido. Esses anéis de crescimento, presentes na forma de anéis concêntricos, podem ser observados no microscópio óptico, e são facilmente identificados por meio de hidrólise enzimática sugerindo que o material recém-sintetizado é depositado na superfície, incrementando gradativamente o tamanho do grânulo (Denardin \& Silva, 2009; Tester et al., 2004).

Os diferentes graus de ordenamento na estrutura dos grânulos de amido são responsáveis pelas propriedades de birrefringência e cristalinidade onde as regiões amorfas contêm estruturas não ordenadas e não podem ser distinguidas desde o fundo. Este padrão de interferência observado toma a forma de uma "cruz de Malta" quando observadas sob luz polarizada (Wang et al., 1998). A birrefringência é devido ao alto grau de orientação molecular interna. No grânulo de amido a amilose pode localizar entre as moléculas de amilopectina e se associar com as regiões lineares da mesma, contribuindo com alto grau de ordem dentro das regiões cristalinas da molécula de amilopectina (Bello-Pérez et al., 2006).

A cristalinidade do amido encontra-se associada principalmente à amilopectina de 15 a 45\%, já a ausência da amilose não afeitaria a cristalinidade do amido, isso é observado principalmente em amidos cerosos que apresentam um baixo teor de amilose (Salgado et al., 2005; Corradini et al., 2007; Cheetham \& Tao, 1998; Cooke \& Guidley, 1992; Rocha et al., 2008).

Os grânulos de amido por serem estruturas semicristalinas podem ser caracterizados por difração de raios- $X$ em dois padrões principais $A$ e $B$ e um intermediário $\mathrm{C}$ resultantes da variação do conteúdo de água e do empacotamento em dupla hélice das cadeias ramificadas. Estes padrões de cristalinidade para amidos no estado nativo são variáveis com as fontes vegetais (Riley et al., 2006; Buleón, 1998). 
O padrão A é caracterizado de amidos de cereais, apresenta duplas hélices em arranjo monoclínico. Possui uma estrutura relativamente compacta com um baixo conteúdo de água resultando em uma conformação altamente cristalina. Amidos deste tipo apresentam cadeias curtas de amilopectina e baixos teores de fósforo (Tester et al., 2004; Gallant et al., 1997; Parker \& Ring, 2001).

O padrão $B$, presente em amidos de raízes, frutas, tubérculos e outros amidos ricos em amilose, apresenta uma estrutura mais aberta com as duplas hélices dispostas em arranjo hexagonal e contendo um núcleo helicoidal hidratado. Amidos desta classe são compostos por longas cadeias de amilopectina e altos níveis de fósforo (Buleón et al., 1998; Glaring et al., 2006; Tester et al., 2004; Hizukuri, 1985; Gallant et al., 1997; Riley et al., 2006; Wang et al., 2009).

$\mathrm{O}$ padrão $\mathrm{C}$, presente em amidos de leguminosas e alguns cereais cultivados em condições específicas de temperatura e umidade, é uma mistura dos tipos $A$ e $B$ apresentando características de ambos os tipos, com predomínio de $\mathrm{A}$. Este padrão ainda pode ser classificado em tipos $\mathrm{Ca}, \mathrm{Cb}$ e Cc (Buleón et al., 1998). A TAB. 1 mostra os tipos de cristalinidade de amidos.

TABELA 1 - Tipos de Cristalinidade de amidos obtidos de espectros de raios- $X$

\begin{tabular}{ccc}
\hline \hline Origem Botânica & $\begin{array}{c}\text { Tipo Cristalino } \\
\text { Cereais }\end{array}$ & Cristalinidade (\%) \\
\hline \multicolumn{3}{c}{$\mathrm{A}$} \\
\hline Milho & Tuberosas \\
\hline Mandioca & $\mathrm{C}=\mathrm{A}+\mathrm{B}$ & 40 \\
\hline Batata & $\mathrm{B}$ & 25 \\
\hline \hline & Fonte: Adaptado de Mestres (1996).
\end{tabular}

Todos os amidos são semicristalinos e a cristalinidade é calculada a partir da área dos picos de difração. A interpretação destes picos permite calcular a estrutura molecular dos tipos cristalinos, sendo a organização das hélices pareadas (zonas cristalinas) que diferencia os picos cristalinos (Mestres, 1996). 
As diferenças entre as moléculas de amilose e amilopectina podem ser evidenciadas através do peso molecular, grau de polimerização e outras propriedades físico-químicas (TAB. 2). A amilose diferencia-se também da amilopectina devido à quantidade relativa de componentes minoritários associados a sua molécula, visto que sua molécula apresenta-se complexada com os lipídios presentes no grânulo, influenciando as propriedades reológicas do amido.

TABELA 2 - Características comparativas entre as cadeias de amilose e de amilopectina

\begin{tabular}{lcc}
\hline \multicolumn{1}{c}{ Características } & Amilose & Amilopectina \\
\hline Porcentagem do peso molecular no grânulo & $15-35 \%$ & $65-85 \%$ \\
Porcentagem de ramificações $\alpha(1 \rightarrow 6)$ & $<1 \%$ & $4-6 \%$ \\
Massa Molecular (Da) & $10^{4}-10^{5}$ & $10^{7}-10^{8}$ \\
Grau de polimerização & $10^{2}-10^{3}$ & $10^{3}-10^{4}$ \\
Comprimento da cadeia & $3-100$ & $3-50$ \\
\hline \hline
\end{tabular}

Fonte: Soares (2003).

De amido para amido os teores de amilose e amilopectina podem variar nas quantidades relativas, tamanho, forma e modo de associação no grânulo, o que determina a extensão e o tipo de estrutura cristalina (Amante, 1986). A proporção destas moléculas é característica da espécie vegetal (TAB. 3).

TABELA 3 - Teores de amilose e amilopectina de amidos de algumas espécies vegetais

\begin{tabular}{ccc}
\hline \hline Origem & Amilose (\%) & Amilopectina(\%) \\
\hline Mandioca & 17 & 83 \\
Milho & 24 & 76 \\
Trigo & 25 & 75 \\
Batata & 20 & 80 \\
Erviha & 40 & 60 \\
\hline \hline
\end{tabular}

Fonte: Ciacco \& Cruz (1982); Vilela \& Ferreira (1987)

Outros compostos que se encontram em quantidades relativamente pequenas $(<0,4 \%)$ são os minerais como cálcio, magnésio, sódio, potássio e 
fósforo, os quais, com exceção do fósforo, são irrelevantes para a funcionalidade do amido (Tester et al., 2004).

O fósforo é o mineral mais importante nos amidos de raízes e tubérculos, sendo encontrado na forma de grupos fosfato monoéster, carregados negativamente e unidos covalentemente ao amido (Hoover, 2001; Blennow et al., 2000b). No entanto, nos amidos de cereais o fósforo se encontra principalmente na forma de fosfolipídios. O conteúdo e a forma do fósforo podem ser influenciados pelas condições de crescimento da planta, da temperatura e do armazenamento (Hoover, 2001).

A presença de grupos fosfato nas partes cristalinas do grânulo indica uma influência direta na estrutura geral do amido e pode afetar a cristalinidade e integridade dos grânulos (Blennow et al., 2000, 2000a, 2000b).

\subsection{Solubilidade e poder de inchamento dos grânulos}

O poder de inchamento é a medida da capacidade de hidratação dos grânulos, e essa determinação é feita pela massa do grânulo de amido intumescido (inchado ou expandido) e de sua água oclusa. A qualidade de um alimento amiláceo está comumente associada à retenção de água pelos grânulos. A consequência direta do intumescimento é o aumento na solubilidade, claridade e viscosidade da pasta de amido (Ciacco \& Cruz, 1982).

Durante o aquecimento de uma suspensão aquosa de amido as áreas amorfas absorvem água rapidamente e incham, permanecendo unidas pelas regiões cristalinas, que mantêm a integridade dos grânulos pois permitem que ocorra o inchamento dos grânulos, mas não a completa dispersão das macromoléculas.

Amidos de diferentes fontes botânicas apresentam distinto poder de inchamento (intumescimento) e solubilidade. $\mathrm{O}$ amido de milho, por exemplo, apresenta intumescimento limitado, que ocorre em dois estágios. Isto sugere dois tipos de forças envolvidas nas interações entre as cadeias poliméricas que relaxam a diferentes temperaturas. Féculas como as de mandioca e de batata 
apresentam grande inchamento a temperaturas mais baixas, o que indica interações mais fracas e uniformes (Leach et al., 1959).

A taxa de amilose/amilopectina, as características de cada fração em termos de distribuição da massa molecular, o grau e extensão de ramificações e conformação são alguns dos fatores que afetam o poder de inchamento e a solubilidade. A presença de substâncias acompanhantes do amido, como lipídios, pode restringir a expansão e a solubilização do amido (Swinkels, 1985).

\subsection{Gelatinização do amido}

O amido, quando aquecido acima de uma determinada temperatura em excesso de água, dá início a um processo chamado de gelatinização, este por sua vez, é caracterizado pela desestruturação do arranjo cristalino dos grânulos (Franco et al., 2002). Este fenômeno ocorre quando o grânulo de amido intumesce com gradual hidratação devido ao rompimento das pontes de hidrogênio mais fracas das áreas amorfas (National Starch and Chemical Industrial Ltda, 1995).

Os grupamentos hidroxila são liberados, ficando disponíveis para as ligações com as moléculas de água e em conseqüência disto ocorre a expansão dos grânulos de amido (Rickard et al., 1991), resultando em um sistema formado por uma fase rica em amilose (dispersa na solução) e grânulos inchados e parcialmente desintegrados de amido, constituídos principalmente de cadeias de amilopectina (Conde-Petit et al., 1998). A FIG. 7 representa esquematicamente as mudanças que sofrem os grânulos de amido durante a gelatinização e posterior geleificação de uma suspensão de amido. 


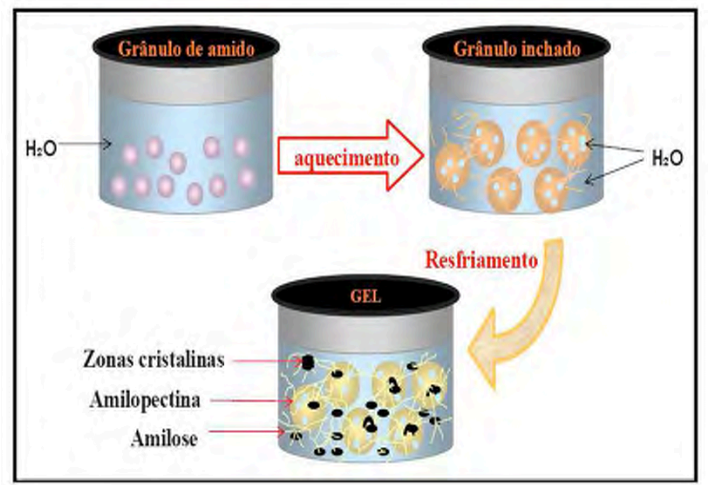

FIGURA 7 - Alterações dos grânulos de amido em suspensões submetidos a processos térmicos (Pereira, 2004).

Os grânulos não gelatinizam à mesma temperatura, devido à heterogeneidade dos seus cristais. Pode-se dizer que a temperatura de gelatinização representa uma soma de eventos particulares e ocorre em uma faixa de temperatura. De acordo com Yu e Christie (2001) há um pico endotérmico na temperatura na faixa entre 54 e $73^{\circ} \mathrm{C}$, para diferentes amidos, e isto foi definido como temperatura de gelatinização. Para cada amido, tem-se uma faixa de temperatura de gelatinização diferente, correspondente ao ponto de máxima viscosidade do amido (TAB. 4). Esse intervalo de temperatura é medido a partir do início do desaparecimento das zonas cristalinas do grânulo até seu fim, e pode ser visualizado através do microscópio com luz polarizada (Bobbio \& Bobbio, 2001).

TABELA 4 - Características do grânulo de amido de diferentes fontes botânicas

\begin{tabular}{ccc}
\hline \hline Fonte & Diâmetro $(\boldsymbol{\mu m})$ & $\begin{array}{c}\text { Temperatura de } \\
\text { gelatinização }\left({ }^{\circ} \mathbf{C}\right)\end{array}$ \\
\hline Milho & $5-30$ & $62-72$ \\
Batata & $5-100$ & $59-68$ \\
Mandioca & $4-35$ & $62-73$ \\
Trigo & $1-45$ & $58-64$ \\
Arroz & $3-8$ & $68-78$ \\
\hline \hline
\end{tabular}

Fonte: Murphy (2000). 
A temperatura de gelatinização é influenciada pelas forças de ligações no grânulo, de acordo com cada espécie (Franco et al., 2002), isto é: composição do grânulo (conteúdo de fósforo, enzimas, razão amilose lamilopectina, lipídios e proteínas), estrutura molecular da amilopectina (massa molecular e arquitetura granular, razão entre regiões cristalinas e amorfas, extensão da ramificação), morfologia e tamanhos dos grânulos do amido.

As características dos grânulos refletem diretamente as propriedades dos amidos. Por exemplo, a pasta de amido de tubérculos e raízes apresenta géis mais fracos e pouco consistentes, porém são de alta viscosidade, translúcidos, longos, coesivos, fibrosos (Whistler \& Bemiller, 1997; Freitas, 2002) e de baixa tendência para retrogradar pelo seu baixo conteúdo de amilose (aproximadamente 17\%) e baixo conteúdo de lipídios (Rakshit, 2004). Na TAB. 5, são apresentadas algumas propriedades dos amidos.

TABELA 5 - Propriedades dos amidos

\begin{tabular}{ccccc}
\hline Amido & $\begin{array}{c}\text { Viscosidade } \\
\text { da pasta }\end{array}$ & $\begin{array}{c}\text { Textura da } \\
\text { pasta }\end{array}$ & $\begin{array}{c}\text { Claridade da } \\
\text { pasta }\end{array}$ & $\begin{array}{c}\text { Grau de } \\
\text { retrogradação }\end{array}$ \\
\hline Batata & muito alta & longa & clara & médio \\
Milho & médio baixa & curta & opaca & alto \\
Mandioca & alta & longa & muito clara & baixo \\
\hline \hline
\end{tabular}

Fonte: Rasksit (2004)

A gelatinização do amido é um processo de absorção de energia, portanto, pode ser caracterizada através de calorimetria diferencial de varredura (DSC), pela perda de birrefringência e pelo desaparecimento da cristalinidade evidenciado pela difração de raios-X (Garcia et al.,1996).

\subsection{Retrogradação}

A retrogradação é o fenômeno que ocorre quando a dispersão de amido gelatinizado é esfriada e suas moléculas começam a se reassociar, fazendo com que ocorra a formação de cristais, favorecendo uma estrutura mais 
ordenada (FIG.8). Esta transformação pode ser acompanhada da expulsão de água das moléculas de amilose, fenômeno conhecido por sinerese (Atwell et al., 1988).

Com o resfriamento do gel, as cadeias do amido perdem energia e as pontes de hidrogênio entre os grupos hidroxila das moléculas de amilose adjacentes ficam mais fortes, proporcionando firmeza do gel e aumento da opacidade do mesmo (Hoseney, 1996).

Amido Gelatinizado

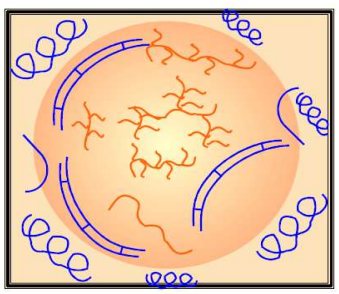

Amido Retrogradado

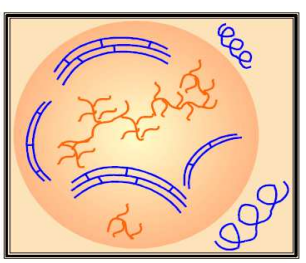

FIGURA 8 - Retrogradação do amido (Palma et al., 2015).

As características de retrogradação da amilose e amilopectina são cineticamente diferentes. A amilose retrograda mais rapidamente, tendo forte tendência a associar-se por meio da formação de interações de hidrogênio com outras moléculas de amilose adjacentes, formando estruturas cristalinas de duplas hélices quando a solução esfria e se mantém por longo período de tempo. Por outro lado, a amilopectina retrograda em uma taxa muito menor durante um longo período de tempo (Tharanathan, 2002).

De acordo com Sandhu et al. (2007), entre os vários fatores que influenciam a retrogradação, os três mais importantes são: a concentração de amilose presente, o tamanho das moléculas de amilose e o estado de dispersão das cadeias lineares. 


\subsection{Fécula de batata}

Os carboidratos constituem cerca de $80 \%$ do total de sólidos encontrados nas batatas. Eles são os constituintes de maior concentração e consistem predominantemente de amido, assim como em outros tubérculos. $O$ amido presente na batata contém amilose e amilopectina, com 0,093\% de fósforo. O conteúdo de amilose aumenta com a maturidade e a fertilização do solo influencia no conteúdo de amido de tubérculos. O conteúdo de amido na batata pode oscilar de acordo com a temperatura de armazenamento, doenças do vegetal e aplicação de produtos químicos (Salunkhe \& Kadam, 1998).

\subsection{Amido de milho}

De acordo com Brambilla (2001), o milho (Zea maiz) é um cereal de grande utilização industrial, seja para indústrias processadoras de ração animal ou para o consumo humano, que contém de 60 a $68 \%$ de amido (Jacques et al., 1999). É largamente utilizado para diversos tipos de aplicações gerando, assim, produtos diversos.

\subsection{Fécula de mandioca}

De acordo com Hoover (2001), as culturas tuberosas recebem diversas denominações populares conforme o país em questão. Com relação às propriedades agronômicas existe vasta documentação acerca destas culturas, no entanto, quanto às propriedades físico-químicas ainda há muito a ser estudado. Por ser a mandioca rica em amido, este é o principal produto obtido a partir dela, pois dele obtém-se o maior número de aplicações e subprodutos. A matéria-prima contém de 25 a $30 \%$ de amido em sua constituição (Jacques et al., 1999). Segundo Passos (2002) a mandioca (Manihot esculenta) representa um alimento energético para mais de 400 milhões de pessoas no mundo, sobretudo nos países em desenvolvimento. A mandioca apresenta uma série de vantagens em relação a outros cultivos como: fácil propagação, elevada tolerância a longas estiagens; ainda, apresenta um alto teor de amido nas raízes. Industrialmente, 
seu processamento gera uma série de produtos e subprodutos para a alimentação humana, animal ou outros usos industriais (Demiate \& Cereda, 2000; Passos, 2002).

O processo de produção de amido consiste na colheita ou recebimento das raízes, lavagem, descascamento, picagem e/ou ralação, prensagem, tamisação da massa sob água corrente. O bagaço acumulado é eliminado e a fécula é arrastada pela água e separada desta por decantação em tanques ou planos inclinados ou por centrifugação.

Sriroth et al. (1999) e Chatakanonda et al. (2002) mostraram que alguns fatores influem na qualidade da fécula de mandioca. A quantidade de chuva durante a colheita influência na temperatura de pasta, a qual aumenta na estação seca e diminui na estação chuvosa. Também a idade da colheita influencia, pois as raízes de mandioca estão maduras após 12 meses e, geralmente, são colhidas com 14 a 16 meses. Esta demora resulta no aumento do conteúdo de amido, diminuição no conteúdo de água e aumento no teor de fibras, o que dificulta a extração do amido. Nos amidos de grânulos mais velhos há a diminuição no teor de amilose e alteração da distribuição do tamanho do grânulo. As condições do meio ambiente alteram o poder de inchamento, a temperatura de pasta e de gelatinização.

\subsubsection{Polvilho azedo}

A fécula fermentada, popularmente conhecida por polvilho azedo, é obtida pela fermentação natural da fécula doce de mandioca e secagem ao sol (Cereda, 1983 a, b, 1987; Cereda et al., 1995; Ascheri \& Vilela, 1995; Maeda \& Cereda, 2001). O polvilho azedo é considerado um tipo de amido modificado. Existe grande interesse nos estudo e obtenção de amidos modificados para uso na indústria.

A Legislação, através das Normas Técnicas Especiais Relativas a Alimentos e Bebidas (Brasil, 1978), classifica o polvilho em doce e azedo, tendo por base apenas a acidez titulável que, para alimentos fermentados, deve ser no máximo 5,0 mL de $\mathrm{NaOH} \mathrm{N} / 100 \mathrm{~g}$. Os limites de umidade, amido e cinzas são os mesmos para ambos os produtos. 
As modificações ocorridas durante o processo fermentativo do polvilho azedo são a diminuição do pH, formação de ácidos orgânicos, aumento da acidez titulável, ataque de enzimas amilolíticas, aumento do poder de inchamento, da solubilidade e diminuição da viscosidade do polvilho (Aschieri \& Vilela, 1995).

\subsection{Filmes à base de amido}

A produção de filmes a base de amidos baseia-se nas propriedades físicas, químicas e funcionais da amilose para formar géis e no seu desempenho para formar filmes. Devido à linearidade das moléculas de amilose em solução, elas tendem a orientar-se paralelamente, aproximando-se para formar ligações de hidrogênio entre hidroxilas de polímeros adjacentes (Wurzburg, 1986).

O desenvolvimento de polímeros provenientes de fontes naturais estão atraindo cada vez mais à atenção da indústria. Entre os filmes produzidos à base de polissacarídeos, destacam-se os produzidos à base de amido (Famá et al., 2006; Kechichian, 2007; Lourdin et al., 1995; Mali et al., 2010; Meneses et al., 2007; Parra et al., 2004; Souza, 2011; Veiga-Santos, 2004; Veiga-Santos et al., 2005; Veiga-Santos; Ditchfield; Tadini, 2011).

Os filmes à base de amido são transparentes, fáceis de processar, fornecem boa barreira contra oxigênio e dióxido de carbono, são facilmente biodegradáveis e compatíveis com a maioria dos materiais, o que facilita a mistura na sua elaboração. Suas principais desvantagens são a alta permeabilidade ao vapor de água e solubilidade em água (Souza et al., 2010).

\subsection{Propriedades reológicas dos amidos}

A reologia estuda o comportamento mecânico (escoamento da matéria) e da deformação de corpos devido à ação de tensões, sob determinadas condições termodinâmicas ao longo de um intervalo de tempo (Brodkey, 1967).

O amido é muito utilizado como agente espessante em diversos produtos, como por exemplo, produtos à base de leite, molhos, sobremesas, 
sopas, maioneses e alimentos semi-prontos, por isso, conhecer o seu comportamento reológico é muito importante. A viscosidade pode ser afetada por algumas variáveis, tais como, taxa de deformação, temperatura, concentração, pressão e tempo de cisalhamento (Marcotte et al., 2001).

O postulado de Newton descreve o conceito de viscosidade no qual a magnitude da resistência ao escoamento é devido à forças de cisalhamento dentro de um fluido, segundo a equação 1 (Singh \& Heldman, 1993):

$$
\tau=\mu \gamma
$$

onde:

- $\tau$ é tensão de cisalhamento (Pa) (força aplicada tangencialmente a uma área)

- $\mu$ é a viscosidade Newtoniana (Pa.s)

- $\gamma$ é a taxa de cisalhamento $\left(\mathrm{s}^{-1}\right)$ (velocidade relativa das camadas líquidas dividida pela distância entre elas)

A FIG. 9 representa o escoamento de um fluido contido entre duas placas planas paralelas, sendo uma placa (superior) móvel e a outra estacionária, de área $A$, separadas por uma distância $y$. Uma força $\vec{F}$, em sentido contrário denominada força de cisalhamento, é aplicada na parte superior, de modo a movimentar a placa a uma velocidade constante $\vec{u}$ em relação à placa inferior, que é mantida fixa (Scharamm, 2000). 


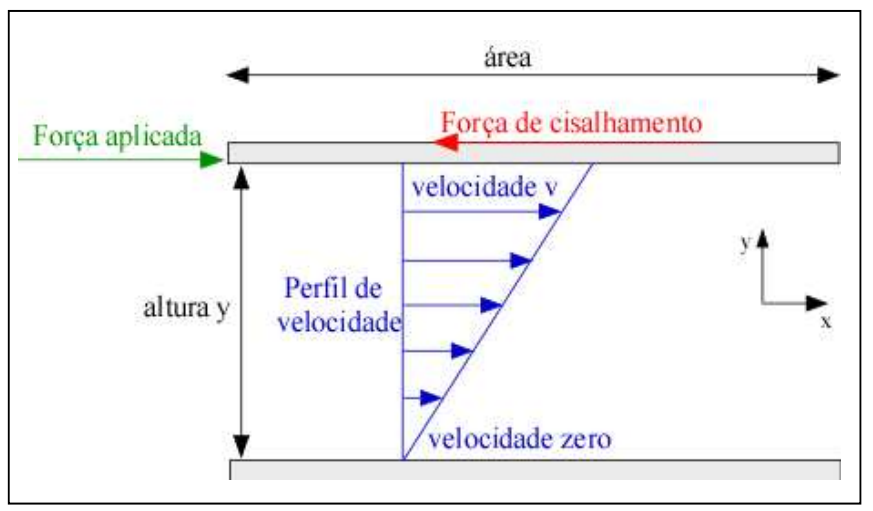

FIGURA 9 - Força de cisalhamento aplicada sobre um fluido (Brodkey, 1967).

A tensão de cisalhamento pode ser definida como uma força $(F)$ aplicada tangencialmente a uma área $(A)$ sendo a interface entre uma placa superior e o líquido abaixo, resultando no escoamento da camada líquida. $A$ velocidade do escoamento, que pode ser mantida por uma força aplicada, é controlada pela resistência interna do fluido, isto é, por sua viscosidade (Scharamm, 2000).

$$
\tau=\frac{\mathrm{F}}{A}=\frac{\mathrm{N}}{m^{2}}=P a
$$

A velocidade diminui à medida que a distância y se aproxima da placa fixa. Já a velocidade máxima de fluxo (Vmáx) é encontrada na camada superior. $A$ velocidade relativa das camadas líquidas dividida pela distância entre elas é chamada de taxa de cisalhamento e é matematicamente definida pela equação 3 (Scharamm, 2000):

$$
\gamma=\frac{d v}{d y}=\frac{m / s}{m}=\frac{1}{s}=s^{-1}
$$


A correlação entre a taxa e a tensão de cisalhamento define o comportamento de fluxo de um fluido (Scharamm, 2000). Os fluidos podem ser classificados em dois tipos: Newtonianos e não-Newtonianos.

De acordo com a Lei de Newton da viscosidade, quando a relação entre a tensão de cisalhamento e a taxa de deformação de um fluido é definida como linear estes são denominados como Newtonianos, conforme indica a equação 4.

$$
\tau y x=-\mu \frac{\partial u x}{\partial \gamma}
$$

onde:

$\tau x y=$ Tensão de cisalhamento na direção $\times\left(\mathrm{N} / \mathrm{m}^{2}\right)$

$\frac{\partial u x}{\partial \gamma}=$ Taxa de deformação ou gradiente de velocidade $\left(\mathrm{s}^{-1}\right)$

$\mu=$ Viscosidade $($ Pa.s)

A FIG. 10 ilustra o comportamento de um fluido Newtoniano relacionando a viscosidade e tensão de cisalhamento com a taxa de deformação à pressão e temperaturas constantes:

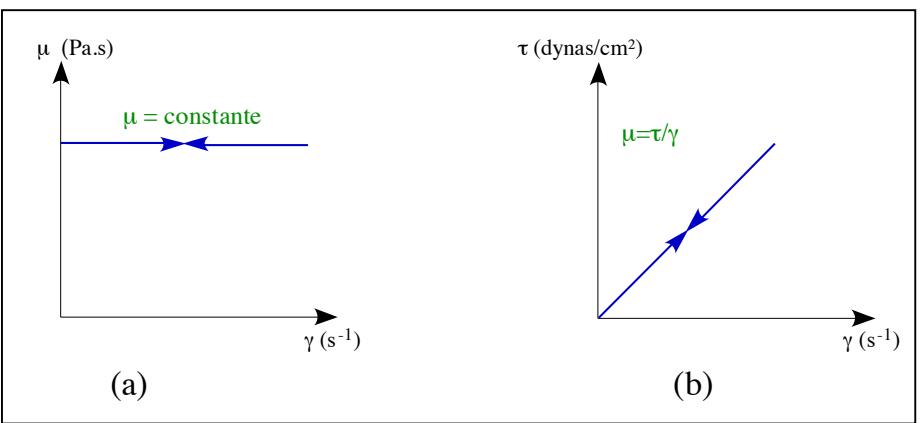

FIGURA 10 - Comportamento de um fluido Newtoniano (Brodkey, 1967). 
Conforme mostrado na FIG. 10, as propriedades reológicas de fluidos Newtonianos são independentes da taxa de cisalhamento, sendo dependentes somente da composição e da temperatura (Sharma et al., 2000).

Muitos alimentos, como leite, sucos, vinho e cerveja apresentam comportamento Newtoniano, assim como, líquidos simples (como a água), soluções de baixa massa molecular, dispersões diluídas e soluções poliméricas diluídas.

Para fluidos não-Newtonianos, a relação entre a tensão de cisalhamento $(\tau)$ e a taxa de cisalhamento (deformação) $(\gamma)$ não é constante mesmo em escoamento laminar a temperatura e pressão constantes. Define-se uma viscosidade aparente que varia com a magnitude da taxa de deformação $(\gamma)$. Qualquer fluido não-Newtoniano pode ser representado pela relação:

$$
\mu \alpha=\frac{\tau}{\gamma}
$$

sendo, $\mu \alpha$ a viscosidade aparente válida para uma determinada taxa de deformação. Esses fluidos podem ser classificados em: viscoelásticos, dependentes e independentes do tempo, conforme pode ser visto na FIG.11.

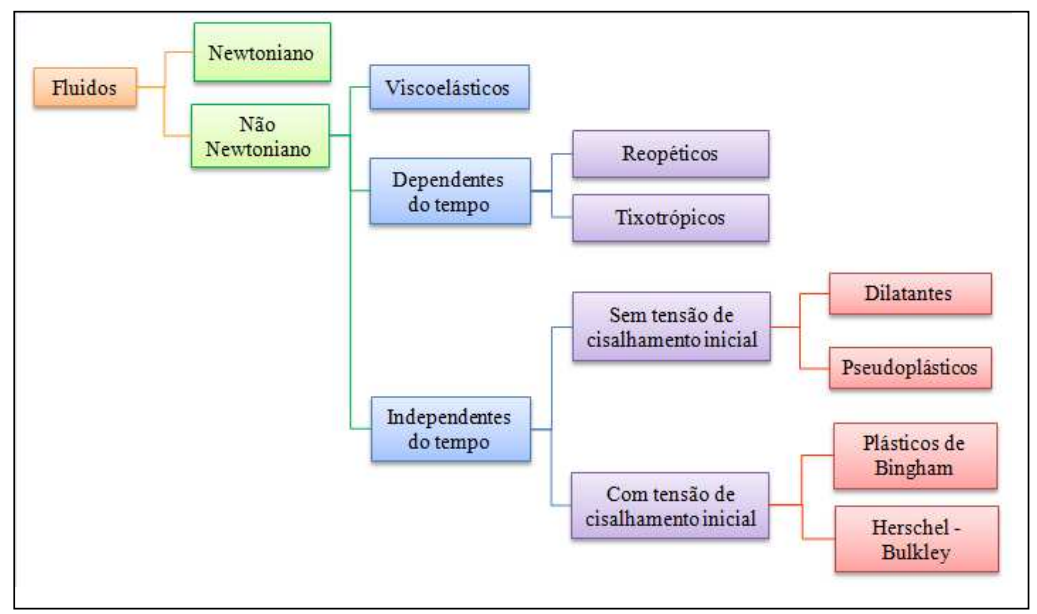

FIGURA 11 - Classificação dos fluidos segundo seu comportamento reológico (Brodkey, 1967). 
Os fluidos não-Newtonianos podem ser dependentes ou independentes do tempo. Para os fluidos não-Newtonianos independentes do tempo, à temperatura e composição constantes, a viscosidade aparente depende da taxa ou da tensão de cisalhamento (Rao \& Rizvi, 1986). Estes podem ainda ser classificados sem ou com tensão de cisalhamento inicial.

Os fluidos não-Newtonianos independentes do tempo, não necessitam de uma tensão de cisalhamento inicial para começarem a escoar e compreendem a maior parte dos fluidos. Dentro dessa classe, destacam-se os fluidos pseudoplásticos, que apresentam um estado desordenado em repouso e quando submetidos a uma tensão de cisalhamento suas moléculas tendem a se orientar na direção da força aplicada (FIG.12). Quanto maior a tensão aplicada, maior será a ordenação das moléculas do fluido. Portanto, a viscosidade aparente será menor (Holdsworth, 1971).

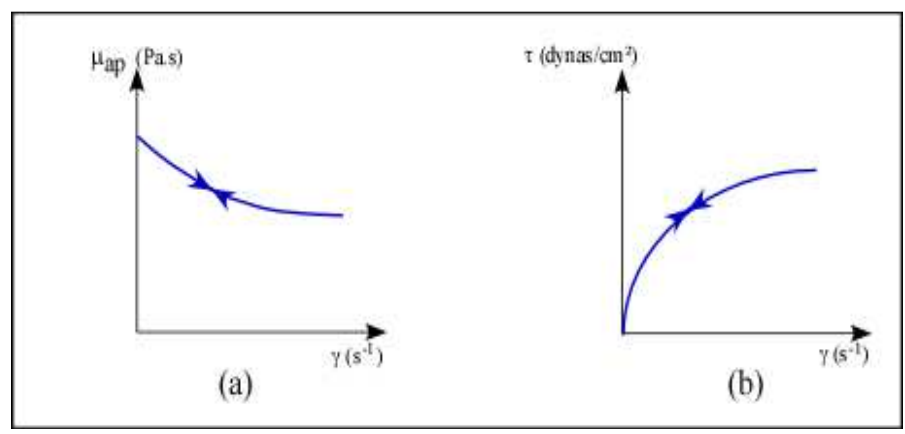

FIGURA 12 - Curvas de (a) viscosidade e (b) de fluxo de fluidos pseudoplásticos (Brodkey, 1967).

Para os fluidos dilatantes a viscosidade aumenta à medida que aumenta a taxa de cisalhamento. Sendo portanto, o inverso ao fenômeno da pseudoplasticidade. Como as partículas se movem umas sobre as outras rapidamente, elas necessitam de mais espaço e o fluido como um todo dilata. Como não existe líquido suficiente para preencher os espaços vazios maiores, a viscosidade aparente aumenta, conforme indica a FIG.13. 


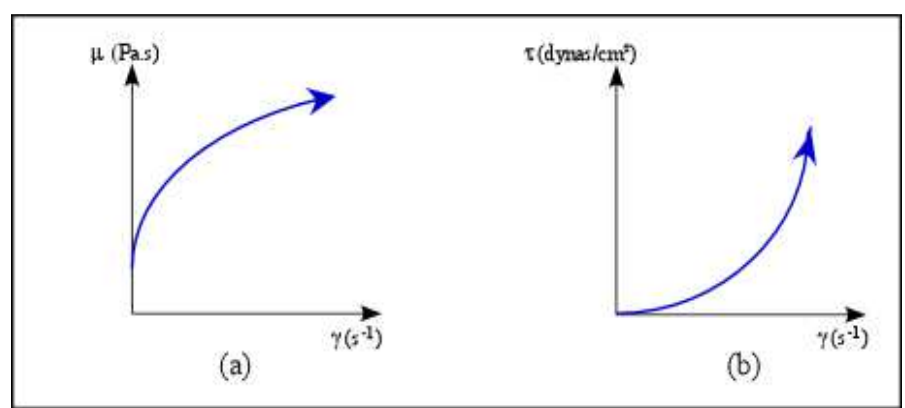

FIGURA 13 - Curvas de (a) viscosidade e (b) de fluxo de fluidos dilatantes (Brodkey, 1967).

Quando o fluido é não-Newtoniano, para que o fluido comece a escoar é necessário uma tensão de cisalhamento mínima inicial, denominado de limite de escoamento, para que haja alguma deformação cisalhante (FIG.14). Pode ser dividido em duas classes: os fluidos plásticos de Bingham e de Herschel-Bulkley.

Segundo McClements (2015), o fluido de Bingham se comporta como um sólido sob condições estáticas. Uma certa quantidade de força deve ser aplicada antes que o fluxo seja induzido (tensão inicial). Exemplos de fluidos alimentícios que representam esse comportamento são: molhos de tomate, maionese, clara de ovo batida e margarina.

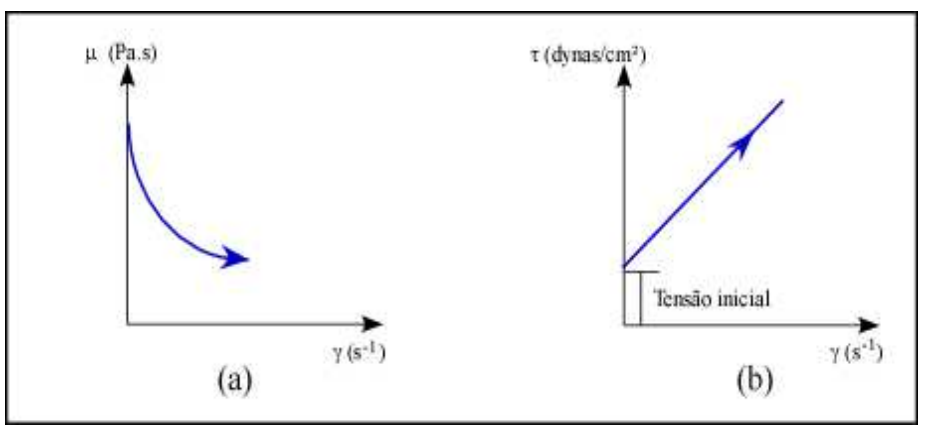

FIGURA 14 - Curvas de (a) viscosidade e (b) de fluxo de fluidos plásticos de Bingham (Skelland, 1967).

A FIG. 15 mostra as curvas de escoamento do comportamento reológico de fluidos não-Newtonianos dependentes do tempo de cisalhamento. 


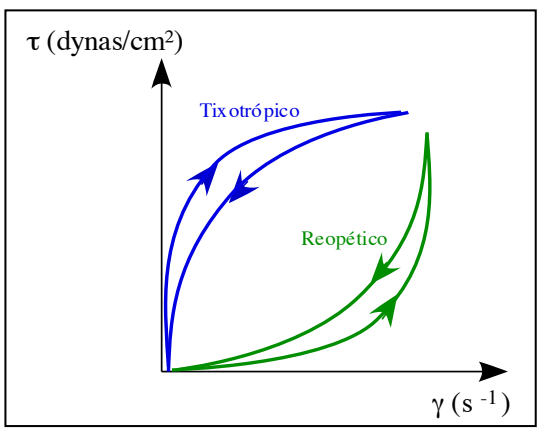

FIGURA 15 - Curvas de escoamento de fluidos não newtonianos de propriedades dependentes do tempo de cisalhamento (Skelland, 1967).

Materiais tixotrópicos e reopéticos, exibem, respectivamente, aumento e diminuição na tensão de cisalhamento (e viscosidade aparente) sob tempo e taxa de cisalhamento fixo (Steffe, 1996).

A tixotropia é observada quando diminui a viscosidade aparente com o tempo de cisalhamento, a uma taxa de deformação constante. Como na pseudoplasticidade, a diminuição da viscosidade aparente com o tempo é também devido à quebra de uma estrutura organizada no fluido (FIG.16).

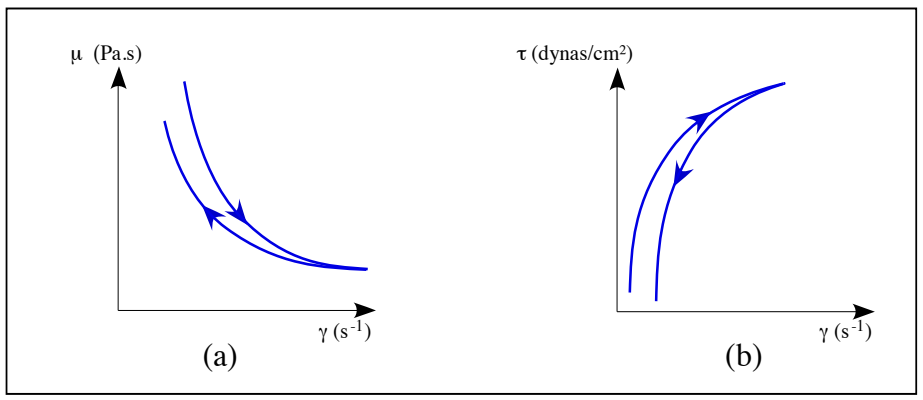

FIGURA 16 - Curvas de (a) viscosidade e (b) de fluxo de fluidos tixotrópicos (Skelland, 1967).

Já os fluidos reopéticos apresentam um comportamento inverso ao dos tixotrópicos, ou seja, a viscosidade aparente destes fluidos aumenta com o tempo de aplicação da tensão, retornando à viscosidade inicial quando a força cessa (FIG. 17). 


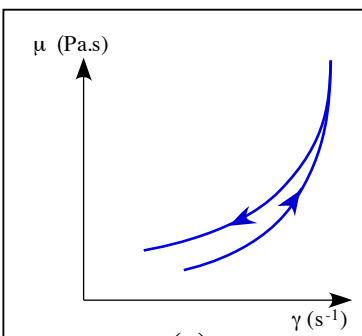

(a)

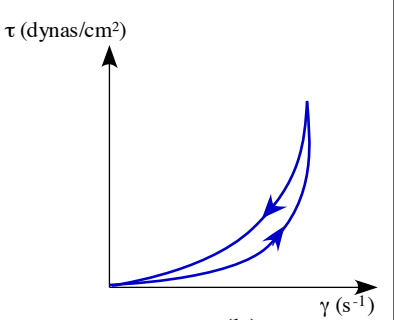

(b)

FIGURA 17 - Curvas de viscosidade (a) e de fluxo (b) de fluidos reopéticos (Skelland, 1967).

Através do levantamento da curva de tensão de cisalhamento e taxa de deformação, pode-se caracterizar o fluido reologicamente. De acordo com Brodkey (1967), o levantamento da curva de escoamento em escala logarítmica auxilia na caracterização. A FIG. 18 ilustra o comportamento de alguns fluidos em escala linear e logarítmica.

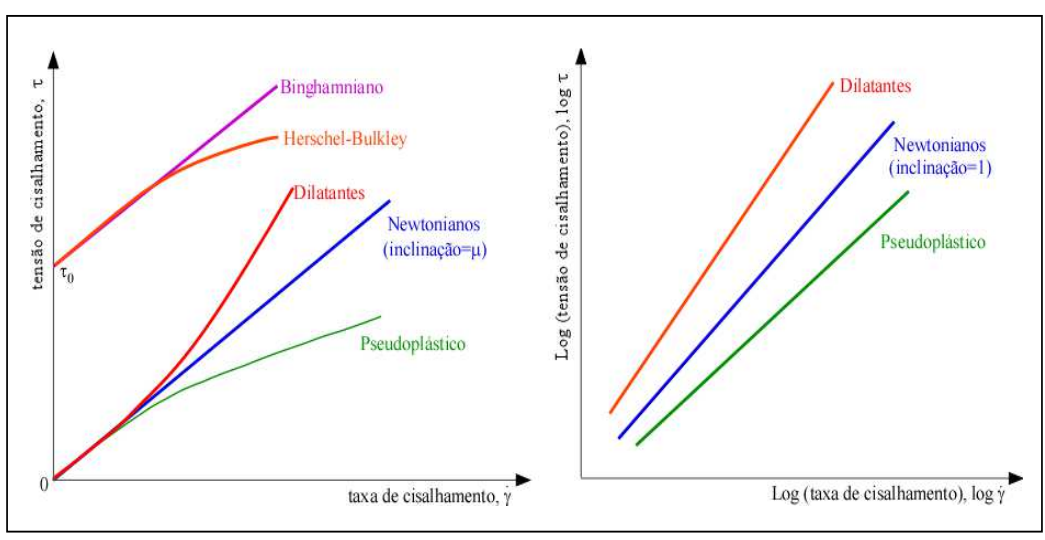

FIGURA 18 - Diagrama ilustrativo dos comportamentos reais dos fluidos (Brodkey, 1967).

Os modelos reológicos são usados para caracterizar diferentes produtos alimentícios. Alguns dos modelos reológicos mais utilizados são os modelos Lei da Potência, (Ostwald-De-Walle) de dois parâmetros e Herschel Bulkley de três parâmetros (Pelegrine et al., 2002). 
Muitos fluidos alimentícios exibem comportamento pseudoplástico e são caracterizados através do modelo Lei da Potência, equação 6 (Steffe, 1996):

$$
\tau=K \gamma^{\mathrm{n}}
$$

onde:

- $\mathrm{K}=$ Coeficiente de consistência (Pa.s)

- $\tau=$ Tensão de cisalhamento $(\mathrm{Pa})$

- $\gamma=$ Taxa de cisalhamento $\left(s^{-1}\right)$

- $\mathrm{n}=$ Índice de comportamento (adimensional)

A viscosidade aparente é expressa como (equação 7):

$$
\eta \text { ap }=\frac{\tau}{\gamma}=\mathrm{K} \cdot \gamma^{\mathrm{n}-1}
$$

Se o índice de comportamento reológico $\mathrm{n}$ for $>1$ o fluido é considerado dilatante, o qual corresponde ao fenômeno inverso da pseudoplasticidade, pois a viscosidade do fluido aumenta à medida que aumenta a taxa de cisalhamento. Se $\mathrm{n}$ for $<1$ o fluido é considerado pseudoplástico (Steffe, 1996).

Os modelos reológicos de três parâmetros têm sido muito utilizados para o ajuste de dados reológicos obtidos de diversos produtos alimentícios. A relação geral que descreve o comportamento dos fluidos não-Newtonianos é o modelo de Herschel-Bulkley (equação 8). Esse modelo é uma forma modificada da Lei da Potência (Rao \& Cooley, 1982), o que diferencia um do outro é a presença ou ausência do termo da tensão de cisalhamento inicial.

$$
\tau=\tau o+K \gamma^{\mathrm{n}}
$$

onde: 
$\tau=$ Tensão de cisalhamento $(\mathrm{Pa})$

$\tau o=$ Tensão de cisalhamento inicial $(\mathrm{Pa})$

$\mathrm{K}=$ Coeficiente de consistência $\left(\mathrm{Pa} \cdot \mathrm{s}^{n}\right)$

$\mathrm{n}=$ Índice do comportamento do fluido (adimensional)

$\gamma=$ Taxa de cisalhamento $\left(\mathrm{s}^{-1}\right)$

Dispersões gelatinizadas de amido geralmente são representadas pela Lei da Potência (Self et al., 1990; Ramaswamy et al., 1995; Okechukwu \& Rao, 1995; Nguyen et al., 1998, Xu \& Raphaelides, 1998; Nurul et al., 1999) ou pelo modelo de Herschel-Bulkley (Christianson \& Bagley, 1984; Doublier et al., 1987, Ramaswamy et al., 1995; Bhattacharya \& Bhattacharya, 1996) outros modelos como o plástico de Bingham, Casson, Mizrahi-Berk tem sido testados (Lagarrigue \& Alvarez, 2001).

\subsection{Análises Térmicas}

Trata-se de um sistema capaz de medir continuamente a massa de um material enquanto este é submetido a uma programação controlada de temperatura. Esse sistema foi denominado de termobalança e fez surgir a técnica termoanalítica e a termogravimetria (TG) (Ionashiro, 2005).

Modificações da estrutura molecular ocorrem quando grânulos (amido, por exemplo) são submetidos ao aquecimento. Tal informação é de extrema importância no sentido de avaliar a decomposição de diferentes produtos. A termogravimetria permite conhecer detalhadamente as alterações que 0 aquecimento pode causar na massa das substâncias e ainda estabelecer a faixa de temperatura em que as mesmas adquirem composição química definida, ou sofrem processos de decomposição (Carvalho Filho, 2000).

As curvas TG permitem obter conclusões sobre a estabilidade térmica da amostra, composição, estabilidade dos compostos intermediários, além da composição do resíduo sendo, entre as técnicas termo-analíticas, a mais utilizada (lonashiro, 2005). 
Nas curvas de TG, a perda de massa (expressa no eixo vertical em percentagem) é caracterizada por duas temperaturas (no eixo horizontal) Ti e Tf. De acordo com Giolito e Ionashiro (1980), Ti é a temperatura inicial de decomposição e Tf é a temperatura final. A temperatura inicial de decomposição é a temperatura na qual a variação de massa acumulada atinge o valor que a termobalança é capaz de detectar. A temperatura final é a temperatura na qual a variação de massa acumulada atinge seu valor máximo de degradação, correspondendo ao término da reação. A diferença entre essas duas temperaturas (Tf-Ti) é chamada de intervalo de reação. Segundo Matos et al. (2009) a temperatura em que se inicia a perda de massa é a temperatura inicial do evento, ou seja, o ponto onde a amostra deixou de ser estável termicamente e iniciou a liberação de substâncias voláteis.

\subsection{Microscopia e Espectroscopia de amidos}

A microscopia eletrônica de varredura é utilizada em muitos trabalhos para a definição da estrutura dos grânulos, principalmente quando se estuda amidos de diferentes fontes botânicas com diferentes tratamentos de modificação (Adebowale et al., 2006; Lewandowicza \& Soralsmietana, 2004; Martinez-Bustos et al., 2007 e Scmitz et al., 2006).

A espectroscopia na região do infravermelho é uma técnica de inestimável importância na análise orgânica qualitativa, sendo amplamente utilizada nas áreas de química de produtos naturais, síntese e transformações orgânicas. A espectroscopia na região do infravermelho tem sido, também, amplamente utilizada em linhas de produção, no controle de processos industriais (Lopes \& Fascio, 2004).

\subsection{Aplicações do amido}

Os amidos naturais e modificados, além do seu valor nutritivo, apresentam inúmeras aplicações industriais (alimentícia e farmacêutica). Estes podem ser usados como: gelificantes, espessantes, adesivos, retentores de umidade, estabilizantes e texturizantes (Silva et al., 2006), assim como ser 
utilizados na embalagem final do produto (National Starch and Chemical Industrial Ltda, 1995) ou na fabricação de plásticos biodegradáveis, como por exemplo em conjunto com polietileno de baixa densidade (Lim et al.,1992). Segundo Vieira (2004), não é possível generalizar sobre propriedades e comportamento dos amidos de diferentes fontes botânicas, uma vez que cada amido possui características próprias e, tendo isso reconhecido, a pesquisa e desenvolvimento de novos produtos têm caminhos abertos.

\subsection{Conservação de produtos alimentícios pela radiação}

A irradiação de alimentos consiste na exposição do alimento à radiação ionizante proveniente de feixes de elétrons ou de fontes radioativas (Silva \& Roza, 2010). A radiação refere-se à energia radiante que se move através do espaço na forma de ondas eletromagnéticas, enquanto irradiação é um processo no qual uma faixa de energia eletromagnética conhecida como radiação ionizante penetra o produto exposto às fontes de radiação. Assim, radiações ionizantes são partículas ou fótons com energia suficiente para produzir íons (partículas eletricamente carregadas) nos materiais com os quais entram em contato (Souza, 2006).

Existem três tipos de energia radiante utilizada para a irradiação de alimentos: feixes de elétrons, raios- $X$ e raios gama. Os dois primeiros utilizam eletricidade como fonte de energia, enquanto, para a radiação gama, são utilizadas fontes radioativas de ${ }^{60} \mathrm{Co}$ ou ${ }^{137} \mathrm{Cs}$ (Mastro, 2015).

As fontes de ${ }^{60} \mathrm{Co}$ e ${ }^{137} \mathrm{Cs}$ são as mais utilizadas para uso comercial, devido à produção de raios gama de energias adequadas, disponibilidade e custo, sendo a fonte de ${ }^{60} \mathrm{Co}$ com maior aceitação por apresentar-se na forma metálica e ser insolúvel em água, proporcionando assim maior segurança ambiental (Silva \& Roza, 2010).

O mecanismo de ação da radiação gama e raios- $X$ envolve os processos de: i) efeito fotoelétrico; ii) produção de pares e iii) efeito Compton, este último, o principal mecanismo de transferência de energia em alimentos irradiados. Neste processo, um fóton incidente interage com o átomo e transfere 
sua energia, provocando a ejeção de elétrons. Os elétrons ejetados contêm energia suficiente para causar excitação e ionização nos átomos restantes. A radiação penetra profundamente no alimento e, por meios físicos, interage com átomos e moléculas, provocando transformações químicas e biológicas (Urbain, 1986).

A radiação ionizante penetra no alimento e pode agir diretamente sobre os componentes essenciais da célula ou, indiretamente, proporcionando a formação de produtos radiolíticos, particularmente, os radicais livres formados a partir da água. Entretanto, o processo de formação de radicais livres é rápido e o rearranjo entre as moléculas acontece na mesma velocidade (Worcman-Barninka \& Langraf, 2003).

As doses de radiação são quantificadas em termos de energia absorvida pelo produto irradiado, sendo expressa em quilogray (kGy), no qual 1 kGy correspondente a 1 quilojoule de energia absorvida por quilograma de produto irradiado (Kong et al., 2009; Silva \& Roza, 2010). A Agência Nacional de Vigilância Sanitária (ANVISA), não estabelece um limite de dose para irradiação de alimentos nem restrição a utilização de alimentos irradiados. Estabelece, entretanto, que qualquer alimento pode ser tratado por radiação desde que a dose mínima absorvida seja suficiente para atender a finalidade pretendida e a dose máxima absorvida seja inferior àquela que comprometem as propriedades funcionais e/ou os atributos sensoriais do alimento. Estabelece ainda que qualquer produto irradiado mesmo usado como ingrediente em outro alimento, deve ser mencionado na embalagem final (Brasil, 2001).

Dentre as vantagens do processo de irradiação pode-se citar: pouco ou nenhum aquecimento, os alimentos podem ser submetidos à irradiação embalados e/ou congelados exigindo baixo custo de energia e operacional, além da automação do processo de controle. A principal desvantagem é o alto custo de implantação de uma unidade de irradiação (Bao et al., 2005; Bhat \& Karim, 2009; Lima Filho et al., 2012).

A utilização da irradiação em alimentos visa inativar microrganismos, retardar o amadurecimento, o envelhecimento ou brotamento dos vegetais $\mathrm{e}$ desinfestar os grãos, utilizando-se para isso doses adequadas de modo a manter 
as características sensoriais e nutricionais mais próximas do natural (Lima Filho et al., 2012).

A irradiação de alimentos, assim como outras técnicas de processamento, induz certas alterações que podem modificar a composição química e o valor nutritivo dos alimentos, principalmente em se tratando de carboidratos, proteína, aminoácidos e lipídeos (Kilcast, 1994; Wiendl, 1984). Essas modificações incluem: despolimerização de macromoléculas, ligações cruzadas ou reticulação, onde cadeias poliméricas são unidas e ligações de alta massa molecular são formadas (Mastro, 2011). Normalmente, a reticulação traz uma melhoria das propriedades mecânicas, resistência química, estabilidade térmica e outras propriedades importantes (Bosch, 2005). Se a degradação polimérica for o fenômeno predominante há uma redução da massa molecular pela quebra de cadeias, e a propriedade física de escoamento desse polímero aumenta e o tamanho das partículas podem ser reduzidos (Choe \& Min, 2006). São necessários estudos específicos para a aplicação desta técnica em diversos alimentos.

No processo de irradiação ocorre a formação de radicais livres. Esse processo se dá por meio da absorção da radiação pela água com formação de íons e radicais (radiólise da água). O radical hidroxila $(\mathrm{OH})$ formado é um poderoso agente oxidante e reage, preferencialmente, com compostos insaturados presentes nos alimentos, especialmente com polienos conjugados e com hidrogênio presente em ligações $\mathrm{C}-\mathrm{H}$ e $\mathrm{S}-\mathrm{H}$. Os radicais livres e os íons formados por efeito primário são muito reativos, podendo interagir entre si ou com constituintes do alimento. Essas reações ocorrem rapidamente e são denominadas de efeitos secundários, responsáveis por $80 \%$ dos efeitos provocados pela radiação (Souza, 2006).

A capacidade dos radicais de se difundir no meio depende das condições que se encontram os alimentos. Em alimentos sólidos secos ou congelados, a difusão é restrita. Quando o material absorve umidade ou ocorre descongelamento, esses radicais começam a se movimentar, reagindo entre si ou com os constituintes dos alimentos, resultando na formação de produtos finais estáveis (Lagunas-Solar, 1995). Os produtos resultantes dessas reações são denominados produtos radiolíticos sendo que frequentemente esses produtos 
estão naturalmente presentes nos alimentos, gerados por outros processos (ICGFI, 1999; FAO, 1999).

\subsection{Efeito da radiação gama no amido}

A irradiação é um método de modificação física sobre o amido, com as vantagens de ser um processo rápido e extensivo. A energia ionizante penetra no grânulo do amido podendo causar maiores alterações na sua estrutura quando comparada com outros métodos como: micro-ondas, ultravioleta, pressão hidrostática ultra-alta e tratamento hidrotérmico (Bao et al., 2005).

Foi descrito na literatura o efeito da radiação gama no amido, agindo de forma direta e indireta. Na forma direta, o amido absorve energia dos raios gama e suas ligações glicosídicas são clivadas, levando à decomposição das macromoléculas do amido em cadeias menores, já na forma indireta a interação ocorre com a água, produzindo radicais livres e peróxidos que, por sua vez, são capazes de induzir alterações moleculares como a fragmentação das cadeias poliméricas (FIG. 19). Além disso, outros produtos podem ser gerados a partir de carboidratos irradiados como o ácido fórmico, acetaldeído e formaldeído (Bhat \& Karim, 2009; Yoon et al., 2010).

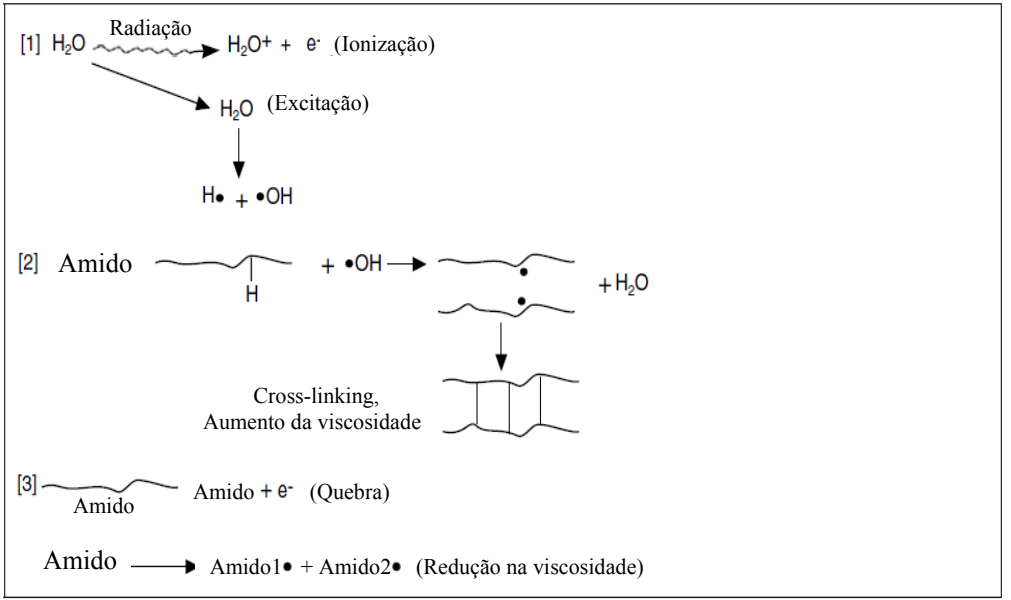

FIGURA 19 - Promoção da degradação [3] e Cross-linking [1] e [2] nas cadeias de amido pela irradiação gama (Bhat \& Karim, 2009 com adaptações). 
O processo de irradiação também pode levar à formação de ligações cruzadas ou reticulação (cross-linking) [2] na matriz do amido (FIG. 19). Segundo Chung e Liu (2009) a formação de ligações cruzadas é maior quando a radiação gama é aplicada com menor taxa de dose. Este fenômeno é bastante importante, pois vários métodos empregados atualmente para formação das ligações cruzadas na indústria alimentícia utilizam agentes químicos de reticulação (Bhat \& Karim, 2009).

A radiação gama age nas regiões amorfas e cristalinas do amido, no entanto, a amilopectina por apresentar alto grau de polimerização comparada com a amilose, possue maior probabilidade de alteração molecular (Chung \& Liu, 2010; Yu \& Wang, 2007).

Aparentemente a estrutura do grânulo do amido permanece visualmente sem danos quando irradiado em baixas doses de radiação, mas pode apresentar fissuras em doses maiores (20, $50 \mathrm{kGy}$ ), dependendo da fonte botânica. A cristalinidade relativa e a entalpia de gelatinização podem aumentar ou diminuir com o aumento da dose, novamente, de acordo com o genótipo. Em contrapartida, as cadeias de amilose e amilopectina diminuem progressivamente, com o aumento da dosagem de radiação (Bao et al., 2005; Chung \& Liu, 2009; 2010; Gani et al., 2012; Kong et al., 2009). 


\section{MATERIAL E MÉTODOS}

\subsection{Material}

Amido de milho, fécula de batata e polvilho azedo adquiridos no comércio local de produtos alimentícios.

\subsection{Irradiações}

As amostras na forma de pó foram colocadas em embalagens de polietileno (60 kGy é dose máxima permitida para este material pelo Food and Drug Administration dos EUA, segundo consta no Packaging Materials Listed in 21 CFR 179.45 for Use During Irradiation of Prepackaged Foods) e submetidas a irradiação no Centro de Tecnologia das Radiações (CTR), Instituto de Pesquisas Energéticas e Nucleares (IPEN/CNEN-SP), em fonte de cobalto-60 Gammacell 220 da Atomic Energy of Canada Ltd (AECL) com doses de 0, 1, 5, 10 e $15 \mathrm{kGy}$, taxa de dose em torno de $1 \mathrm{kGy} / \mathrm{h}$ e fator de uniformidade de dose de 1.13. As doses foram escolhidas de acordo ao critério, doses baixas, até $1 \mathrm{kGy}$, médias, até 10 kGy e altas, acima de 10 kGy.

\subsection{Preparo dos hidrogéis}

As amostras foram preparadas com $5 \mathrm{~g}(\mathrm{~m} / \mathrm{v})$ de amido $\left(\mathrm{C}_{6} \mathrm{H}_{10} \mathrm{O}_{5}\right)_{n}, 3 \mathrm{~g}$ $(\mathrm{m} / \mathrm{m})$ de glicerol $\left(\mathrm{C}_{3} \mathrm{H}_{8} \mathrm{O}_{3}\right), 0,5 \mathrm{~g}$ de propionato de cálcio $\left(\mathrm{C}_{6} \mathrm{H}_{10} \mathrm{CaO}_{4}\right)$ e completados para $100 \mathrm{~mL}$ com água destilada, sendo a seguir, aquecidas em bico de Bunsen com agitação constante para que ocorresse a completa gelatinização de cada tipo de amido. As amostras foram analisadas no viscosímetro Brookfield. 


\subsection{Preparo dos filmes}

As amostras foram preparadas conforme descrito anteriormente (item 4.3) até a obtenção da gelatinização. Posteriormente, $60 \mathrm{~g}$ de cada amostra, foram distribuídas na forma de camada (espessura 1,5-1,7 mm) em placas de vidro quadrada $(18 \times 20 \mathrm{~cm})$ forradas com polietileno de $15 \mathrm{~cm}$ de diâmetro e conduzidas a secagem em estufa a $25{ }^{\circ} \mathrm{C}$ por 72 horas ou até secagem dos filmes. Após, os filmes foram removidos manualmente das placas e cortados de acordo com a medida adequada para cada teste. As análises realizadas nos filmes foram colorimetria, textura, solubilidade e absorção de água.

\subsection{Análises realizadas nos pós de amidos}

\subsubsection{Morfologia e tamanho dos grânulos}

Para a análise da forma e tamanho dos grânulos dos diferentes amidos, utilizou-se a microscopia eletrônica de varredura e a microscopia óptica.

\subsubsection{Microscopia Óptica}

As análises de microscopia óptica foram realizadas no Centro de Biotecnologia (CB-IPEN). As amostras analisadas foram aquelas irradiadas com 0 e $15 \mathrm{kGy}$ de cada tipo de amido. A diluição foi preparada na proporção de 100 $\mathrm{mg} / \mathrm{mL}$ com solução tampão fosfato salino ou phosphate buffered saline (PBS). A seguir a amostra foi disposta em uma lâmina de vidro e coberta com lamínula para observação dos grânulos a um aumento de 10x, em um microscópio Nikon Eclipse 80i (FIG. 20) e fotografadas com o auxílio do software NIS-Elements. Foram feitas 5 fotografias de campos diferentes de cada lâmina. As fotografias foram analisadas mediante o programa ImageJ, para avaliação do tamanho dos grânulos. Em função da irregularidade nos formatos foram tomadas medidas do diâmetro maior e menor ( $\mu \mathrm{m})$. 


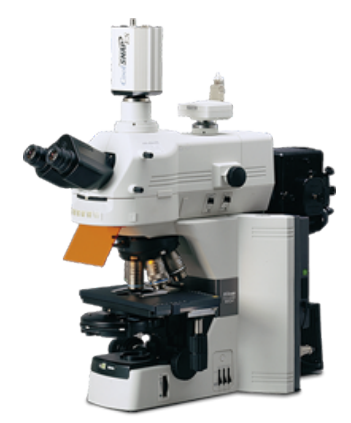

FIGURA 20 - Microscópio Óptico Nikon Eclipse 80i.

\subsubsection{Microscopia Eletrônica de Varredura (MEV)}

A caracterização morfológica dos grânulos de amido das amostras foi realizada empregando a microscopia eletrônica de varredura (MEV) do laboratório de Microscopia \& Microanálise do CCTM, IPEN-CNEN/SP. As amostras nas doses de 0 e 15 kGy foram colocadas em suportes apropriados (stubs) com fita adesiva dupla face e submetidas à aplicação de camada de $20 \mathrm{~nm}$ de ouro em metalizador, à vácuo por 20 minutos. As amostras metalizadas foram observadas em microscópio eletrônico de varredura (MEV) da marca Hitashi, modelo TM3000 (FIG. 21), utilizando uma aceleração de voltagem de $15 \mathrm{kV}$, as micrografias foram tiradas nas escalas de 500x e 1000x de magnificação.

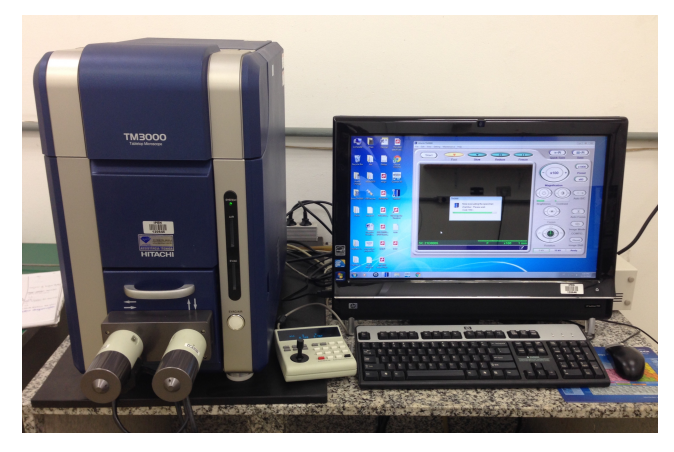

FIGURA 21 - Microscópio Eletrônico de Varredura (IPEN-CCTM).

\subsubsection{Termogravimetria (TG)}

As análises térmicas foram realizadas no CTR, utilizando o analisador termogravimétrico modelo SDT Q600 (FIG. 22). Foi realizada termogravimetria 
dinâmica, onde a massa da amostra foi registrada em função do aumento da temperatura.

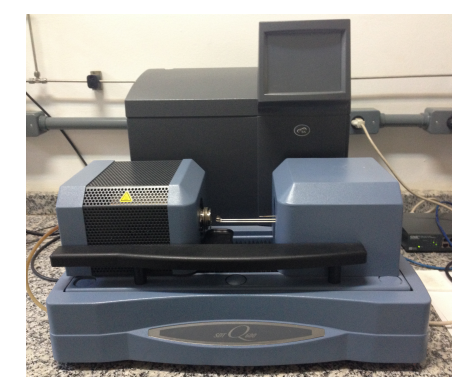

FIGURA 22 - Analisador Termogravimétrico modelo SDT Q600 (IPEN-CTR).

As amostras analisadas foram aquelas irradiadas com 0 e $15 \mathrm{kGy}$ para cada tipo de amido estudado. As amostras foram pesadas e acondicionadas em cadinhos de platina. As condições de análise foram: massa da amostra de 5,0 $\pm 1,0$ $\mathrm{mg}$, vazão de $\mathrm{N}_{2}$ de $20 \mathrm{~mL} \cdot \mathrm{min}^{-1}$, razão de aquecimento de $20^{\circ} \mathrm{C} \cdot \mathrm{min}^{-1}$ e faixa de temperatura de 25 a $600^{\circ} \mathrm{C}$.

\subsubsection{Espectroscopia no Infravermelho por Transformada de Fourier (FTIR)}

As análises espectroscópicas no infravermelho foram realizadas utilizando um espectrofotômetro Spectrum 1000 da Perkin-Elmer com transformada de Fourier, localizado no CTR-IPEN/SP. O espectro foi obtido com 16 repetições na faixa de 4000 a $400 \mathrm{~cm}^{-1}$. As amostras analisadas foram aquelas irradiadas com doses de 0 e $15 \mathrm{kGy}$.

\subsubsection{Difração de raios-X (DRX)}

Essa análise foi realizada no Laboratório de Difração de raios-X do Centro Combustível Nuclear (CCN-IPEN/SP). O equipamento utilizado foi um Bruker D8 Advance, equipado com tubo de Cu operando em $40 \mathrm{kV}$ e $30 \mathrm{~mA}$, monocromador de grafite e detector de cintilação. $O$ raio do goniômetro é de 250 $\mathrm{mm}$. Foram utilizadas as seguintes identificações: fendas antiespalhamento e 
divergente de 2,0 $\mathrm{mm}$ e fenda de recepção de 0,4 $\mathrm{mm}$, a velocidade de varredura foi de $2^{\circ}$ por minuto, sob ângulo $2 \theta$ variando de 4 a $40^{\circ} \mathrm{C}$. A relação entre a área dos picos e a área total resultou na cristalinidade relativa. As amostras analisadas foram nas doses de 0 e $15 \mathrm{kGy}$ de cada amido. Esta análise foi utilizada a fim de estimar as frações cristalinas e amorfas de cada amostra.

O índice de cristalinidade foi quantitativamente estimado pelo método de Nara e Komiy (1983), através da plotagem computacional entre a área dos picos e a área total dos gráficos. Os mesmos foram plotados entre os ângulos $2 \theta$ de 4 e $40{ }^{\circ} \mathrm{C}$. Os índices de cristalinidade foram calculados com o auxílio do software Bruker EVA ${ }^{\circledR}$. Considerou-se para os cálculos a razão do somatório das áreas dos picos cristalinos pela área total de todas as curvas gaussianas de acordo com a Equação 9:

$$
\mathrm{Xc}=\frac{\mathrm{Ac}}{(\mathrm{Ac}+\mathrm{Aa})}
$$

onde:

$\mathrm{Xc}=$ Índice de cristalinidade

Ac $=$ Área cristalina

$\mathrm{Aa}=$ Área amorfa

\subsection{Análises realizada nos hidrogéis}

\subsubsection{Viscosimetria}

A viscosimetria foi realizada em viscosímetro Brookfield, modelo LVDVIII, com adaptador de pequenas amostras (SSA) e o "spindle" adequado dependendo da viscosidade do fluido, com banho termostatizado Neslab modelo RTE-210, precisão $\pm 0,1{ }^{\circ} \mathrm{C}$ (FIG. 23) localizado no CTR. As diluições foram preparadas mediante aquecimento até o ponto de gelatinização de cada amido. $O$ viscosímetro, acoplado a um software Rheocalc VI.1, forneceu para cada amostra o valor de velocidade de rotação do spindle, a viscosidade aparente, tensão e 
taxa de cisalhamento para cada valor de temperatura. As amostras foram analisadas a temperatura de $50^{\circ} \mathrm{C}$ e realizadas em duplicatas.
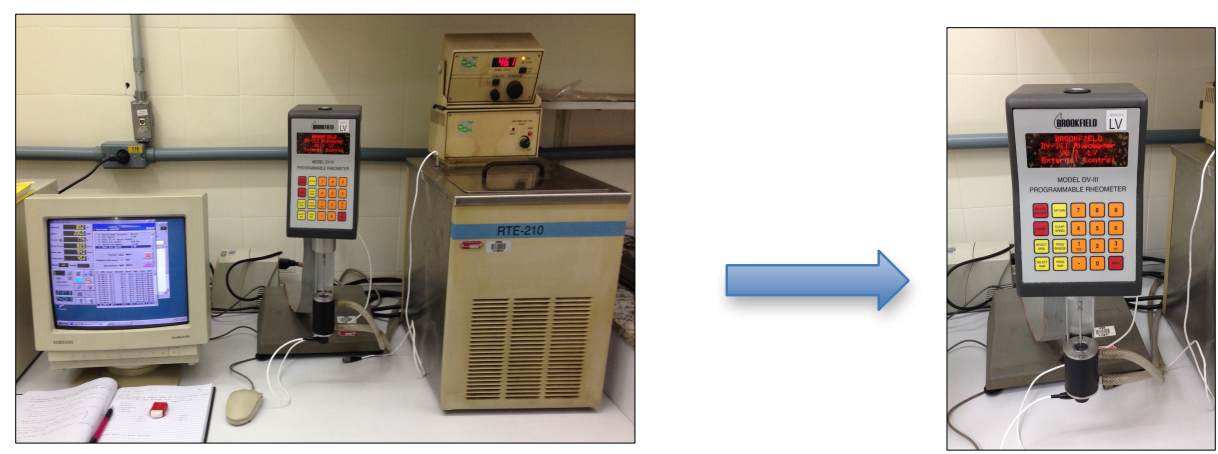

FIGURA 23 - Viscosímetro Brookfield com banho termostatizado Neslab.

\subsection{Análises realizadas nos filmes}

\subsubsection{Análise instrumental de textura}

A textura foi analisada utilizando o texturômetro Stable Micro Systems TA-XT2 com capacidade de compressão de $50 \mathrm{~kg}$ (FIG. 24). Os filmes foram cortados em quadrados de $30 \times 30 \mathrm{~mm}$ para a análise. Os acessórios utilizados foram: probe esférico de aço inox, de $35 \mathrm{~mm}$ de diâmetro $(P / 35)$ e um suporte para filme (HDP/FSR). As amostras foram comprimidas a uma velocidade de 1 $\mathrm{mm} \mathrm{s}^{-1}$ até $6 \mathrm{~mm}$ de compressão. $\mathrm{O}$ parâmetro avaliado foi a força máxima de ruptura $(\mathrm{N})$ dos filmes. Foram analisadas em torno de 15 amostras para cada dose de amido irradiado. Todas as análises foram realizadas em triplicata.

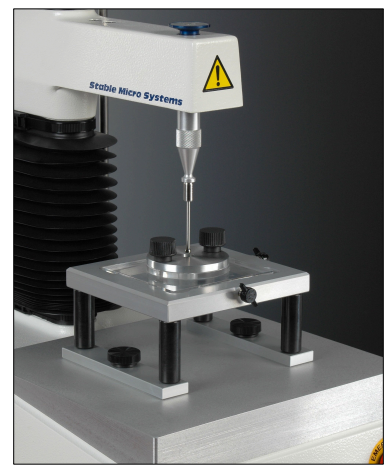

FIGURA 24 - Texturômetro Stable Micro Systems TA-XT2 (Extralab). 


\subsubsection{Análise instrumental da cor}

A avaliação da cor foi realizada utilizando-se colorímetro Chroma meter, modelo CR-400 (Konica Minolta Camera Co., Osaka, Japão) e a placa de calibração branco padrão CR-A43 (FIG. 25). Os filmes foram cortados em quadrados de $30 \times 30 \mathrm{~mm}$ e analisados.

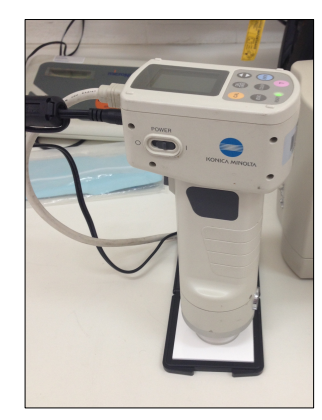

FIGURA 25 - Colorímetro Chroma meter e a placa de calibração branco padrão.

Os resultados foram expressos em CIELAB que é o sistema de cor mais utilizado para a avaliação de cor em alimentos. O colorímetro utilizado realizou as leituras por reflectância. O software utilizado para tratamento dos dados foi Spectra Magic NX. A análise de cor foi realizada segundo o espaço de cor CIE (Commission Internationale de l'Eclairage) $1976\left(\mathrm{~L}^{*}, \mathrm{a}^{*}, \mathrm{~b}^{*}\right)$ em que mede as três dimensões da cor: $L^{*}$, que representa o eixo da luminosidade, que vai de 0 (preto) a 100 (branco); $a^{*}$, que representa o eixo vermelho-verde (valores $+a^{*}$ direção para o vermelho, -a* direção para o verde); $b^{*}$, que representa o eixo amarelo-azul (+b* direção para o amarelo e -b* direção para o azul) (FIG. 27). O croma $\left(C^{*}\right)$ expressa a saturação ou intensidade da cor (Voss, 1992). O ângulo Hue quantifica a cor, no qual vermelho-arroxeado $=0^{\circ}$, amarelo $=90^{\circ}$, verde azulado $=180^{\circ}$ e azul $=270^{\circ}($ Voss, 1992$)$. 


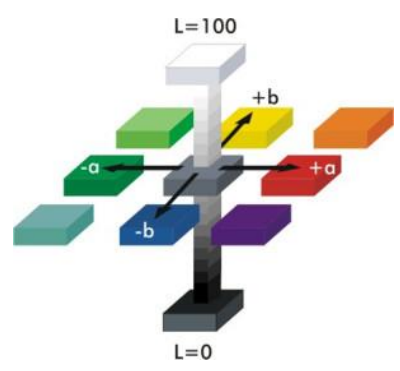

FIGURA 26 - Representação esquemática da escala Cielab.

Três leituras de valores $\left(L^{*}, a^{*}, b^{*}\right)$ foram medidas para cada filme e foram utilizados 15 filmes para cada ensaio para todas as doses estudadas. As análises foram feitas em triplicatas. O Croma e o ângulo Hue foram calculados usando as seguintes equações:

$$
\begin{gathered}
\mathrm{C}=\sqrt{(\mathrm{a})^{2}+(\mathrm{b})^{2}} \\
\mathrm{H}=180^{\circ}+\tan ^{-1}(b / a) \quad \text { para } \mathrm{a}^{*}<0
\end{gathered}
$$

\subsubsection{Capacidade de absorção de água (CAA)}

A capacidade de absorção de água dos filmes foi realizada utilizando o método descrito por Chiono et al. (2008). Amostras dos filmes foram cortadas em quadrados (10 x $10 \mathrm{~mm}$ ) e pesadas (Mi). Em seguida, foram colocadas em água destilada e armazenadas em temperatura ambiente durante $24 \mathrm{~h}$. Após, os filmes intumescidos foram removidos da água, secos com papel absorvente e pesados (Mf). Cada ensaio foi realizado em triplicata. Assim, o cálculo de absorção do filme (A) foi realizado de acordo com a seguinte equação:

$$
A(\%)=\frac{M f-M i}{M i} \times 100
$$




\subsection{4 Índice de solubilidade em água (ISA)}

O índice de solubilidade dos filmes à base de amido foi determinado pelo método proposto por Colla et al. (2006). Colocou-se uma secção do filme de $10 \times 10 \mathrm{~mm}$ em estufa a $105 \pm 1^{\circ} \mathrm{C}$ por $24 \mathrm{~h}$. Em seguida, a amostra foi pesada (mi) e inserida em um béquer com $50 \mathrm{~mL}$ de água destilada a $25^{\circ} \mathrm{C}$ (temperatura ambiente) por $24 \mathrm{~h}$. Logo após, os filmes foram novamente colocado em estufa a $105 \pm 1{ }^{\circ} \mathrm{C}$ por $24 \mathrm{~h}$ para secagem e posterior pesagem do mesmo para obtenção da massa final (mf). O procedimento para determinação da solubilidade foi realizado em triplicata. Com essa técnica foi possível determinar a perda de massa (pm) do filme por solubilização através da equação a seguir:

$$
\mathrm{pm}=\frac{\mathrm{mi}-\mathrm{mf}}{\mathrm{mi}}
$$

onde, pm é a perda de massa, mi é a massa inicial obtida na primeira pesagem e mf é a massa final.

\subsection{Análise estatística}

Os resultados obtidos foram analisados por Análise de Variância (ANOVA), a qual compara todas as médias em um único teste, objetivando identificar se existe diferença estatisticamente significativa entre as amostras. Caso esta diferença exista, aplicou-se, então, o teste Tukey que é uma técnica de comparação múltipla, para que se possam identificar quais médias diferem entre si. Foi utilizado para todos os testes estatísticos o nível de significância de $95 \%$ com o auxílio do software Statgraphics Plus 3.1 (Statistical Graphics Corp). 


\section{RESULTADOS E DISCUSSÃO}

\subsection{Análises dos amidos em pó}

\subsubsection{Morfologia e tamanho dos grânulos}

Os grânulos de amido diferem entre si na forma, tamanho e outras características, de acordo com a planta de origem (Franco et al., 2002). A microscopia eletrônica de varredura e óptica foi utilizada para o estudo da morfologia dos grânulos de amido e distribuição de tamanho. Os amidos irradiados e não irradiados foram observados por microscopia eletrônica de varredura. As FIG. 27-28, 30-31 e 33-34 apresentam as fotografias de MEV dos diferentes amidos irradiados e não irradiados, pelo qual pode-se verificar os diferentes formatos e tamanhos dos grânulos.
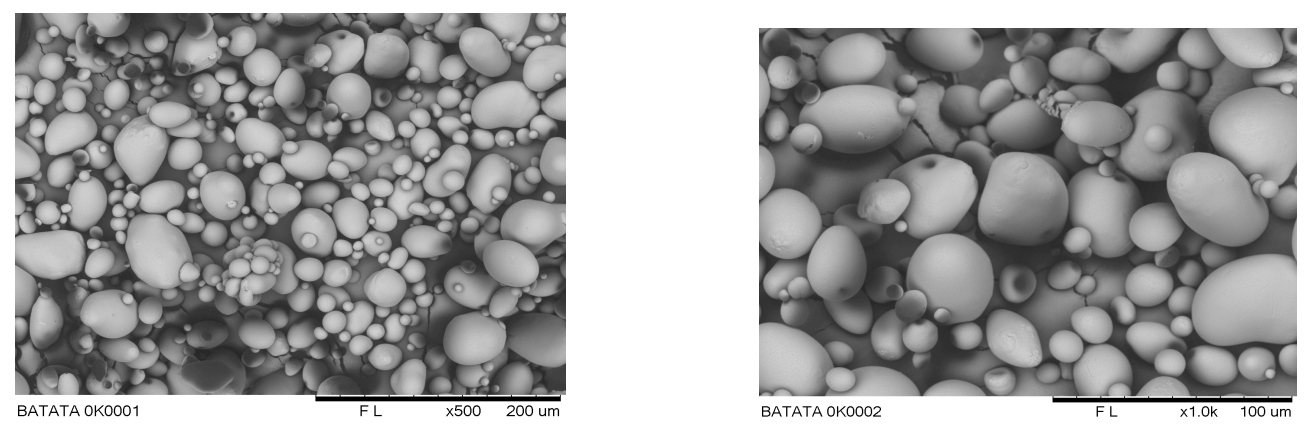

FIGURA 27 - Fotomicrografias de grânulos de fécula de batata não irradiada (aumento 500x e 1000x). 

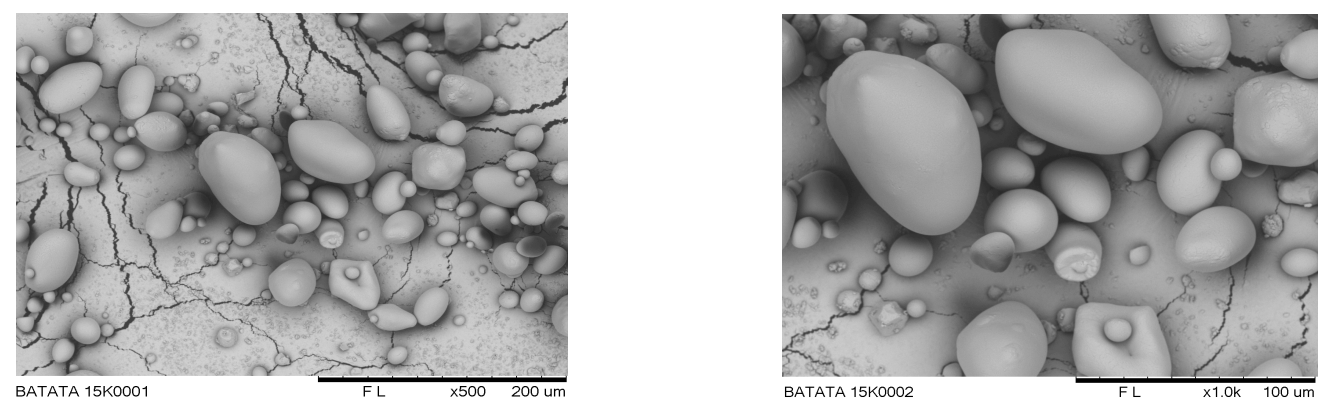

FIGURA 28 - Fotomicrografias de grânulos de fécula de batata 15 kGy (aumento 500x e 1000x).

Com relação à morfologia do grânulo de amido de batata, as formas geométricas predominantes são as circulares, oval e poliédricas, tanto das amostras irradiadas quanto das não irradiadas; a superfície dos grânulos é bastante lisa, sem apresentar irregularidades ou porosidade superficial, também observados no amido de milho e mandioca (Bello-Pérez et al., 2006).

Nas FIG. 29, 32 e 35 são apresentadas as distribuições de tamanho máximo e mínimo de grânulos de batata, milho e polvilho azedo, respectivamente, dos amidos irradiados e não irradiados.

A análise do tamanho dos grânulos de amido de batata irradiados com 0 e 15 kGy mostrou predomínio de grânulos com diâmetro maior na faixa de 20 a $24 \mu \mathrm{m}$, apresentando uma faixa de distribuição de tamanho de 6 a $30 \mu \mathrm{m}$ (FIG. 29).

Leonel (2007) descreve que o diâmetro médio de grânulos de amido de batata está entre 30,5 e 39,5 $\mu \mathrm{m}$. Os resultados do presente trabalho confirmam o descrito por Alexander (1995), que encontrou que os grânulos de amido de batata apresentavam formas oval e esférica com diâmetro variando de 5 a $100 \mu \mathrm{m}$. Observa-se que os grânulos com diâmetro menor apresentaram heterogeneidade de tamanhos.

Comparando as fotomicrografias dos grânulos irradiados e não irradiados pode-se observar que não houve mudanças nos grânulos de amidos de batata. Chung e Liu (2010) observaram, que em pesquisa com fécula de batata irradiada até 50 kGy, a superfície dos grânulos também não foram afetadas pela irradiação, mas encontraram grânulos fissurados em amido de feijão, e 
associaram esta suscetibilidade ao padrão de difração de raios- $X$, sendo 0 polimorfo B (batata), mais resistente que o padrão tipo C (feijão).
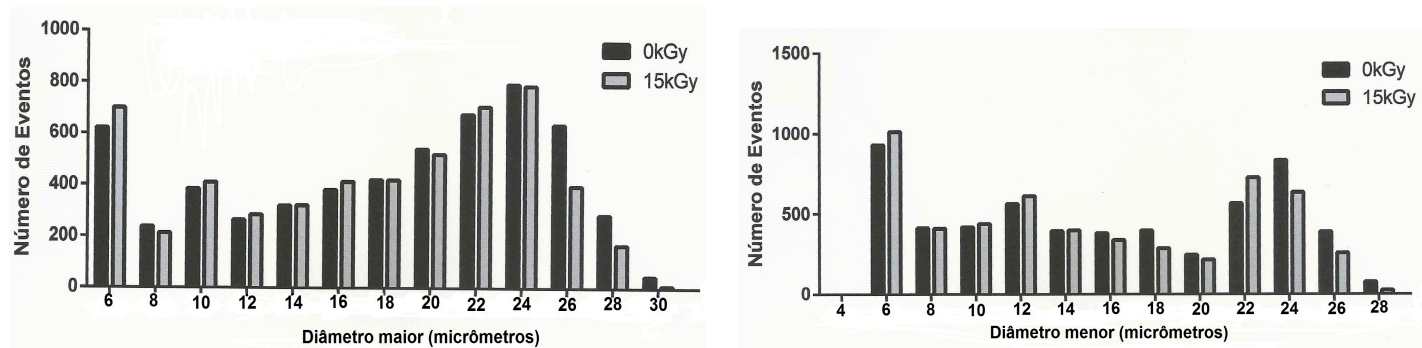

FIGURA 29 - Distribuição do tamanho dos grânulos de batata em função da dose de radiação.

As FIG. 30 e 31 apresentam os grânulos de amido milho com formas circulares e poliédricas. O diâmetro maior apresentou picos entre os valores de 16 a $24 \mu \mathrm{m}$ para amostra controle e o diâmetro menor entre 12 a 20 m (FIG. 32). Já para as amostras irradiadas, 14 a $20 \mu \mathrm{m}$ para o diâmetro maior e 12 a $18 \mu \mathrm{m}$ para o diâmetro menor. Conforme observado nas fotomicrografias e FIG. 32 a irradiação não alterou a morfologia e sim o tamanho dos grânulos.
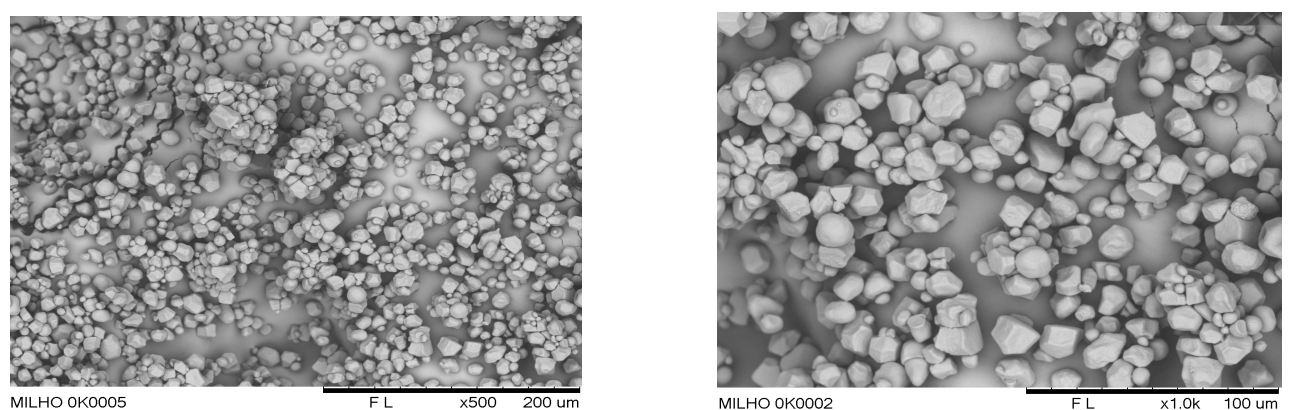

FIGURA 30 - Fotomicrografias de grânulos de amido de milho não irradiada (aumento 500x e 1000x). 

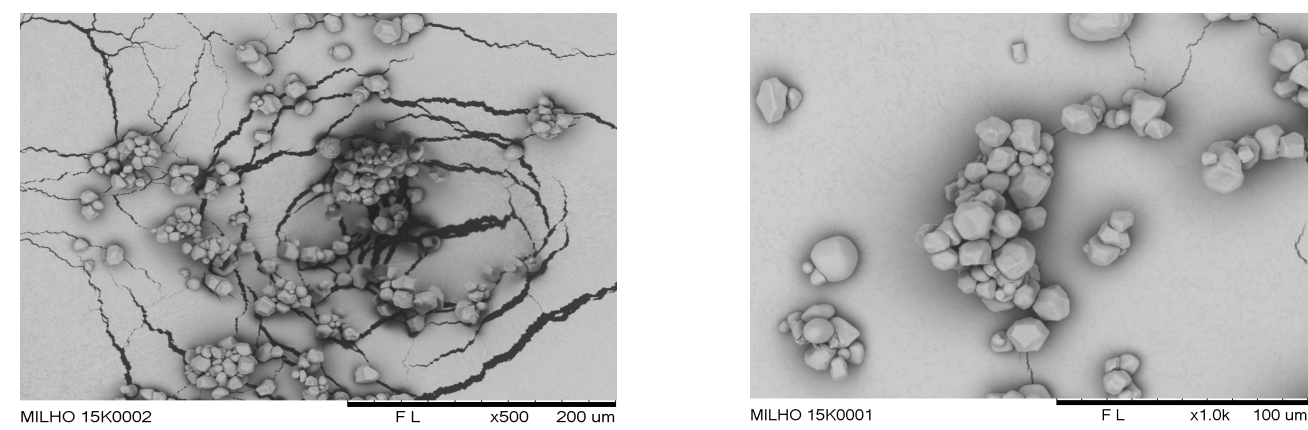

FIGURA 31 - Fotomicrografias de grânulos de amido de milho 15 kGy (aumento 500x e 1000x).

A velocidade com que a radiação é aplicada (taxa de dose) pode influenciar na resistência dos grânulos à ruptura da superfície, modificando a estrutura dos grânulos. De acordo com Chung e Liu (2009), a radiação pode quebrar as macromoléculas do amido e romper as regiões cristalinas e amorfas dos grânulos e também recombinar as estruturas fragmentadas por ligações cruzadas. Essas modificações podem ser responsáveis por leves alterações no tamanho dos grânulos. Na FIG. 32, observa-se que houve uma diminuição do tamanho dos grânulos com a radiação.
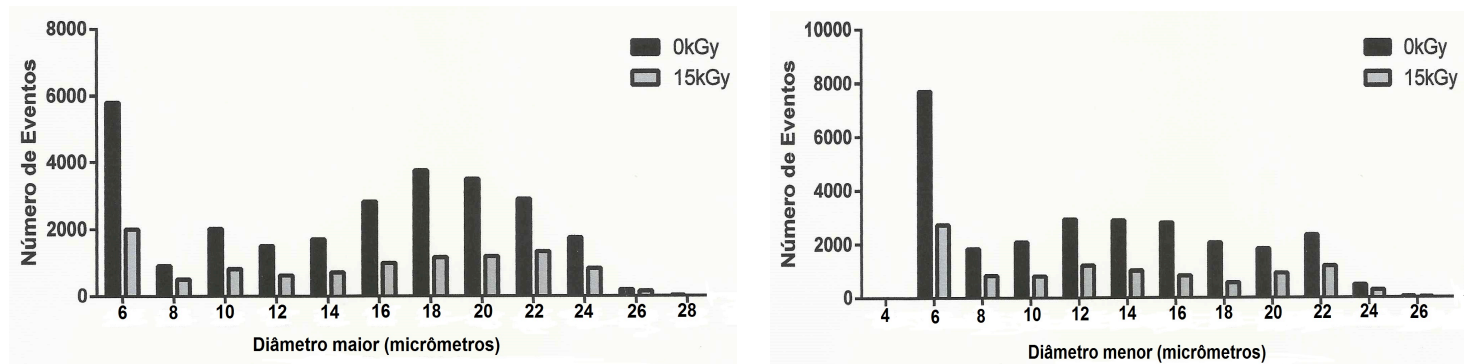

FIGURA 32 - Distribuição do tamanho dos grânulos de milho em função da dose de radiação.

As análises microscópicas para o polvilho azedo mostraram grânulos com formatos arredondados, ovalados e convexo bicôncavos de tamanhos variados. Aparentemente, a irradiação alterou as características dos grânulos, diminuindo o tamanho do grânulo e alterando as suas propriedades físicoquímicas. Segundo a literatura, nos grânulos de amido de mandioca predominam 
as formas redondas ou ovais com alguns côncavo-convexos característicos. Não são vistos estriamentos, o hilo é cêntrico, algumas vezes levemente fissurado e, sob luz polarizada, observa-se perfeitamente a Cruz de Malta. Seu tamanho varia de 5 a $55 \mu \mathrm{m}$ de diâmetro, tendo em média o diâmetro de 20 um (Amante,1986; Franco et al., 2001; Gunaratne \& Hoover, 2002).
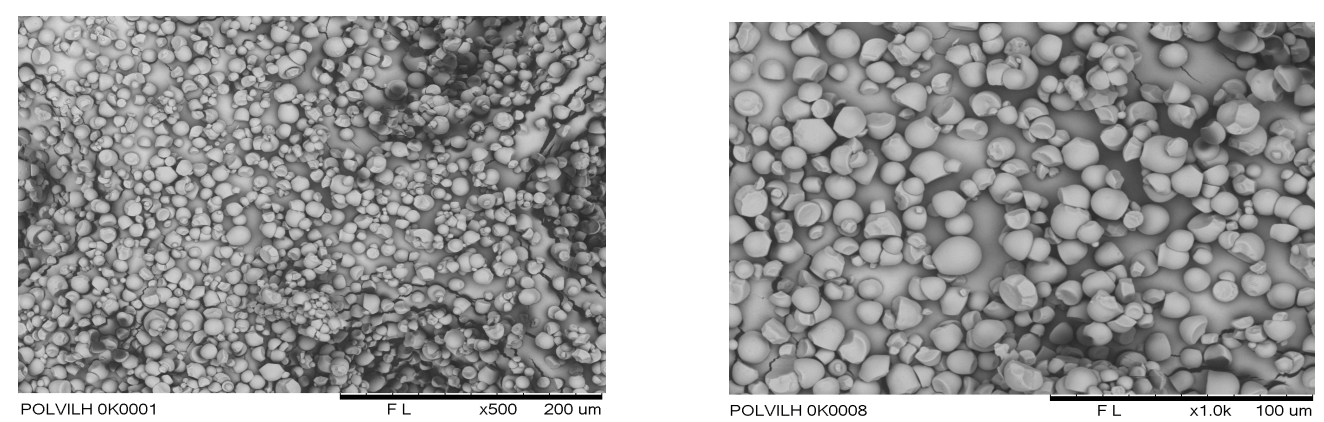

FIGURA 33 - Fotomicrografias de grânulos de amido de mandioca não irradiado (aumento 500x e 1000x).
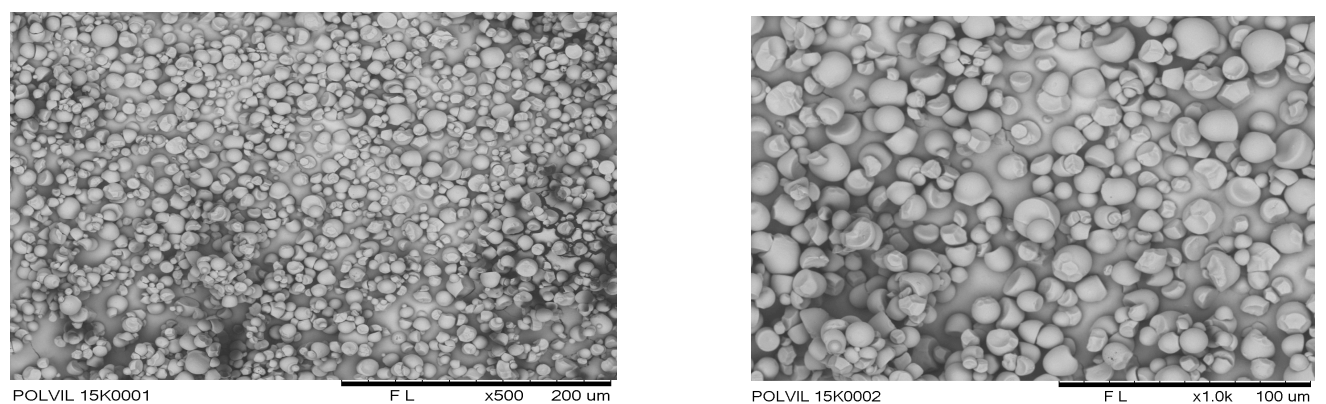

FIGURA 34 - Fotomicrografias de grânulos da fécula de mandioca 15 kGy (aumento $500 x$ e 1000x).
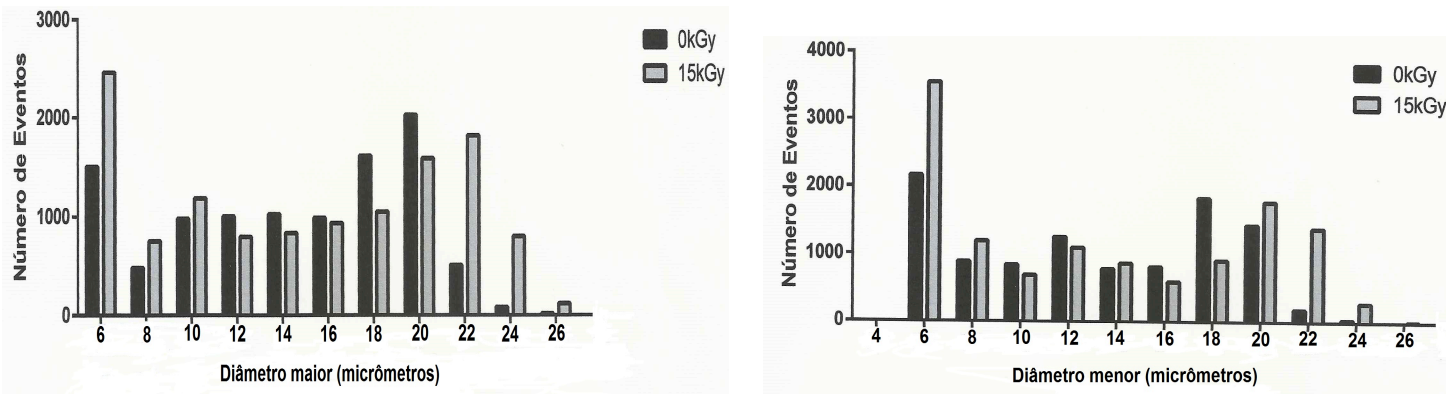

FIGURA 35 - Distribuição do tamanho dos grânulos do polvilho azedo em função da dose de radiação. 
Comparando os três tipos de amidos estudados, os diâmetros encontrados para amido de batata são maiores do que os encontrados para amido de milho e polvilho azedo; também há diferenças na forma dos grânulos, como já fora constatado por outros autores. Estas variações nos tamanhos e forma dos grânulos se devem às diversas origens, fisiologia das plantas e a bioquímica do amiloplasto, decorrentes dos diferentes teores de amilose e amilopectina presentes em cada planta (Kaur et al., 2007). Chung e Liu (2010), ao estudar a morfologia dos grânulos também concluíram que diferentes fontes botânicas de amidos apresentam suscetibilidades diferentes frente à radiação gama. No presente estudo, houve mudanças significativas no tamanho de grânulos por efeito da radiação para o milho e em menor proporção para o polvilho azedo, sendo mais evidente para aqueles grânulos de menor diâmetro.

Raeker et al (1998) tinha descrito que em grande número de amostras de amido de trigo, era possível perceber uma distribuição trimodal de tamanho de grânulos. No presente trabalho, também é possível notar tipo semelhante de agrupamentos.

\subsubsection{Termogravimetria (TG)}

As FIG. $36-38$ e a TAB. 6 ilustram as características das curvas de decomposição térmica e das suas correspondentes derivadas para os amidos de batata, milho e polvilho azedo nas doses de 0 e 15 kGy. Não houve diferença significativa da perda de massa das amostras irradiadas e não irradiadas dos três tipos de amidos estudados. 


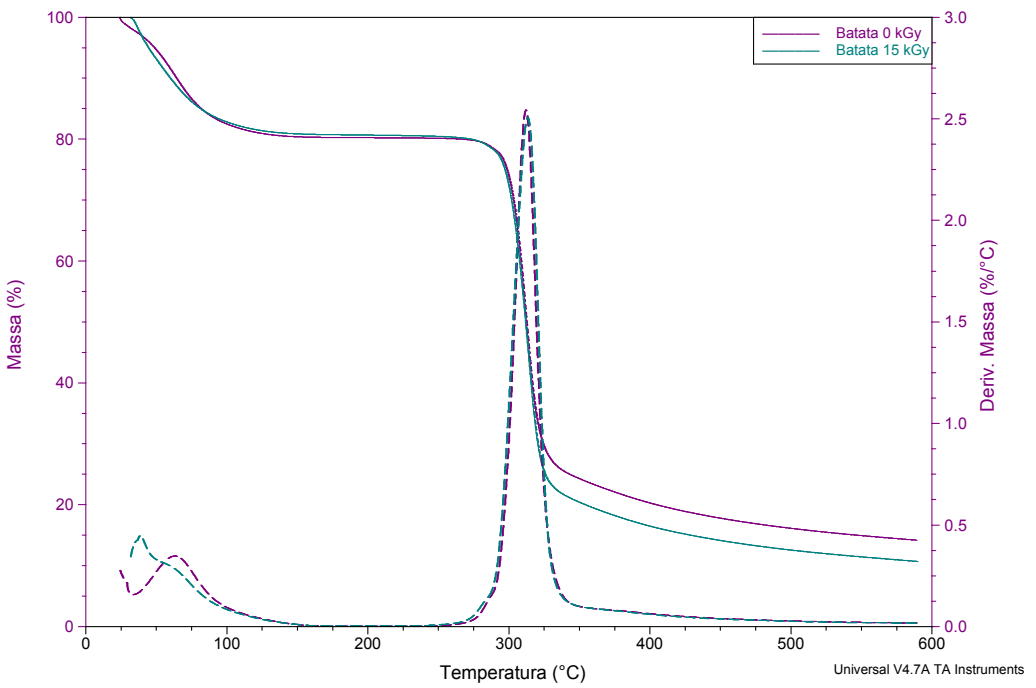

FIGURA 36 - Termogravimetria de amido de batata 0 e 15 kGy.

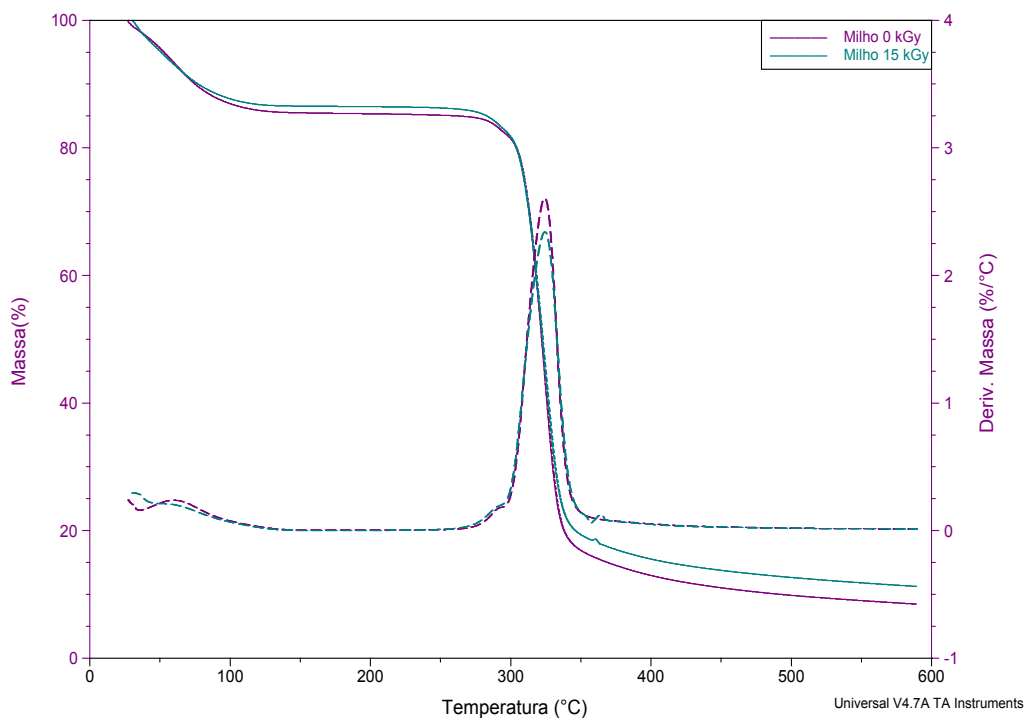

FIGURA 37 - Termogravimetria de amido de milho 0 e 15 kGy. 


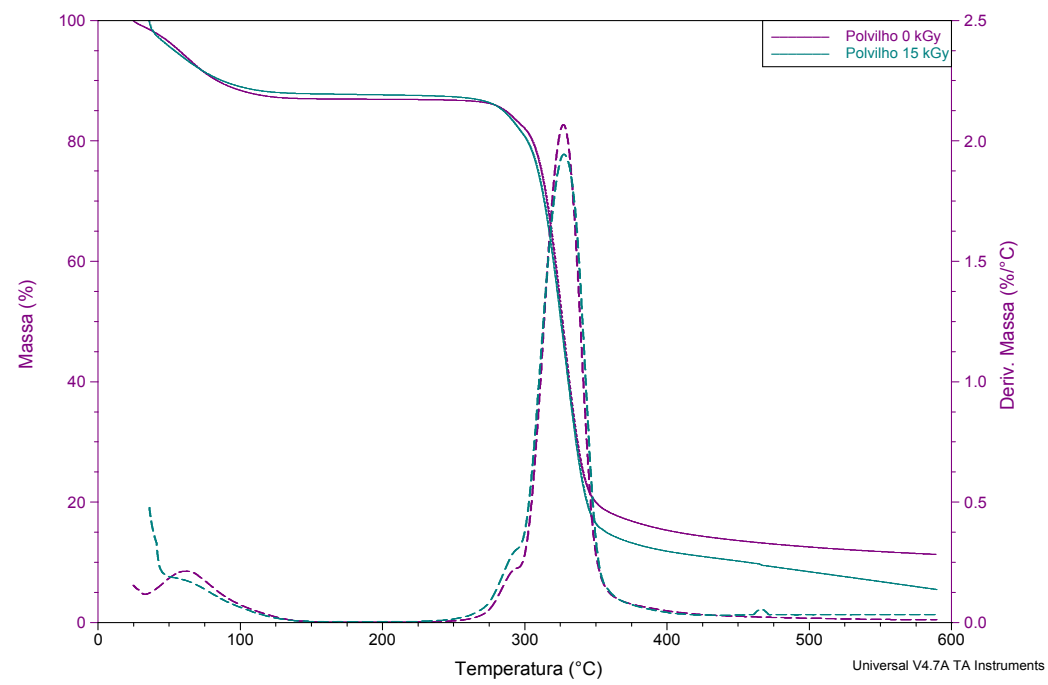

FIGURA 38 - Termogravimetria do polvilho azedo 0 e 15 kGy.

TABELA 6 - Eventos Térmicos com os respectivos intervalos de temperatura e perda de massa (\%) das curvas de TG dos amidos.

\begin{tabular}{lcccccc}
\hline \hline $\begin{array}{c}\text { Amostra } \\
\text { (kGy) }\end{array}$ & \multicolumn{2}{c}{$\mathbf{1}^{\circ}$ Evento } & \multicolumn{2}{c}{$\mathbf{2}^{\circ}$ Evento } & \multicolumn{2}{c}{$\mathbf{3}^{\circ}$ Evento } \\
& Intervalo de & Perda de & Intervalo de & Perda de & Intervalo de & Perda de \\
& Temp. $\left({ }^{\circ} \mathrm{C}\right)$ & Massa $(\%)$ & Temp. $\left({ }^{\circ} \mathrm{C}\right)$ & Massa $(\%)$ & Temp. $\left({ }^{\circ} \mathrm{C}\right)$ & Massa $(\%)$ \\
\hline Batata 0 & $30-150$ & 18 & $275-350$ & 55 & $350-600$ & 25 \\
\hline Batata 15 & $49-140$ & 17 & $260-375$ & 62 & $375-600$ & 18 \\
\hline Milho 0 & $27-127$ & 14 & $270-369$ & 71 & $375-600$ & 15 \\
Milho 15 & $40-125$ & 12 & $265-360$ & 70 & $360-600$ & 18 \\
\hline Polvilho 0 & $37-125$ & 13 & $275-375$ & 70 & $375-600$ & 17 \\
\hline Polvilho15 & $48-127$ & 12 & $250-360$ & 73 & $360-600$ & 15 \\
\hline \hline
\end{tabular}

Para os três tipos de amido, o primeiro evento térmico se refere à eliminação de água (evaporação). O teor de umidade do amido ficou entre 12 e $18 \%$. Já no segundo evento, a batata apresentou menor perda de massa entre os amidos estudados e não houve diferença significativa entre o controle e o amido irradiado. De acordo com Aggarwal e Dollimore (1999), esta etapa corresponde à eliminação dos grupos polihidroxílicos, decomposição e despolimerização das cadeias. Quando a temperatura excede os $300{ }^{\circ} \mathrm{C}$, o tratamento térmico em amidos normalmente leva à sua despolimerização. $O$ amido passa por uma série de alteracões irreversíveis, num primeiro momento a alteração estrutural leva o 
polímero à formação de pirodextrinas. Em temperaturas mais elevadas ainda, a despolimerização das macromoléculas leva à formação de $\beta(1 \rightarrow 6)$ anidro $D$ glicopiranose (levoglicosana), 2-furaldeído (furfural) e produtos carbonáceos (cinzas) (Aggarwal \& Dollimore, 1998).

Guinesi et al. (2006) observaram que a fécula de batata apresentou uma perda de massa de 56,4\% entre $294-349{ }^{\circ} \mathrm{C}$, ou seja, valor próximo observado no segundo evento do presente trabalho da fécula de batata. Esses autores relacionaram essa etapa como a despolimerização e degradação do amido em um processo não-oxidativo. Os valores para o milho e polvilho apresentaram em torno de $70-73 \%$ de perda de massa para o segundo evento. 0 terceiro evento, em temperaturas maiores que $350{ }^{\circ} \mathrm{C}$ foi referente à degradação mais complexa de resíduos carbonáceos (carvão e alcatrão) (Aggarwal \& Dollimore, 1999; Da Róz, 2004). Para os três tipos de amidos não houve mudança significativa para as amostras irradiadas.

\subsubsection{Espectroscopia de Infravermelho por Fourier}

Através da técnica de espectroscopia de infravermelho, na faixa de 4000 e $400 \mathrm{~cm}^{-1}$, pode-se observar mudanças estruturais nas moléculas, ou seja, se houve desaparecimento ou formação de novos agrupamentos químicos. No espectro é possível observar que os diversos grupos de átomos dão origem a bandas que ocorrem mais ou menos na mesma frequência, independente da estrutura da molécula. É através destas bandas e consultas a tabelas de informações estruturais que se baseia para fazer a identificação das estruturas. Através desta técnica pode-se observar se as moléculas dos amidos sofreram alterações com a radiação. A posição das bandas nos espectros depende das massas relativas dos átomos, geometria e constantes de forças de ligação que provocam alterações no momento dipolo (Silva, 2003).

Os espectros para os amidos de batata, milho e polvilho azedo irradiados com doses de 0 e 15 kGy estão apresentados nas FIG. 39 a 41, em que observa-se bandas referentes à deformações moleculares existentes nas moléculas de amido. As bandas na região de 3500-3000 observada a 3340-3334

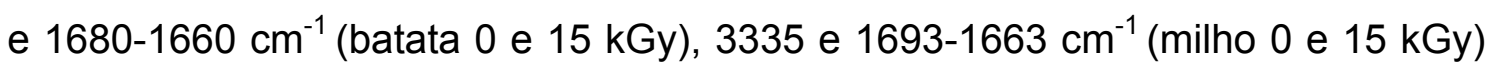


e 3346-3339 e 1692-1656 $\mathrm{cm}^{-1}$ (polvilho 0 e $15 \mathrm{kGy}$ ) são atribuídas ao estiramento e a deformação angular de ligações $-\mathrm{OH}$, respectivamente, que participam das ligações de hidrogênio.

Bandas de absorção a aproximadamente 2951 a $2940 \mathrm{~cm}^{-1}$ indicam estiramento $\mathrm{C}-\mathrm{H}$. Bandas localizadas a aproximadamente $1432-1328 \mathrm{~cm}^{-1}$ são designadas como vibrações associadas com grupos $\mathrm{CH}$. As absorções em 1300 a $1020 \mathrm{~cm}^{-1}$ tem sido relacionadas a deformações de grupos $\mathrm{C}-\mathrm{OH}$. Os modos relacionados a deformações C-O e C-C correspondem a bandas em 1100 a 900 $\mathrm{cm}^{-1}$. As bandas associadas com $\mathrm{C}-\mathrm{O}$ e $\mathrm{C}-\mathrm{O}-\mathrm{H}$ tem sido atribuídas às ligações glicosídicas.

Comparando os amidos não irradiados e irradiados observa-se uma alteração no espectro na banda $2000-1500 \mathrm{~cm}^{-1}$ dos amidos de batata e milho. Já para o polvilho azedo não foi observado alteração aparente.

De acordo com Silverstein et al. (1991), o espectro de infravermelho do amido nativo apresenta bandas na região de $2900-3000 \mathrm{~cm}^{-1}$ (correspondente estiramento $\mathrm{C}-\mathrm{H}$ ), em 1163, 1150, 1124 e $1103 \mathrm{~cm}^{-1}$, que correspondem ao estiramento C-O e C-C com alguma contribuição do estiramento $\mathrm{C}-\mathrm{OH}$. As bandas em 1077, 1067, 1047, 1022, 994 e $928 \mathrm{~cm}^{-1}$ são atribuídas às deformações $\mathrm{C}-\mathrm{OH}$ e $\mathrm{CH}_{2}$. O grupo C-O-C (éter) presente em um anel de seis átomos (como no monômero de glicose) absorve em $1150-1085 \mathrm{~cm}^{-1} \mathrm{e}$ dependendo de deformação axial (simétrica ou assimétrica) essas bandas irão se deslocar. 


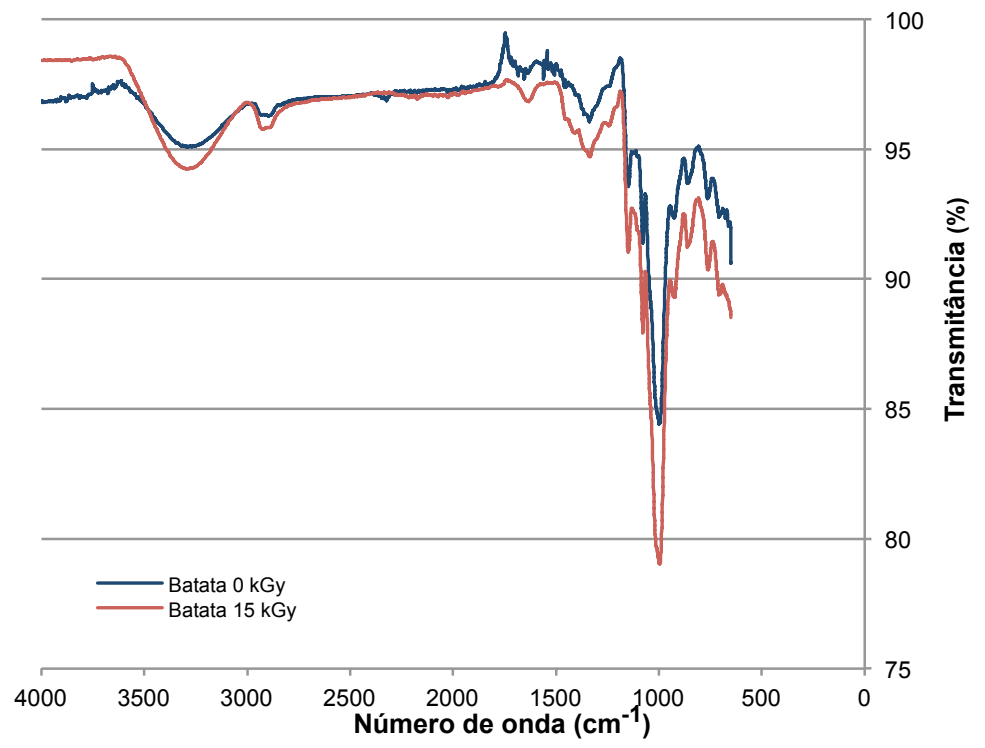

FIGURA 39 - Espectroscopia de infravermelho por Fourier do amido de batata 0 e $15 \mathrm{kGy}$.

TABELA 7 - Principais atribuições para as bandas de absorção no IV para o amido de batata.

\begin{tabular}{ccc}
\hline \hline Banda & Número de onda $\left(\mathbf{c m}^{-1}\right)$ & Atribuição \\
\hline A & 3340 & Deformação axial de \\
a & 3334 & O-H \\
B & 2950 & Deformação axial de \\
b & 2944 & C-H \\
C & 1680 & Deformação angular de \\
C & 1660 & O-H (H $\left.{ }_{2} \mathrm{O}\right)$ \\
D & $1376-1328$ & Deformação angular de \\
d & 1432 & C-H \\
E & $1163-866$ & Deformação axial da \\
e & $1283-899$ & ligação éter \\
\hline \hline
\end{tabular}

Letras maiúsculas correspondem a 0 kGy e letras minúsculas a 15 kGy. 


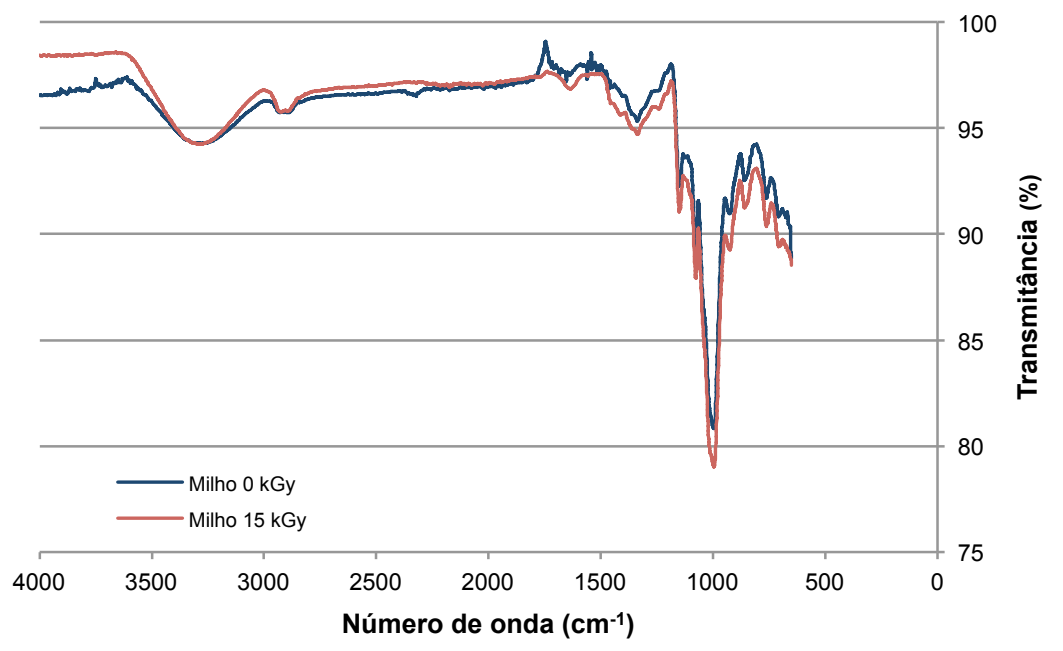

FIGURA 40 - Espectroscopia de infravermelho por Fourier do amido de milho 0 e 15 kGy.

TABELA 8 - Principais atribuições para as bandas de absorção no IV para o amido de milho.

\begin{tabular}{ccc}
\hline \hline Banda & Número de onda $\left(\mathbf{c m}^{-1}\right)$ & Atribuição \\
\hline A & 3335 & Deformação axial de \\
a & 3335 & O-H \\
B & 2941 & Deformação axial de \\
b & 2940 & C-H \\
C & 1693 & Deformação angular de O-H \\
C & 1663 & $\left(\mathrm{H}_{2} \mathrm{O}\right)$ \\
D & 1378 & Deformação angular de \\
d & 1362 & C-H \\
\hline \hline
\end{tabular}

Letras maiúsculas correspondem a 0 kGy e letras minúsculas a 15 kGy. 


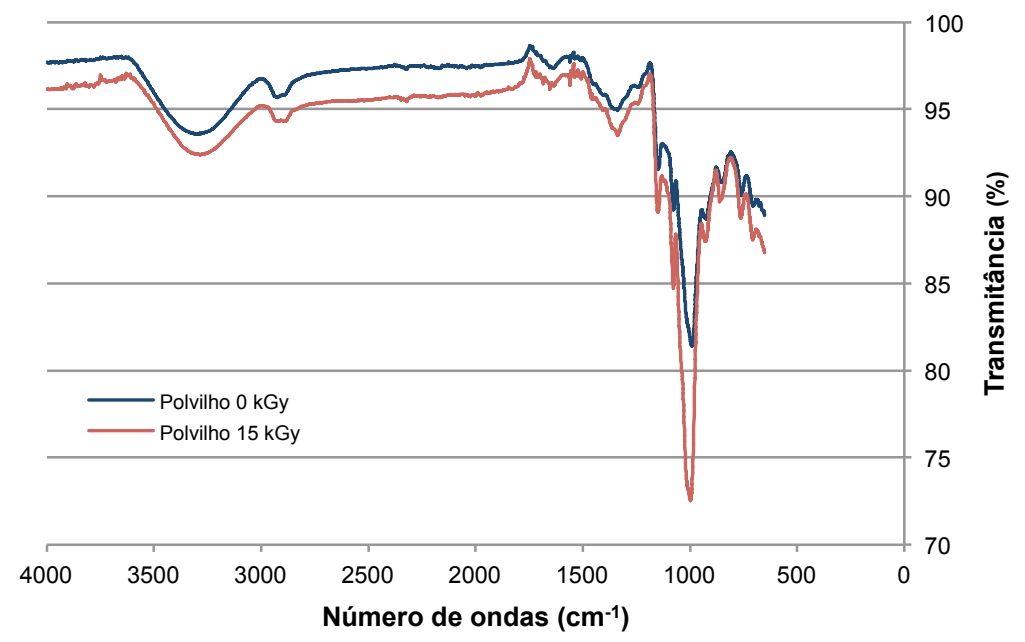

FIGURA 41 - Espectroscopia de infravermelho por Fourier do polvilho azedo 0 e 15 kGy.

TABELA 9 - Principais atribuições para as bandas de absorção no IV para o polvilho azedo.

\begin{tabular}{ccc}
\hline \hline Banda & Número de onda $\left.\mathbf{( c m}^{-1}\right)$ & Atribuição \\
\hline A & 3346 & Deformação axial de \\
a & 3339 & O-H \\
B & 2951 & Deformação axial de \\
b & 2944 & C-H \\
C & 1692 & Deformação angular de O-H \\
C & 1656 & $\left(\mathrm{H}_{2} \mathrm{O}\right)$ \\
D & 1386 & Deformação angular de \\
d & 1348 & C-H \\
\hline \hline
\end{tabular}

Letras maiúsculas correspondem a 0 kGy e letras minúsculas a $15 \mathrm{kGy}$

Kizil et al. (2002) estudaram seis tipos de amidos (amidos de milho, milho com alto conteúdo de proteína e outro com alto conteúdo de óleo, trigo, batata e ceroso) tratados com irradiação. Utilizaram as técnicas espectroscópicas de FT-Raman e FTIR, para caracterizar as mudanças no amido devido à irradiação. Foram identificados grupos químicos específicos e ligações correspondentes à proporção de mudanças químicas. Para o amido de batata e de milho foi identificado na região de 2000 a $1500 \mathrm{~cm}^{-1}$ que pode ter ocorrido 
alguma mudança química na molécula devido à radiação. Já para o polvilho azedo essa alteração não foi observada.

\subsubsection{Difração de raios-X e Cristalinidade relativa}

As FIG. 42 a 44 mostram os difratogramas de difração de raios-X dos amidos estudados. Com base na cristalinidade, o amido é classificado em formas $A, B, C$, das quais a $A$ e $B$ encontram-se presentes nos cereais e a forma $C$, considera-se uma mistura das anteriores, é encontrada na maioria dos tubérculos, leguminosas e sementes, de acordo com Annision e Topping (1994). Segundo esses autores, a cristalinidade é atribuída à amilopectina formada pela associação das longas cadeias de polissacarídeos do grânulo de amido, por meio de pontes de hidrogênio.

O perfil apresentado na FIG. 42 corresponde ao amido de batata irradiado com doses de 0 e 15 kGy e se refere ao padrão de cristalinidade do tipo $B$, com pico forte de intensidade no ângulo $2 \theta 17.16^{\circ}$ e intensidade fraca no ângulo $21.68^{\circ}$. A irradiação não alterou o padrão de cristalinidade com a dose empregada.

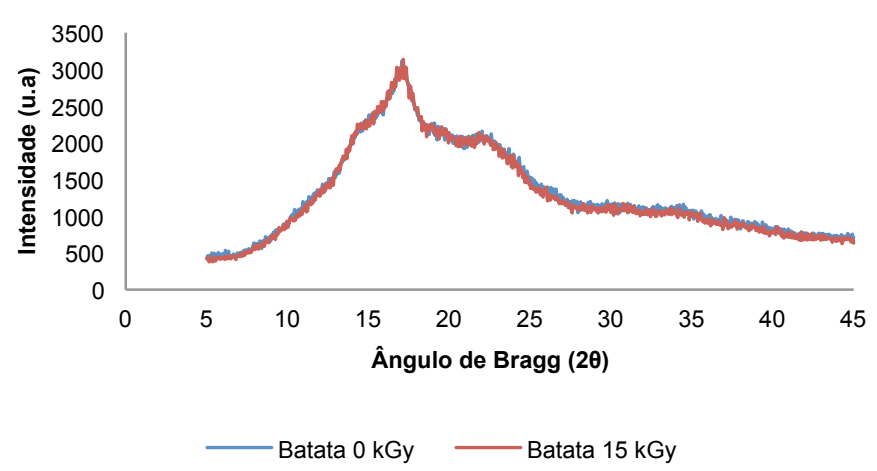

FIGURA 42 - Relação entre a intensidade e o ângulo de Bragg do amido de batata irradiado a 0 e $15 \mathrm{kGy}$.

$\mathrm{Na}$ FIG. 43 pode-se observar que o amido de milho apresenta um padrão do tipo A, confirmando os resultados observados na literatura (Karim et al., 2000). Este padrão é comum em cereais, pico de intensidade fraca a $19.4^{\circ}$, 
média-forte em $15.8^{\circ}$ e $22.4^{\circ}$ e forte no doblete $17 / 17.4^{\circ}$. A radiação ionizante não alterou significativamente o padrão de cristalinidade.

Hizuruki (1985) estudou a correlação entre o tamanho e arranjo das cadeias de amilopectina e a estrutura cristalina dos grânulos de amido. Este pesquisador concluiu que as amilopectinas do amido tipo A têm em média uma proporção maior de moléculas com cadeias curtas do que as amilopectinas dos amidos tipo B.

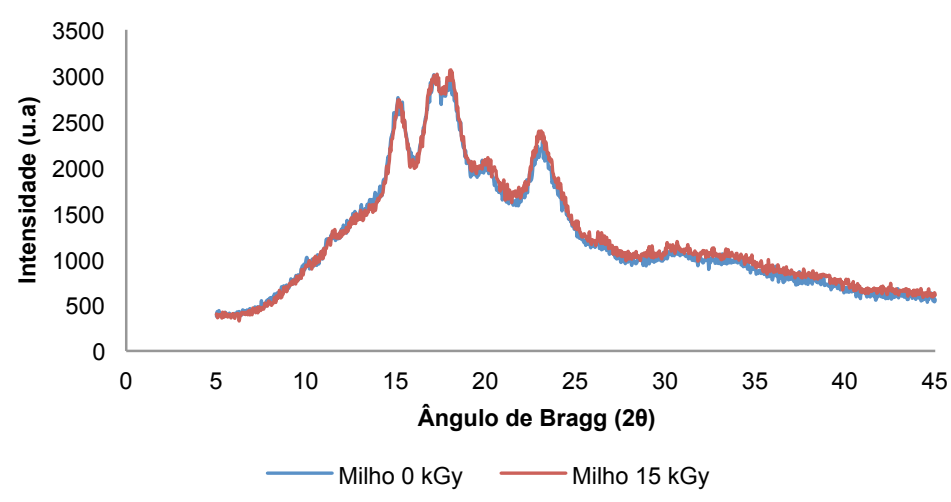

FIGURA 43 - Relação entre a intensidade e o ângulo de Bragg do amido de milho irradiado a 0 e 15 kGy.

Já os resultados obtidos para o polvilho azedo apresentaram um padrão de cristalinidade do tipo C com predomínio de A (FIG.44), apresentando pico de intensidade média-forte em $15.28^{\circ}$ e $23^{\circ}$, forte no doblete $17.08^{\circ}$ e $17.56^{\circ}$. 


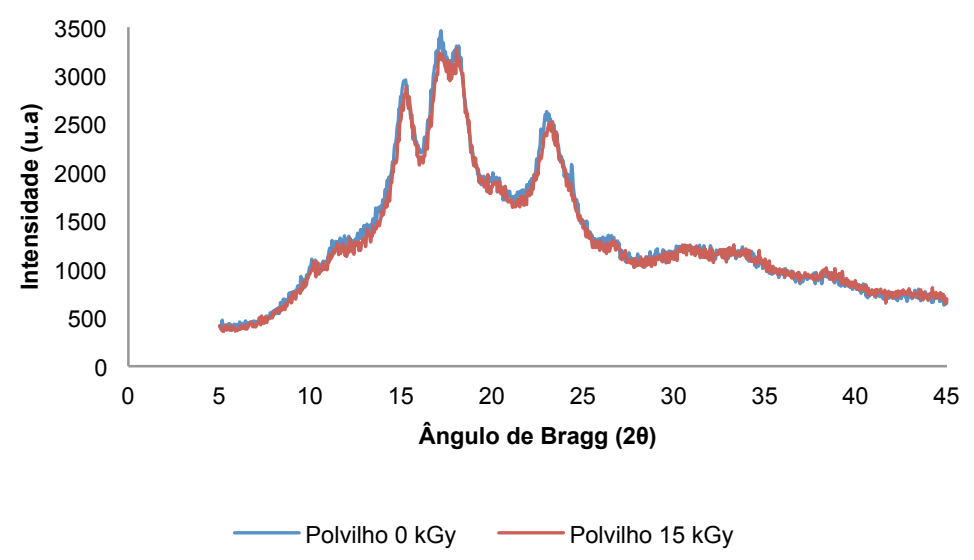

FIGURA 44 - Relação entre a intensidade e o ângulo de Bragg do polvilho azedo irradiado a 0 e 15 kGy.

Segundo a literatura, espectros do tipo A apresentam maiores picos de intensidade nos ângulos de difracão $2 \theta$ em aproximadamente $15.3^{\circ}, 17.1^{\circ}, 18.2^{\circ}$ e $23.5^{\circ}$ sendo evidenciados em amidos de cereais. Já o tipo B apresenta maiores picos de intensidade de difração para os ângulos a $2 \theta$ a $5.6^{\circ}, 15^{\circ}, 17.2^{\circ}, 22.2^{\circ} \mathrm{e}$ $23^{\circ}$ sendo mais comum nos amidos de tuberosas, assim como em amidos com alto teor de amilose (Moore, 2001; Franco et al., 2002; Soares, 2003). O tipo C apresenta uma mistura das características $A$ e $B$, com predominância de $A$ (Mestres, 1996). Há ainda, um quarto tipo de cristalinidade, o tipo $\mathrm{V}$, formado pela cristalização da amilose com lipídios, que apresenta picos de intensidade nos ângulos de difração $2 \theta$ em aproximadamente $12.6^{\circ}, 13.2^{\circ}, 19.4^{\circ}$ e $20,6^{\circ}$ (Corradini et al., 2005).

Os resultados encontrados estão de acordo com os dados relatados por Van Soest e Esser (1997), no qual o autor afirma que os amidos de cereais apresentam cristalinidade do tipo $A$, os amidos de tubérculos cristalinidade do tipo $\mathrm{B}$ e os amidos de raízes e sementes cristalinidade do tipo $\mathrm{C}$. E nenhum amido estudado obteve alteração com dose de radiação de 15 kGy. Os dados do presente trabalho corroboram os dados de Chung e Liu (2009) e Liu et al. (2012) em amido de milho, Gani et al. (2012) e Polesi (2014). Os amidos irradiados exibiram padrão de difração de raios-X similar aos amidos não irradiados, sem mudanças no tipo de padrão. 
De acordo com os presentes resultados apresentados no presente trabalho, houve redução da cristalinidade relativa para o amido de milho e polvilho azedo, enquanto que para o amido de batata a cristalinidade da amostra irradiada foi maior que a do controle. De acordo com Chung e Liu (2009; 2010), a irradiação degrada tanto a estrutura cristalina quanto a região amorfa dos grânulos de amidos. Podendo causar o aumento ou a redução na cristalinidade dependendo de qual região for mais afetada com a dose. Os valores calculados de cristalinidade relativa no presente estudo estão apresentados na TAB.10.

TABELA 10 - Cristalinidade relativa (\%) dos amidos em função das doses de radiação.

\begin{tabular}{ccc}
\hline \hline \multirow{2}{*}{ Amido } & \multicolumn{2}{c}{ Dose (kGy) } \\
\cline { 2 - 3 } & $\mathbf{0}$ & $\mathbf{1 5}$ \\
\hline Batata & $20,6 \pm 0,1^{\mathrm{a}}$ & $21,5 \pm 0,5^{\mathrm{b}}$ \\
Milho & $23,4 \pm 0,3^{\mathrm{c}}$ & $22,9 \pm 0,6^{\mathrm{d}}$ \\
Polvilho & $23,1 \pm 0,5^{\mathrm{e}}$ & $21,8 \pm 0,3^{\dagger}$ \\
\hline
\end{tabular}

Valores representam médias \pm desvio padrão. Letras iguais na mesma linha indica que não há diferença significativa entre os resultados $(P \leq 0,05)$.

Os resultados publicados na literatura são controversos. O aumento de cristalinidade relativa com irradiação tem sido reportado em trabalhos feitos com amido de arroz (Bao et al., 2005), trigo (Macarthur \& D'Apolonia, 1984) e milho (Chung \& Liu, 2009). Porém, casos de redução de cristalinidade relativa, com aumento da irradiação, também foram relatados por Liu et al. (2012), Singh et al. (2011) e Chung e Liu (2010), que pesquisaram amido de milho, fécula de batata e amido de feijão. De acordo com Chung e Liu (2009, 2010), a taxa de dose poderia interferir na cristalinidade, pois em baixas taxas ocorre maior recombinação entre as moléculas do amido. Esses autores constataram que, entre zero e $10 \mathrm{kGy}$, a cristalidade decresceu de 32,8\% para 30,7\% em amidos de batata e de $27,2 \%$ para $26,0 \%$ em amidos de feijão; esse efeito de redução da cristalinidade seria influenciado pelo padrão de cristalinidade de cada tipo de amido, sendo a estrutura do tipo A relativamente mais compacta e, a do tipo $B$, mais aberta e sensível à irradiação. 
As diferenças de cristalinidade, de acordo com Singh et al. (2007), decorrem das diferentes proporções de amilose e da presença de cadeias laterais curtas e longas da amilopectina. As diferenças têm sido atribuídas a: (1) tamanho do cristal, (2) quantidade de regiões cristalinas, que é influenciada pelo teor de amilopectina e comprimento de suas cadeias, (3) orientação das duplas hélices no interior da área cristalina, (4) extensão da interação entre as duplas hélices (Hoover \& Ratnayake, 2002).

\subsection{Análises dos Hidrogéis}

\subsubsection{Viscosidade}

A viscosidade dos hidrogéis preparados com amidos submetidos a diferentes doses de radiação estão apresentados na FIG. 45. Houve redução da viscosidade com a elevação das doses de radiação para os três tipos de amidos.

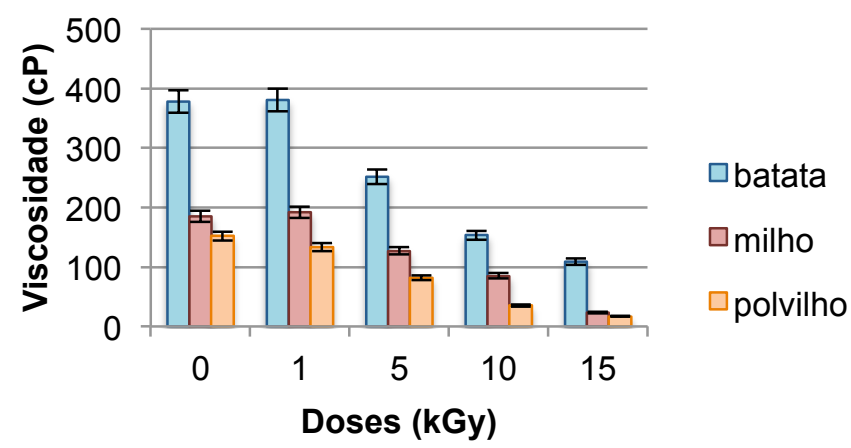

FIGURA 45 - Relação entre a viscosidade dos hidrogéis e as doses de radiação dos três tipos de amidos estudados.

Neste estudo, a dose de $1 \mathrm{kGy}$ nas três variedades de amido não induziu alteração com a exposição à irradiação. O amido de batata foi o que obteve maior viscosidade de aproximadamente $375 \mathrm{cP}$, isso pode ser atribuído ao maior tamanho do grânulo que aumentaria a viscosidade do meio. A batata, conforme abordado neste trabalho, possui maior tamanho do grânulo. 
Segundo a literatura, o comportamento reológico de dispersões de amido gelatinizado é afetado pelo tamanho do grânulo, pela distribuição de tamanho e formato, assim como pela interação entre os grânulos, pela viscosidade da fase contínua e pela taxa e tempo de deformação (Acquarone \& Rao, 2003). Grânulos de amido pequenos têm, no geral, temperatura de pasta mais baixa do que grânulos grandes (Park et al., 1971; Lindeboom et al., 2004). Isso pode ser confirmado pelos resultados do polvilho azedo que possuem menor tamanho dos grânulos e menor temperatura de gelatinização.

Segundo Yu e Wang (2007), a irradiação gera radicais livres nas macromoléculas de amido, que são capazes de hidrolisar ligações químicas e assim, quebrar grandes moléculas em pequenos fragmentos de dextrina, alterando sua estrutura e consequentemente suas funcionalidades, assim como foi observado na presente pesquisa.

Também Bao et al. (2005) reportaram redução da viscosidade em amidos de milho pelo efeito da irradiação indicando que a radiação causa degradação molecular dos grânulos de amido.

Os principais tipos de comportamento do fluxo do fluido podem ser descritos através de diagramas de taxa de deformação versus tensão de cisalhamento (Rao, 1999). Para investigar a influência do comportamento reológico dos géis, foram levantadas as curvas de fluxo com taxas e tensão de cisalhamento (FIG. 46 a 48).

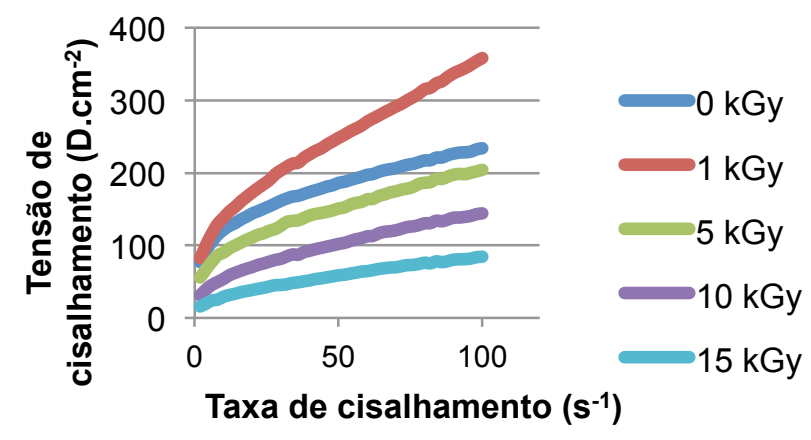

FIGURA 46 - Tensão em relação a taxa de cisalhamento da fécula de batata. 


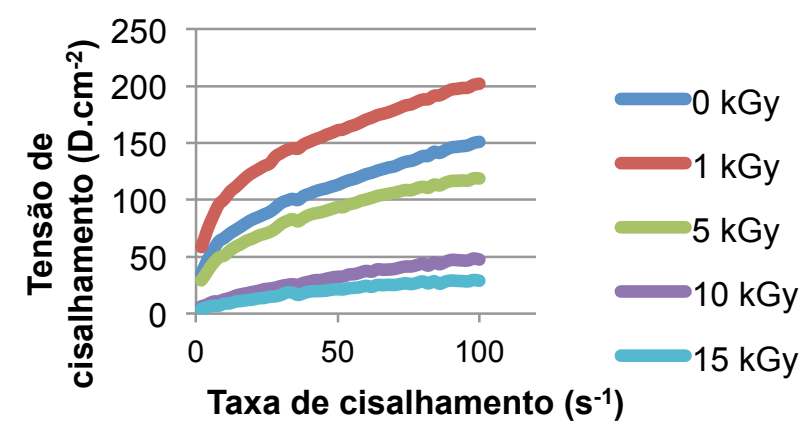

FIGURA 47 - Tensão em relação a taxa de cisalhamento do amido de milho.

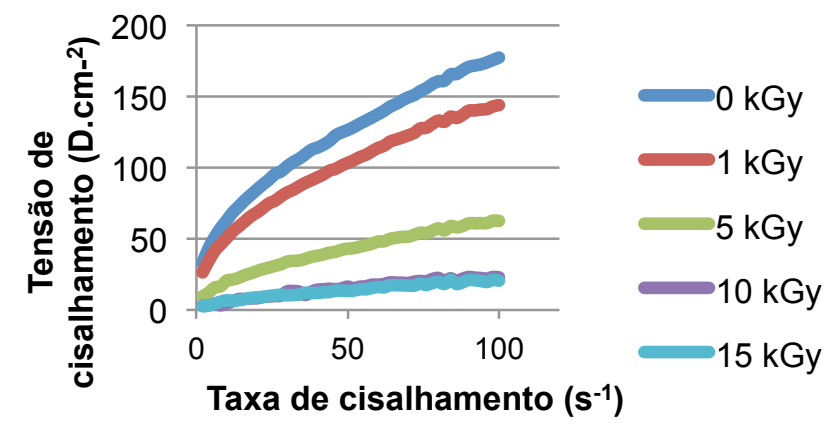

FIGURA 48 - Tensão em relação a taxa de cisalhamento do polvilho azedo.

As propriedades reológicas e de textura variam de acordo com a origem botânica do amido, devido à presença de outros componentes (lipídios, açúcares, hidrocolóides, proteínas), assim como as condições de tratamento térmico (temperatura, condições de mistura, taxas de aquecimento) (Thebaudin et al., 1998).

Através das curvas de escoamento (FIG. 46 a 48), pode-se caracterizar o fluido reologicamente. Foi realizado tratamento matemático dos dados de forma a transformar os valores obtidos em escala logarítmica. A partir das equações das retas obtidas da aproximação dos gráficos nessa escala pode-se estudar o comportamento do fluido.

As equações das retas obtidas das curvas linearizadas para os hidrogéis dos amidos são apresentados na TAB 11. A partir desses dados, foi 
possível obter os parâmetros reológicos através dos coeficientes angular e linear obtidos em cada ensaio.

TABELA 11 - Equações das retas obtidas das aproximações dos gráficos de In (tensão) em função In (deformação).

\begin{tabular}{cccc}
\hline \multirow{2}{*}{ Doses (kGy) } & \multicolumn{3}{c}{ Equações da reta } \\
\cline { 2 - 4 } & Batata & Milho & Polvilho azedo \\
\hline $\mathbf{0}$ & $\mathrm{y}=0,28 \mathrm{x}+4,13$ & $\mathrm{y}=0,36 \mathrm{x}+3,35$ & $\mathrm{y}=0,44 \mathrm{x}+3,14$ \\
$\mathbf{1}$ & $\mathrm{y}=0,39 \mathrm{x}+4,03$ & $\mathrm{y}=0,31 \mathrm{x}+3,89$ & $\mathrm{y}=0,45 \mathrm{x}+2,90$ \\
$\mathbf{5}$ & $\mathrm{y}=0,34 \mathrm{x}+3,71$ & $\mathrm{y}=0,36 \mathrm{x}+3,11$ & $\mathrm{y}=0,5 \mathrm{x}+1,82$ \\
$\mathbf{1 0}$ & $\mathrm{y}=0,41 \mathrm{x}+3,06$ & $\mathrm{y}=0,56 \mathrm{x}+1,30$ & $\mathrm{y}=0,62 \mathrm{x}+0,30$ \\
$\mathbf{1 5}$ & $\mathrm{y}=0,45 \mathrm{x}+2,34$ & $\mathrm{y}=0,53 \mathrm{x}+0,97$ & $\mathrm{y}=0,55 \mathrm{x}+0,52$ \\
\hline \hline
\end{tabular}

O comportamento de fluidos é descrito pelo Modelo de Ostwald de Waele ou Modelo de Power Law, conforme mencionado na Revisão Bibliográfica. O índice de consistência equivale ao valor de In (coeficiente linear), já o índice de fluxo, à equivalência direta do coeficiente angular. Os valores dos parâmetros obtidos são apresentados na TAB 12.

TABELA 12 - Valores de índice de consistência $\left(K_{c}\right)$ e índice de comportamento $\left(n_{c}\right)$ de acordo com o modelo Lei da Potência para os três tipos de amidos.

\begin{tabular}{|c|c|c|c|c|c|c|c|c|c|}
\hline \multirow{3}{*}{$\begin{array}{l}\text { Doses } \\
\text { (kGy) }\end{array}$} & \multicolumn{9}{|c|}{ Parâmetros reológicos } \\
\hline & \multicolumn{3}{|c|}{ Batata } & \multicolumn{3}{|c|}{ Milho } & \multicolumn{3}{|c|}{ Polvilho azedo } \\
\hline & $\mathrm{n}_{\mathrm{c}}$ & $\ln \mathrm{K}_{\mathrm{c}}$ & $\mathrm{K}_{\mathrm{c}}$ & $\mathrm{n}_{\mathrm{c}}$ & $\ln \mathrm{K}_{\mathrm{c}}$ & $\mathrm{K}_{\mathrm{c}}$ & $\mathrm{n}_{\mathrm{c}}$ & $\ln \mathrm{K}_{\mathrm{c}}$ & $\mathrm{K}_{\mathrm{c}}$ \\
\hline 0 & 0,28 & 4,13 & 1,42 & 0,36 & 3,35 & 1,21 & 0,44 & 3,14 & 1,14 \\
\hline 1 & 0,39 & 4,03 & 1,39 & 0,31 & 3,89 & 1,36 & 0,45 & 2,90 & 1,07 \\
\hline 5 & 0,34 & 3,71 & 1,31 & 0,36 & 3,11 & 1,14 & 0,5 & 1,82 & 0,60 \\
\hline 10 & 0,41 & 3,06 & 1,12 & 0,56 & 1,30 & 0,26 & 0,62 & 0,30 & $-1,00$ \\
\hline 15 & 0,45 & 2,34 & 0,85 & 0,53 & 0,97 & 0,03 & 0,55 & 0,52 & $-0,66$ \\
\hline
\end{tabular}

Da análise dos dados da TAB. 12, nota-se que o índice do comportamento de fluxo $\mathrm{n}_{\mathrm{c}}$ (coeficiente angular) aumentou com o aumento da radiação. Esse índice indica o quanto o comportamento de fluxo do fluido se 
afasta do comportamento Newtoniano. Os fluidos com valores próximos à unidade apresentam comportamento próximo de um fluido Newtoniano. Os hidrogéis de amido apresentaram comportamento pseudoplástico $(\mathrm{n}<1)$, obedecendo ao modelo de Fluido de Potência, mas se aproximando do Newtoniano com o aumento da dose.

Já o valor de $\mathrm{K}_{\mathrm{c}}$ diminuiu com o aumento da dose de radiação. $\mathrm{O}$ índice de consistência $\left(\mathrm{K}_{\mathrm{c}}\right)$ indica o grau de resistência do fluido ao escoamento: quanto maior o valor de $\mathrm{K}_{\mathrm{c}}$, maior a sua resistência ao escoamento e, portanto, maior a sua viscosidade aparente.

Rao e Tattiyakul (1999) observaram que o índice de consistência, $K_{c}$, da Lei da Potência aumentou exponencialmente com o aumento de tamanho dos grânulos da fécula de mandioca observado ao longo do tempo de aquecimento. Jacquier et al. (2006) verificaram que as propriedades reológicas de amidos de arroz são fortemente dependentes da taxa de deformação aplicada e da fração volumétrica de grânulos presentes na dispersão, de modo similar aos sistemas com fase dispersa concentrada, com um súbito aumento na viscosidade relativa próximo às condições de empacotamento máximo.

\subsection{Análises do Filme}

\subsubsection{Ensaio Mecânico - Resistência à Tração}

A propriedade mecânica dos filmes de amido de batata, milho e polvilho azedo foi analisada através da força máxima de ruptura $(\mathrm{N})$. Os resultados de força máxima de ruptura estão apresentados nas FIG. 49 a 51, houve uma variação entre os filmes de amidos não irradiados em relação aos filmes de amidos irradiados. 


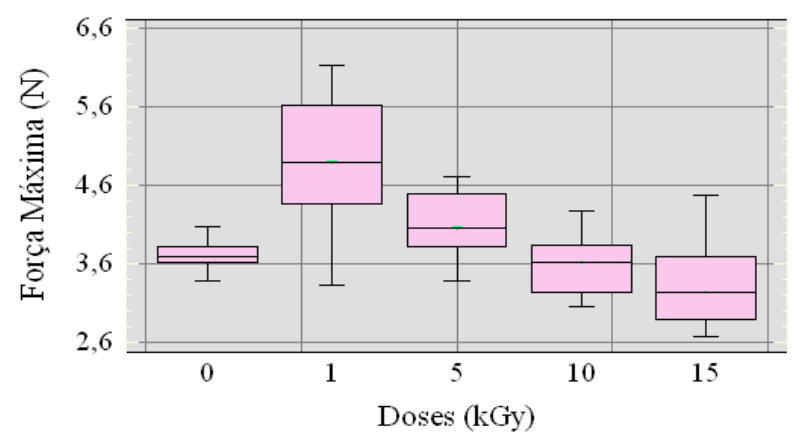

FIGURA 49 - Força máxima de ruptura em função da dose de radiação do filme da fécula de batata.

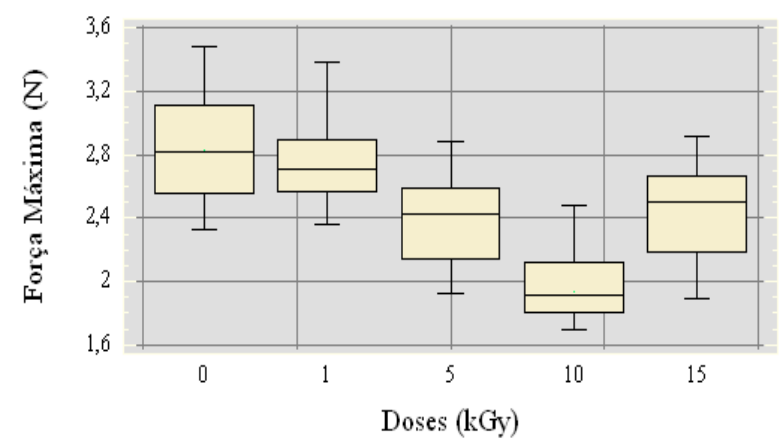

FIGURA 50 - Força máxima de ruptura em função da dose de radiação do filme de amido de milho.

O filme preparado com o polvilho azedo apresentou-se mais rígido com o aumento das doses de radiação. Este comportamento poderia ser atribuído a possível formação de ligações cruzadas devido à radiação ionizante no grânulo do amido.

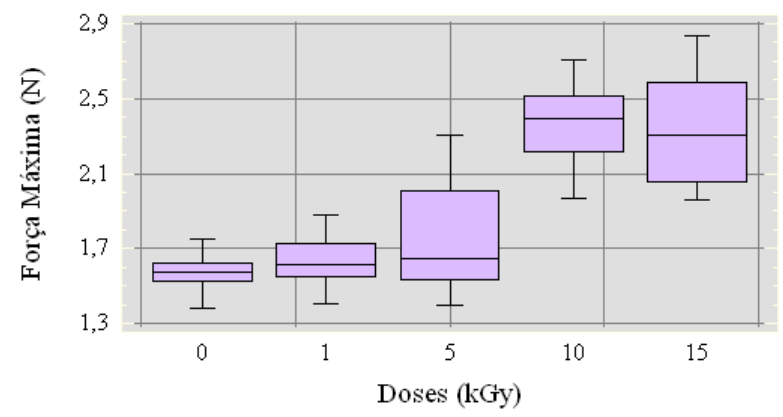

FIGURA 51 - Força máxima de ruptura em função da dose de radiação do filme de polvilho azedo. 


\subsubsection{Análise instrumental da cor}

Os parâmetros de cor analisados nos filmes de amidos foram $L^{*}, a^{*} e$ $b^{*}$, e a partir destes foram calculados o croma (C) e o ângulo Hue. Os valores dos parâmetros estão apresentados na TAB. 13.

TABELA 13 - Parâmetros de cor ( $L^{*}, a^{*}, b^{*}, C$ e ângulo Hue) dos amidos submetidos à diferentes doses de radiação.

\begin{tabular}{ccccccc}
\hline \hline \multirow{2}{*}{ Parâmetros } & \multirow{2}{*}{ Amostra } & \multicolumn{5}{c}{ Dose (kGy) } \\
\cline { 3 - 7 } & & $\mathbf{0}$ & $\mathbf{1}$ & $\mathbf{5}$ & $\mathbf{1 0}$ & $\mathbf{1 5}$ \\
\hline \multirow{3}{*}{$\mathbf{L}^{*}$} & Fécula de batata & $95,6 \pm 0,5^{\mathrm{aA}}$ & $95,7 \pm 0,7^{\mathrm{aA}}$ & $95,6 \pm 0,5^{\mathrm{aA}}$ & $95,5 \pm 0,4^{\mathrm{aA}}$ & $95,6 \pm 0,5^{\mathrm{aA}}$ \\
& Amido de milho & $95,7 \pm 0,5^{\mathrm{aA}}$ & $96,1 \pm 0,5^{\mathrm{aA}}$ & $95,4 \pm 0,5^{\mathrm{aA}}$ & $95,2 \pm 0,6^{\mathrm{aA}}$ & $95,3 \pm 0,5^{\mathrm{aA}}$ \\
& Polvilho azedo & $94,5 \pm 0,6^{\mathrm{aA}}$ & $94,4 \pm 0,6^{\mathrm{aA}}$ & $94,1 \pm 0,4^{\mathrm{aB}}$ & $94 \pm 0,6^{\mathrm{aA}}$ & $93,5 \pm 0,6^{\mathrm{aB}}$ \\
\hline \multirow{3}{*}{$\mathbf{a}^{*}$} & Fécula de batata & $-0,1 \pm 0,2^{\mathrm{aA}}$ & $-0,2 \pm 0,2^{\mathrm{aA}}$ & $-0,4 \pm 0,1^{\mathrm{aA}}$ & $-0,4 \pm 0,1^{\mathrm{aA}}$ & $-0,6 \pm 0,1^{\mathrm{aA}}$ \\
& Amido de milho & $-0,5 \pm 0,2^{\mathrm{aA}}$ & $-0,6 \pm 0,1^{\mathrm{aB}}$ & $-0,7 \pm 0,1^{\mathrm{aB}}$ & $-0,9 \pm 0,1^{\mathrm{aB}}$ & $-1,0 \pm 0,3^{\mathrm{aA}}$ \\
& Polvilho azedo & $-0,1 \pm 0,1^{\mathrm{aA}}$ & $-0,2 \pm 0,1^{\mathrm{aA}}$ & $-0,3 \pm 0,1^{\mathrm{aA}}$ & $-0,6 \pm 0,1^{\mathrm{bA}}$ & $-0,7 \pm 0,1^{\mathrm{bA}}$ \\
\hline \multirow{3}{*}{$\mathbf{b}^{*}$} & Fécula de batata & $3,2 \pm 0,3^{\mathrm{aA}}$ & $3,5 \pm 0,8^{\mathrm{aA}}$ & $3,6 \pm 0,3^{\mathrm{aA}}$ & $4,5 \pm 0,4^{\mathrm{bA}}$ & $5,2 \pm 0,5^{\mathrm{bA}}$ \\
& Amido de milho & $4,1 \pm 0,1^{\mathrm{aB}}$ & $4,1 \pm 0,3^{\mathrm{aA}}$ & $5,3 \pm 0,6^{\mathrm{bB}}$ & $6,2 \pm 0,7^{\mathrm{bB}}$ & $7,0 \pm 0,7^{\mathrm{CB}}$ \\
& Polvilho azedo & $5 \pm 0,6^{\mathrm{aB}}$ & $6 \pm 0,6^{\mathrm{aB}}$ & $6,7 \pm 1^{\mathrm{aB}}$ & $7,6 \pm 1,1^{\mathrm{aB}}$ & $9,2 \pm 1,3^{\mathrm{bC}}$ \\
\hline \multirow{3}{*}{ Croma } & Fécula de batata & $3,2 \pm 0,3^{\mathrm{aA}}$ & $3,6 \pm 0,9^{\mathrm{aA}}$ & $3,6 \pm 0,3^{\mathrm{aA}}$ & $4,6 \pm 0,4^{\mathrm{aA}}$ & $5,3 \pm 0,5^{\mathrm{aA}}$ \\
& Amido de milho & $4,2 \pm 0,3^{\mathrm{aA}}$ & $4,1 \pm 0,3^{\mathrm{aA}}$ & $5,4 \pm 0,6^{\mathrm{bB}}$ & $6,3 \pm 0,9^{\mathrm{bB}}$ & $7,1 \pm 0,7^{\mathrm{bA}}$ \\
& Polvilho azedo & $5,0 \pm 0,6^{\mathrm{aA}}$ & $6,0 \pm 0,6^{\mathrm{aB}}$ & $6,7 \pm 0,5^{\mathrm{aC}}$ & $7,6 \pm 0,6^{\mathrm{bB}}$ & $9,2 \pm 1,3^{\mathrm{bB}}$ \\
\hline \multirow{2}{*}{ Ângulo } \\
Hue & Fécula de batata & $91,3 \pm 0,8^{\mathrm{aA}}$ & $95,5 \pm 0,9^{\mathrm{bA}}$ & $93 \pm 0,9^{\mathrm{bA}}$ & $95,5 \pm 0,9^{\mathrm{bA}}$ & $96,3 \pm 1^{\mathrm{bA}}$ \\
& Amido de milho & $98,3 \pm 0,7^{\mathrm{aB}}$ & $97 \pm 1^{\mathrm{aA}}$ & $98 \pm 1^{\mathrm{aB}}$ & $98,6 \pm 1^{\mathrm{aB}}$ & $98,3 \pm 1,2^{\mathrm{aA}}$ \\
& Polvilho azedo & $91,6 \pm 0,5^{\mathrm{aA}}$ & $91,6 \pm 0,8^{\mathrm{aB}}$ & $93 \pm 1^{\mathrm{aA}}$ & $94,6 \pm 0,8^{\mathrm{aA}}$ & $94,7 \pm 0,7^{\mathrm{bA}}$ \\
\hline \hline \hline
\end{tabular}

Valores representam médias \pm desvio padrão. Letras iguais na mesma linha (minúsculas) ou na mesma coluna (maiúsculas) indicam que não há diferença significativa entre os resultados $(P \leq$ $0,05)$.

Os valores de luminosidade $\left(L^{*}\right)$ variam do claro ao escuro, sendo o valor 0 (zero) correspondente à cor preta e o valor 100 (cem) à cor branca (Cardoso et al., 2007), os três tipos de filme para todas as doses estudadas apresentaram coloração que tendem ao branco. Nesta análise a irradiação com dose de até 15 kGy não interferiu na luminosidade de qualquer filme.

Já para os parâmetros $a^{*}$, os filmes tendem a cor verde e $b^{*}$, para $o$ amarelo. A tendência para a cor amarela também foi constatado por Kang et al. 
(1999). Esses autores atribuíram essa modificação à reação dos monossacarídeos gerados pela clivagem das macromoléculas de amido. Outros pesquisadores, como Falade e Kolawole (2013) e Lee et al. (2007), consideraram a reação de Maillard, como outra atribuição à diferença de coloração, para os quais a irradiação produz radicais livres e produtos de radiólise, açúcares redutores e aminoácidos, que podem se condensar e produzir os compostos coloridos.

Segundo diversos autores (Lee et al., 2007; Roy; Ghosh; Chatterjee, 1991; Sirisoontaralak \& Noomhorm, 2006; Zanão, 2007), a irradiação dos alimentos acarreta o escurecimento destes, proporcionando ênfase a sua cor característica. Além disso, os autores constataram que a alteração e a intensidade da cor dos alimentos irradiados aumentam à medida que aumentam as doses de radiação. O presente trabalho confirma esta afirmação de acordo com os resultados analisados.

Os valores de croma próximos ao zero são indicativos de cores mais neutras (branco e/ou cinza) e aqueles ao redor de 60 indicam cores mais vívidas e/ou intensas (Mcguire, 1992). Dentre as análises houve aumento da intensidade de cor com a irradiação principalmente nas doses de 0 e 15 kGy dos três diferentes filmes. Com a elevação do valor do croma indica que as cores dos filmes ficaram mais intensas após a irradiação. Os valores de croma e ângulo Hue estão em concordância ao amarelamento dos filmes.

\subsubsection{Capacidade de absorção de água e Índice de solubilidade}

Os resultados de solubilidade e absorção de água tratados com diferentes doses de radiação estão resumidos na TAB.14. 
TABELA 14 - Propriedades de absorção de água e solubilidade dos filmes dos amidos irradiados e não irradiados.

\begin{tabular}{ccccccc}
\hline \multirow{2}{*}{ Propriedades } & \multirow{2}{*}{ Amostra } & \multicolumn{5}{c}{ Dose (kGy) } \\
\cline { 3 - 7 } & & $\mathbf{0}$ & $\mathbf{1}$ & $\mathbf{5}$ & $\mathbf{1 0}$ & $\mathbf{1 5}$ \\
\hline \multirow{2}{*}{ Absorção } & Fécula de batata & $63,1 \pm 1,4^{\mathrm{a}}$ & $59,2 \pm 1,2^{\mathrm{b}}$ & $57,4 \pm 2^{\mathrm{b}}$ & $55,2 \pm 1,2^{\mathrm{b}}$ & $51,6 \pm 1,4^{\mathrm{C}}$ \\
de água (\%) & Amido de milho & $116,8 \pm 4,3^{\mathrm{a}}$ & $108,6 \pm 3,1^{\mathrm{b}}$ & $95,8 \pm 2,7^{\mathrm{c}}$ & $72,5 \pm 1,1^{\mathrm{d}}$ & $69,3 \pm 2,9^{\mathrm{d}}$ \\
& Polvilho azedo & $165,5 \pm 2,9^{\mathrm{a}}$ & $134,1 \pm 6,9^{\mathrm{b}}$ & $98,6 \pm 4,1^{\mathrm{c}}$ & $74,7 \pm 2,8^{\mathrm{d}}$ & $55,1 \pm 2,6^{\mathrm{e}}$ \\
\hline \multirow{2}{*}{ Solubilidade } & Fécula de batata & $26,8 \pm 1,0^{\mathrm{a}}$ & $27,3 \pm 0,8^{\mathrm{a}}$ & $26 \pm 1,0^{\mathrm{a}}$ & $27,5 \pm 0,4^{\mathrm{a}}$ & $30,2 \pm 1,4^{\mathrm{b}}$ \\
do filme (\%) & Amido de milho & $25,8 \pm 1,4^{\mathrm{a}}$ & $24,5 \pm 1,4^{\mathrm{a}}$ & $27,6 \pm 2,4^{\mathrm{a}}$ & $27,4 \pm 2,4^{\mathrm{a}}$ & $29,5 \pm 2,7^{\mathrm{a}}$ \\
& Polvilho azedo & $31,6 \pm 2,1^{\mathrm{a}}$ & $29,2 \pm 2,7^{\mathrm{a}}$ & $32,2 \pm 1,3^{\mathrm{a}}$ & $35,6 \pm 2,0^{\mathrm{b}}$ & $39,6 \pm 2,2^{\mathrm{b}}$ \\
\hline \hline
\end{tabular}

Valores representam médias \pm desvio padrão. Letras iguais na mesma linha indica que não há diferença significativa entre os resultados $(P \leq 0,05)$.

Para a solubilidade do filme da fécula de batata não houve diferença significativa entre a dose controle e as doses intermediárias até 10 kGy. Observase um aumento da solubilidade na dose de $15 \mathrm{kGy}$ em comparação com as demais. Os filmes tiveram uma tendência aumentada para a solubilidade. Alguns autores afirmam que o aumento da dose de radiação está invariavelmente associado com o aumento da solubilidade em água devido à degradação do grânulo de amido por este processo (Bhat \& Karim, 2009; Bao \& Corke, 2002; Bao et al., 2001).

De Kelf et al. (2001) reportaram o aumento da solubilidade nos amidos de milho e batata, utilizando irradiação gama e feixe de elétron; MacArthur e D’Appolonia (1984), também, melhoraram a solubilidade de amido de trigo com baixa dose de irradiação gama. Esse comportamento pode ter sido promovido pelo aumento da polaridade, devido à cisão das cadeias (quebra da ligação glicosídica) e pela redução de ligação de hidrogênio intercadeias, que favoreceu a ligação de pontes de hidrogênio com a água, consequentemente, melhorando a solubilidade de amido irradiado (Liu et al., 2012).

O poder de inchamento e solubilidade varia de acordo com a fonte do amido, fornecendo evidências da interação entre as cadeias de amido dentro dos domínios amorfos e cristalinos (Denardin \& Silva, 2009). Féculas como a de mandioca e de batata apresentam grande inchamento e a temperaturas mais baixas, o que indica interações mais fracas e uniformes. 
De acordo com Ciesla e Eliasson (2002) a degradação dos grânulos de amido devido ao processo de irradiação pode causar redução na absorção de água. O presente estudo corrobora essa afirmação, já que os resultados obtidos apresentaram redução da CAA (capacidade de absorção de água) com o aumento das doses, observada nos filmes. A absorção de água pelos grânulos de amido em temperatura ambiente decorre da difusão e absorção das moléculas de água nas regiões amorfas (Bello-Pérez et al., 2006).

De acordo com Leonel et al. (2010) o ISA (índice de solubilidade em água) normalmente é utilizado para avaliar a degradação dos componentes moleculares, havendo uma relação da CAA com a disponibilidade de hidroxilas que se ligam a moléculas de água. Para Marcon et al. (2009) a interação amidoágua de produtos como o polvilho azedo depende dos grupos carboxilas e hidroxilas disponíveis para formar ligações com hidrogênios livres, formando assim ligações com a água. A fração amorfa, portanto, controla a variação de volume do grânulo devido à sua capacidade de absorver e liberar água dos grânulos de amido nativo (Gallant et al., 1997). 


\section{CONCLUSÃO}

A partir dos resultados obtidos neste estudo de amidos de batata, milho e polvilho azedo, é possível destacar:

- A morfologia dos grânulos não sofreu alteração pela ação da radiação nas doses aplicadas, porém houve forte diminuição do diâmetro dos grânulos do amido de milho e praticamente o tamanho dos grânulos de batata permaneceram sem ser afetados.

- A termogravimetria mostrou as etapas de perda de massa referente a desidratação, decomposição e cinzas das amostras dos amidos.

- Houve, aparentemente, pequenas modificações nos espectros infravermelho analisados pela transformada de Fourier nas amostras irradiadas, especialmente no caso dos amidos de batata e milho.

- A difratometria de raios-X comprovou dados da literatura em relação ao padrão de cristalinidade dos grânulos dos amidos, mas há discrepâncias em relação aos percentagens de cristalinidade relativa.

- O comportamento reológico dos hidrogéis dos amidos, mostrou diminuição da viscosidade com o aumento da dose de radiação. As amostras apresentaram-se como fluidos não-Newtonianos e pseudoplásticos.

- No teste de força de ruptura dos filmes preparados com os amidos, estes responderam diferentemente segundo o tipo de amido com o aumento da dose de radiação, não obtendo uma correlação comportamental.

- O Croma e a cor amarela dos filmes foram incrementadas com o aumento da dose de radiação.

- Nos filmes preparados com os amidos, a ação da radiação induziu a diminuição da capacidade de absorção de água e aumentou a respectiva solubilidade.

- Os presentes resultados são uma contribuição para o conhecimento do comportamento frente à radiação ionizante de três tipos de amido muito utilizados como alimento e também empregados de maneira crescente por 
outras indústrias. Como exemplo, pode-se salientar o crescente uso de amidos naturais e modificados na fabricação de plásticos biodegradáveis como solução sustentável e inovadora em benefício do meio ambiente. 


\section{REFERÊNCIAS BIBLIOGRÁFICAS}

ACQUARONE, V. M.; RAO, M. A. Influence of sucrose on the rheology and granule size of cross-linked waxy maize starch dispersions heated at two temperatures. Carbohydrate Polymers, v. 54, n. 4, p. 451-458, 2003.

ADEBOWALE, K. O.; AFOLABI, T. A.; OLU-OWOLABI, B. I. Functional, physicochemical and rrogradation properties of sword bean (Canavalia gladiata) acetylated and oxidized. Carbohydrate Polymers, v. 65, p. 93-101, 2006.

ADEBOWALE, K. O.; OLU-OWOLABI, B. I.; OLAWUMI, E. K.; LAWAL, O. S. Functional properties of native, physically and chemically modified breadfruit (Artocarpus artilis) starch. Ind. Cr. and Prod., v.21, p.343-351, 2005.

AGGARWAL, P.; DOLLIMORE, D. A method of comparison between corn starch and its products using thermal analysis. Instrumentation Science \& Technology, v. 27 , p. 191-197, 1999.

AGGARWAL, P.; DOLLIMORE, D. A thermal analysis investigation of partially hydrolyzed starch. Thermochimica Acta, v.319, p.17-25, 1998.

AMANTE, E. R. Caracterização de amidos de variedades de mandioca (Manihot esculenta, Crantz) e de Batata-doce (Ipomoea). 1986. Dissertação de mestrado em Ciência e Tecnologia de Alimentos, Viçosa, Minas Gerais.

ANNISON, G.; TOPPING, D. L. Nutritional role of resistant starch: chemical structure vs physiological function. Annual Review Nutrition, v. 14, p.297-320, 1994.

ASCHERI, D. P. R.; VILELA, E. R. Alterações do polvilho da mandioca pela fermentação, no fabrico de biscoitos. Pesquisa Agropecuária Brasileira., v.30, n.2, p.269-279, 1995.

ATWELL, W. A; HOOD, L. F; LINEBACK, D. R; VANIANS-MARSTON, E; ZOBEL, $H$. F. The terminology and methodology associated with basic starch phenomena. Cereal Foods World, v.33, p. 306-311, 1988.

BALL, S. G.; MORELL, M. K. From bacterial glycogen to starch: understanding the biogenesis of the plant starch granule. Annual Review of Plant Biology, v.54, p. 207-233, 2003.

$\mathrm{BAO}$, J. et al. Effects of gamma irradiation on aspects of milled rice (Oryza sativa) and use quality. Journal of Food Quality, v.24, n.4, p.327-336, 2001. 
BAO, J.; AO, Z. H.; JANE, J. Characterization of physical properties of flour and starch obtained from gamma-irradiated white rice. Starch-Starke, v. 57, n. 10, p. 480-487, 2005.

$\mathrm{BAO}, \mathrm{J} . ;$ CORKE, H. Pasting properties of gamma-irradiated rice starches as affected by $\mathrm{pH}$. Journal of Agricultural and Food Chemistry, v.50, n.2, p.336$341,2002$.

BELLO-PÉREZ, L. A.; MONTEALVO, M. G. M.; ACEVEDO, E. G. Almidón: definición, estructura y propriedades. In: LAJOLO, F. M. e MENEZES, E. W. Carbohidratos em Alimentos Regionales Ibero-americano. São Paulo: Edusp, p.646, 2006b.

BELLO-PÉREZ, L. A.; MONTEALVO, M.G.M.; ACEVEDO, E. A. Almidón: definición, estrutura y propriedades. In: LAJOLO, F.M.; MENEZES, E. W. Carbohidratos em alimentos regionales ibero-americano. São Paulo: Edusp, p.17-46, 2006.

BERTOFT, E. On the nature of categories of chains in amylopectin and their connection to the super helix model. Carbohydrate Polymers, v. 57, p. 211-224, 2004.

BHAT, R.; KARIM, A. A. Impact of radiation processing on starch. Comprehensive Reviews. Food Science and Food Safety, v. 8, n. 2, p. 44-58, 2009.

BHATTACHARYA, S.; BHATTACHARYA, S. Rheology of cooked debranned maize flour suspensions. Journal of Food Engineering, v. 27, p. 97-105, 1996.

BICUDO, S. C. W. Caracterização de amidos nativos de diferentes fontes botânicas através de técnicas termoanalíticas e teor de amilose. 2008. Dissertação de Mestrado - Faculdade de Tecnologia de Alimentos - Universidade Estadual de Ponta Grossa.

BLENNOW, A.; BAY-SMIDT, A. M.; OLSEN, C. E.; MOLLER, B. L. The distribution of covalently bound phosphate in the starch granule in relation to starch crystallinity. International Journal of Biological Macromolecules, v. 27, n. 3, p. $211-218,2000$.

BLENNOW, A.; BAY-SMIDT, A.M.; OLSEN, C.E.; MOLLER, B.L. The distribution of covanlently bound phosphate in the starch granule in realtion to starch crystallinity. Interantional Journal of Biological Macromolecules, v.27, p.211218, 2000b.

BLENNOW, A.; ENGELSEN, S.B.; MUNCK, L.; MOLLER, B.L. Starch molecular structure and phosphorylation investigated by a combined chromatographic and chemometric approach. Carbohydrate Polymers, v.41 p.163 -174, 2000a. 
BOBBIO, P. A.; BOBBIO, F. O. Química do processamento de alimentos. São Paulo: Varela, p.143, 2001.

BOSCH, V. A., La irradiación de los alimentos. Seguridad Nuclear, n.35, 2005.

BRAMBILLA, E. M. Obtenção do amido de milho através da moagem via úmida e seus diferentes tipos de modificação química. 2001. Monografia (Conclusão de curso superior)-Universidade do Norte do Paraná, Arapongas.

BRASIL. Resolução no $12 / 78$ da Comissão Nacional de Normas e Padrões para Alimentos. Diário Oficial da República Federativa do Brasil. Poder Executivo, Brasília, 24 de julho de 1978.

BRASIL. Resolução RDC n.21, de 26 de jan. de 2001. Aprova o Regulamento Técnico para Irradiação de Alimentos. Diário Oficial da União, Brasília, p.35, 29 de janeiro de 2001.

BRODKEY, R. S. - The phenomena of fluid motions - Dover Publications, Inc. New York, 1967.

BROUILLET-FOURMAM, S.; CARROT, C.; MIGNARD, N. Gelatinization and gelation of corn starch followed by dynamic mechanical spectroscopy analysis. Rheological Acta, v. 42, p.110-117, 2003.

BULÉON, A.; COLONNA, P.; PLANCHOT, V.; BALL, S. Starch granules: structure and biosynthesis. International Journal of Biological Macromolecules, v.23, n.2, p.85-112, 1998.

CARdoso, W. S.; PINHEIRO, F. A.; PATELLI, T.; PEREZ, R.; RAMOS, A. M. Determinação da concentração de sulfito para a manutenção da qualidade da cor em maçã desidratada. Revista Analytica, v. 29, p. 69-72, 2007.

CARVALHO FILHO, M. A. S. Preparação e estudo termoanalítico dos cinamatos de terras raras, exceto (escandio), no estado sólido. 2000. Tese de Doutorado. Universidade Estadual Paulista, Araraquara.

CEREDA, M., VILPOUX, O. F. Tecnologia, usos e potencialidades de tuberosas amiláceas latino americanas. Fundação Cargill, São Paulo, v.3, p.711, 2003.

CEREDA, M.P. Avaliação da qualidade de duas amostras de fécula fermentada de mandioca (polvilho azedo). Boletim da Sociedade Brasileira de Ciência e Tecnologia de Alimentos. Campinas, v.17, n.3, p.305-320. 1983a.

CEREDA, M. P. Padronização para ensaios de qualidade da fécula de mandioca fermentada (polvilho azedo). II - Ensaios de absorção de água. Boletim da Sociedade Brasileira de Ciência e Tecnologia de Alimentos. Campinas,v.17, n.3, p.297-304, 1983. 
CEREDA, M. P. Padronização para ensaios de qualidade da fécula de mandioca fermentada (polvilho azedo). I- Formulação e preparo de biscoitos. Boletim da Sociedade Brasileira de Ciência e Tecnologia de Alimentos. Campinas. V.17, n.3, p.287-295. 1983 b.

CEREDA, M. P.; NUNES, O. L. G.; VILPOUX, O. Tecnologia da produção de polvilho azedo. Botucatu. Centro de Raízes Tropicais (CERAT). Universidade Estadual Paulista, 1995.

CHAPLIN, M. Polysaccharide Hydratation, 2010. Disponível em: <http://www.lsbu.ac.uk/water/hysta.html> .Acesso em: 28 maio 2015.

CHATAKANONDA, P.; CHINACHOTI, P.; SRIROTH, K.; PIYACHOMKWAN, K.; CHOTINEERANAT, S.; TANG, H.; HILLS, B. The influence of time and conditions of harvest on the functional behaviour of cassava starch - a proton NMR relaxation study. Carbohydrate Polymers, v.53, p.233-240, 2002.

CHEETHAM, N.W.H.; TAO, L. Variation in crystalline type with amylose content in maize starch granules: a X-ray powder diffraction study. Carbohydrate Polymers, v.36, n.4, p.277-284, 1998.

CHIONO, V.; PULIERI, E.; VOZZI, G.; CIARDELLI, G.; AHLUWALIA, A.; GIUSTI, $P$. Genipin-crosslinked chitosan gelatin blends for biomedical applications. J. Mater. Sci.: Mater, v. 19, p. 889-898, 2008.

CHOE, E.; MIN, D. B. Chemistry and reactions of reactive oxygen species in foods. Critical reviews in food Science and nutrition, v.46, n.1, p.1-22, 2006.

CHRISTIANSON, D. D.; BAGLEY, E. B. Yield stress in dispersions of swollen, deformable corn starch granules. Cereal Chemistry, v.61, p. 500-503, 1984.

CHUNG, H. J.; LIU, Q. Effect of gamma irradiation on molecular structure and physicochemical properties of corn starch. Journal of Food Science, Chicago, v. 74, n. 5, p. 353-361, 2009.

CHUNG, H. J.; LIU, Q. Molecular structure and physicochemical properties of potato and bean starches as affected by gamma irradiation. International Journal of Biological Macromolecules, v. 47, n. 2, p. 214 - 222, 2010.

CIACCO, C. F.; CRUZ, R. Fabricação do amido e sua utilização. São Paulo: Secretaria de Indústria e Comércio. Ciência e Tecnologia, p.152, 1982.

CIESLA, K.; ELIASSON, A. C. Influence of gamma radiation on potato starch gelatinization studied by differential scanning calorimetry. Radiation Physics and Chemistry, v. 64, n. 2, p. 137-148, 2002.

COLLA, E.; SOBRAL, P. J. A.; MENEGALLI, F. C. Amaranthus cruentus flour 
edible films: influence of stearic acid addition, plasticizer concentration, and emulsion stirring speed on water vapor permeability and mechanical properties. Journal Agric. Food Chemistry, v. 54, n. 18, p. 6645-6653, 2006.

CONDE-PETIT, B.; NUESSLI, J.; HANDSCHIN, S.; ESCHER, F. Comparative characterisation of aqueous starch dispersions by light microscopy, rheometry and iodine binding behaviour. Starch/Stärke, v. 50, n. 5, p.184-192, 1998.

COOKE, D.; GUIDLEY, M.J. Loss of crystalline and molecular order during gelatinization: origin of the enthalpic transition. Carbohydrate Research, v.227, p.103-112, 1992.

CORDENUNSI, B. R.; LAJOLO, F. M.; MENEZES, E. W. Utilização de novas técnicas de microscopia na caracterização do amido. Carbohidratos em Alimentos Regionales Iberoamericanos. Editora da USP, São Paulo, p.646, 2006.

CORRADINI, E.; LOTTI, C.; MEDEIROS, E. S.; CARVALHO, A. J. F.; CURVELO, A. A. S.; MATTOSO, L. H. C. Polímeros, v.15, p.268, 2005.

CORRADINI, E.; TEIXEIRA, E. M.; AGNELLI, J. A. M.; MATTOSO, L. H. C. Amido termoplástico. Embrapa Instrumentação Agropecuária, n.30, p. 27, 2007.

DA RÓZ, A. L. Preparação e caracterização de amidos termoplásticos. 2004. Tese (Doutorado em Ciências e Engenharia de Materiais) - Interunidades em Ciências e Engenharia de Materiais, Universidade de São Paulo, São Carlos.

DEMIATE, I. M.; CEREDA, M. P. Some physicochemical characteristics of modified cassava starches presenting baking property. Energia na Agricultura, v.15, n.3, p.36-46, 2000.

DENARDIN, C. C.; SILVA, L. P. Estrutura dos grânulos de amido e sua relação com propriedades físico-químicas. Ciência Rural, v.39, n.3, p.945-954, 2009.

DENYER, K.; JOHNSON, P.; ZEEMAN, S.; SMITH, A.M. The control of amylose synthesis. Journal of Plant Physiology, v.158, p.479-487, 2001.

DOUBLIER, J-L.; LLAMAS, G.; LE MEUR, M. A rheological investigation of cereal starches pastes and gels. Effects of pasting procedures. Carbohydrates Polymers, v.7, p. 251-275, 1987.

FALADE, K. O.; KOLAWOLE, T. A. Effect of $y$-irradiation on colour, functional and physicochemical properties of pearl millet (Pennisetum glaucum) cultivars. Food and Bioprocess Technology, v. 6, n.9, p. 2429-2438, 2013.

FAMÁ, L.; FLORES, S. K.; GERSCHENSON, L.; GOYANES, S. Physical characterization of cassava starch biofilms with special reference to dynamic 
mechanical properties at low temperatures. Carbohydrate Polymers, v. 66, p. 815, 2006.

FAO. Food and Agriculture Organization. FAOSTAT. Database. Rome, 1999. Disponível em: <http://faostat.fao.org> . Acesso em: 15 março 2016.

FARRO, P. C. A. Biodegradáveis a partir de derivados do grão de quinoa (Chenopodium quinoa Willdenow) da variedade "Real". 2008. Tese de Doutorado - Faculdade de Engenharia de Alimentos - Universidade Estadual de Campinas, Campinas.

FIROUZABADI, F. N. In planta modification of potato starch granule biogenesis by different granule-bound fusion proteins. 2007 . Tese de Doutorado - Wageningen University, Wageningen.

FRANCO, C. M. L. et al. Propriedades do Amido. In: Culturas de Tuberosas Amiláceas Latino Americanas, Propriedades Gerais do Amido. Campinas: Fundação Cargill, v.1, 2001.

FRANCO, C. M. L.; DAIUTO, E. R.; DEMIATE, I. M.; CARVALHO, L. J. C. B.; LEONEL, M.; CEREDA, M. P.; VILPOUX, O. F.; SARMENTO, S. B. S. Culturas de Tuberosas amiláceas latino americanas - Propriedades gerais do amido. Fundação Cargill, Campinas, 2002.

FREITAS, M. C. J. Amido resistente: propriedades funcionais. Nutrição Brasil, Rio de Janeiro, v. 1, n. 1, p. 40-49, maio/jun. 2002.

FRENCH, D. Chemical and physical properties of starch. Journal of Animal Science, v.37, n.4, p.1048-1061, 1973.

GALLANT, D.; BOUCHET, B.; BALDWIN, P. M. Microscopy of starch: evidence of a new level of granule organization. Carbohydrate Polymers, v.32, p.177-191, 1997.

GALLIARD, T.; BOWLER, P. Mophology and composition of starch. In: GALLIARD, D. T., Starch: properties and potential, v.13, p.55-78, 1987.

GANI, A. et al. Modification of bean starch by gamma-irradiation: Effect on functional and morphological properties. Food Science and Technology, v. 49, n. 1, p. 162-169, 2012.

GARCIA, V., COLONNA, P., LOURDIN, D., BULEON, A., BIZOT, H., OLLIVON, $M$. Thermal transitions of cassava at intermediate water contents. Journal of Thermal Analysis, v.47, p.1213-1228, 1996.

GIOLITO, I.; IONASHIRO, M. A. Nomenclatura, padrões e apresentação dos resultados em análise térmica. Cerâmica, v.26, n.121, p.17-24, 1980. 
GLARING, M. A.; KOCH, C. B.; BLENNOW, A. Genotype-specific spatial distribution of starch molecules in the starch granule: a combined CLSM and SEM approach. Biomacromolecules, v. 7, p. 2310-2320, 2006.

GUILBOT, A.; MERCIER, C. Starch in the polysaccharides. Editora O. Aspinall. Academic Press. New York, p.209-282, 1985.

GUINESI L. S., RÓZ, A. L.; CORRADINI, E., MATTOSO L. H. C., TEIXEIRA E. M.; CURVELO A. A. S. Therm. Acta, v.447, p.190, 2006.

GUNARATNE, A., HOOVER, R. Effect of heat- moisturetreatment on the structure and physicochemical properties of tuber and root starches. Carbohydr. Polym., v.49, p.425-437, 2002.

HIZUKURI, S. Relationship between the distribution of the chain length of amylopectin and the crystalline structure of starch granules. Carbohydrate Research, v.141, p. 295-306, 1985.

HOLDSWORTH, S. D. Applicability of rheological models to the interpretation of flow and processing behaviour of fluid food products. Journal of Texture Studies, v. 2, p. 393-418, 1971.

HOOVER, R. Composition, molecular structure, and physicochemical properties of tuber and root starches: a review. Carbohydrate Polymers, v. 45, p. 253-267, 2001.

HOOVER, R.; RATNAYAKE, W. S. Starch characteristics of black bean, chick pea, lentil, navy bean and pinto bean cultivars grown in Canada. Food Chemistry, Barking, v. 78, p. 489-498, 2002.

HOSENEY, R. C. Principles of Cereal Science and Technology. Cereal Chemistry, v.2, 1996.

ICGFI, Database of Food Irradiation Clearances, 1999. Disponível em: <http://www.iaea.org/icgfi> . Acesso em: 7 nov. 2015.

IONASHIRO, M. Fundamentos de Termogravimetria e Análise térmica Diferencial/Calorimetria Exploratória Diferencial. 1a edição. São Paulo: Giz, p. 80, 2005.

JACQUES, K.; LYONS, T. P.; KELSALL, D. R. The alcohol textbook. 3. ed. Nottingham: Nottingham Press, p.386, 1999.

JACQUIER, J. C. et al. Influence of granule size on the flow behavior of heated rice starch dispersions in excess water. Carbohydrate Polymers, v. 66, p. 425434, 2006. 
JAMES, M.G.; DENYER, K.; MYERS, A.M. Starch synthesis in the cereal endosperm. Current Opinion in Plant Biology, v.6, p.215-222, 2003.

JANE, J. Current understanding on starch granule structure. The Japanese Society of Applied Glycoscience, v. 53, n. 3, p. 205-213, 2006.

KARIM, A. A.; NORZIAH, M. H.; SEOW, C. C. Methods for the study of starchretrogradation. Food Chemistry, v. 71, p. 9-36, 2000.

KAUR, L.; SINGH, J.; MCCARTHY, O. J.; SINGH, H. Physicochemical, rheological and structural properties of fractionated potato starches. Journal of Food Engineering, v. 82, p. 383-394, 2007.

KECHICHIAN, V. Adição de ingredientes antimicrobianos em filmes biodegradáveis à base de fécula de mandioca. 2007. Dissertação (Mestrado em Engenharia Química) - Escola Politécnica, Universidade de São Paulo, São Paulo.

KILCAST, D. Effect of irradiation on vitamins. Food Chemistry, v.49, p.157-164, 1994.

KIZIL, R., IRUDAYARAJ, J., SEETHARAMAN, K., Characterization of irradiated starches by using FT-Raman and FTIR spectroscopy. Journal of Agriculture and Food Chemistry, v.50, p.3912-3918, 2002.

KONG, X. L. et al. Effect of gamma irradiation on the thermal and rheological properties of grain amaranth starch. Radiation Physics and Chemistry, v. 78, n. 11, p. 954-960, 2009.

KOSSMANN, J.; LLOYD, J. Understanding and influencing starch biochemistry. Critical Reviews in Plant Sciences, v. 19, n. 3, p. 171-226, 2000.

LAGARRIGUE, A.; ALVAREZ, G. The rheology of starch dispersions at high temperatures and high shear rates: a review. Journal of Food Engineering, $n$. 50, p. 189-202, 2001.

LAGUNAS-SOLAR, M. C. Radiation processing of foods: an overview of scientific principles and current status. Journal of food Protection, v.58, p. 186-192, 1995.

LEACH, H. W.; McDOWEN, L. D.; SCHOCH, T. J. Structure of the starch granule. I. Swelling and solubility patterns of various starches. Cereal Chemistry, v. 36, n. 6, p. 534-549, 1959.

LEE, J. et al. The effect of irradiation temperature on the non-enzymatic browing reaction in cooked rice. Radiation Physics and Chemistry, v. 76, n. 5, p. 886892, 2007. 
LEONEL, M., Análise da forma e tamanho de grânulos de amidos de diferentes fontes botânicas. Ciência e Tecnologia de Alimentos, v.27, p. 579-588, 2007.

LEONEL, M.; CEREDA, M. P. Caracterização físico-quimica de algumas tuberosas amiláceas. Ciência e Tecnologia de Alimentos, v.22, n.1, p.65-69, jan/abr.2002.

LEONEL, M.; MARTINS, J. C.; MISCHAN, M. M. Produção de snacks funcionais à base de farinha de soja e polvilho azedo. Ciência Rural, Santa Maria, v. 40, p. 1418-1423, 2010.

LEWANDOWICZA G.; SORAL-SMIETANA, M. Starch modification by iterated syneresis. Carbohydrate Polymers, v. 56, p. 403-413, 2004.

LIM, S.; JANE, J.L. RAJAGOPALAN, S.; SEIB, P.A. Effect of starch granule size on physical properties of starch-filled polyethylene film. Biotechnol. Prog, v.8, n.1, p.51-57, 1992.

LIMA FILHO, T. et al. Energia ionizante na conservação de alimentos: revisão. Boletim do Centro de Pesquisa de Processamento de Alimentos, Curitiba, v.30, n.2, p.243-254, 2012.

LINDEBOOM, N.; CHANG, P. R.; TYLER, R. T. Analytical, biochemical and physicochemical aspects of starch granule size, with emphasis on small granule starches: a review. Starch/Stärke, v. 56, n. 3-4, p. 89-99, 2004.

LIU, T. Y. et al. Modifications of structure and physicochemical properties of maize starch by gamma-irradiation treatments. Food Science and Technology, v. 46, n. 1, p. 156-163, 2012.

LOPES, W. A.; FASCIO, M. Esquema para interpretação de espectros de substâncias orgânicas na região do Infravermelho. Quim. Nova, v. 27, n. 4, p. 670-673, 2004.

LOURDIN, D.; DELLA VALLE, G.D.; COLONNA P. Influence of amylose content on starch films and foams. Carbohydrate Polymers, v.27, p.261-270, 1995.

MACARTHUR, L. A.; D'APPOLONIA, B. L. Gamma radiation of wheat. II. Effects of low dosage radiations on starch properties. Cereal Chemistry, v.61, p.321326, 1984.

MAEDA, K.C.; CEREDA, M.P. Avaliação de duas metodologias de expansão ao forno do polvilho azedo. Ciência e Tecnologia de Alimentos, v.21, n.2, p.139143, 2001.

MALI, S; GROSSMANN, M. V. E.; YAMASHITA, F. Starch films: production, properties and potential of utilization. Semina: Ciências Agrárias, Londrina, v. 
31, n. 1, p. 137- 156, 2010.

MARCON, M. J. A.; KURTZ, D J.; RAGUZZONI, J. C.; DELGADILLO, I.; MARASCHIN, M.; SOLDI, V.; REGINATTO, V.; AMANTE, E. R. Expansion properties of sour cassava starch. Variables related to its practical application in bakery. Starch/Stärke, v. 61, p. 716-726, 2009.

MARCOTTE, M.; HOSHAHILI, A. R. T.; RAMASWAMY, H. S. Rheological properties of selected hydrocolloids as a function of concentration and temperature. Food Research International, v. 34, p. 695-703, 2001.

MARTINEZ-BUSTOS, F.; AMAYA-LLANO, S. L.; CARBAJAL-ARTEAGA, J. A.; CHANG, Y. K.; ZAZUETA-MORALES, J. J. Physicochemical proprties of cassava, potato and jicama starche oxidised with organic acids. Journal of the Science of Food and Agriculture, v. 87, p. 1207-1214, 2007.

MASTRO, N. L. d. A radiação ionizante na promoção da alimentação adequada e saudável. Vigilância Sanitária em Debate: Sociedade, Ciência \& Tecnologia, v. 3, p. 114-121, 2015.

MASTRO, N. L. d. Role of irradiation treatment in the food industry. International Journal of Nuclear Governance, Economy and Ecology, v.3, p. 266-273, 2011.

MATOS, J. R.; MERCURI, L., BARROS, G. Análise térmica aplicada a fármacos e medicamentos. In:STORPIRTIS, S. et al. Biofarmacotécnica. Rio de Janeiro: Guanabara Koogan, v.4, p.32-65, 2009.

MATSUGUMA, L. S. Caracterização do amido de mandioquinha salsa (Arracacia xanthorrhiza) nativo e modificado por oxidação. 2006. Dissertação de Mestrado - Faculdade de Tecnologia de Alimentos - Universidade Estadual de Ponta Grossa, Ponta Grossa.

MCCLEMENTS, J. Food Biopolymers and Colloids Research Laboratory. University of Massachusetss Amherst. Disponivel em: <http://wwwunix.oit.umass.edu/ mcclemen/581Rheology.html. > Acesso em: 12/12/2015.

MCGUIRE, R. G. Reporting of objective color measurements. Horticultural Science, v. 27, n. 12, p. 1254-1255, 1992.

MENESES, J.; CORRALES, C.; VALENCIA, M. Síntesis y caracterización de un polímero biodegradable a partir del almidón de yuca. Revista EIA, n. 8, p.57-67, 2007.

MESTRES, C. Los estados físicos del almidón. In.:Conferencia Internacional del almidón. Quito. Anais...Quito, p. 2, 1996.

MOORE, G. R. P. Amido de milho e mandioca na produção de 
maltodextrinas. 2001. Dissertação (Mestrado em Ciências dos Alimentos), Universidade Federal de Santa Catarina.

MURPHY, P. In PHILLIPS, G.O e WILLIAMS, P. A. Handbook of hydrocolloids: Cap 3, Starch. New York: CRC Press LLC Corporate Blvd, 2000.

NABESHIMA, E. H.; EL-DASH, A. A. Modificação Química da Farinha de Arroz como Alternativa para o Aproveitamento dos Subprodutos do Beneficiamento do Arroz. Boletim do Centro de Pesquisa e Processamento de Alimentos, v.22, n.1, p.107-120, jan./jun. 2004.

NATIONAL STARCH AND CHEMICAL INDUSTRIAL Ltda. Divisão de Amidos Alimentícios. Tecnologia de amido alimentício, p.13, 1995.

NGUYEN, Q. D.; JENSEN, C. T. B.; KRISTENSEN, P. G. Experimental and modelling studies of the flow properties of maize and waxy maize starch pastes. Chemical Engineering Journal, v. 70, p. 165-171, 1998.

NIITTYLÄ, T.; MESSERLI, G.; TREVISAN, M.; CHEN, J.; SMITH, A. M.; ZEEMAN, S. C. A previously unknown maltose transporter essential for starch degradation in leaves. Science, v. 303, p. 87-89, 2004.

NURUL, M. I.; AZEMI, B. M. N. M.; MANAN, D. M. A. Rheological behaviour of sago (Metroxylon sagu) starch paste. Food chemistry, v. 64, p. 501-505, 1999.

OKECHUKWU, P. E.; RAO, M. A. Influence of granule size on viscosity of cornstarch suspension. Journal of Texture Studies, v.26, p.501-516, 1995.

PALMA, E. J.; CICHELLO, M. S. F.; PAVANELLI, A. P. Emulsificantes em panificação. Disponível em: $<$ http://www.oxiteno.com.br/aplicacoes/mercados/doc/documento.asp?artigotecnic $\mathrm{o}=1$ \&segmento=0100\&idioma=PO\&r=.pdf>. Acesso em: 03 fev. 2015.

PARK, Y. K.; BAR, W. H.; PAPINI, R. S. Relação entre entumescimento, gelatinização e suscetibilidade dos amidos de mandioca e milho a alfa-amilase bacteriana. Revista Brasileira de Tecnologia, v. 2, p. 95-99, 1971.

PARKER, R.; RING, S. G. Aspects of the physical chemistry of starch. Journal of Cereal Science, v. 34, n.1, p. 1-17, 2001.

PARRA, D. F.; TADINI, C. C.; PONCE, P.; LUGÃO, A. B. Mechanical properties and water vapor transmission in some blends of cassava starch edible films. Carbohydrate Polymers, v. 58, p. 475-481, 2004.

PASSOS, M. Valorização biotecnológica do hidrolisado fosfórico de amido de mandioca: produção de biomassa e astaxantina utilizando a levedura Xanthophyllomyces dendrorhous. 2002. Tese (Doutorado em Processos 
Biotecnológicos) - Universidade Federal do Paraná, Curitiba.

PELEGRINE, D. H., SILVA, F. C., GASPARETTO, C. A. Rheological behavior of pineapple and mango pulps. Food Science and Technology. v.35, p.645- 648, 2002.

PEREIRA, L. B. Caracterização de suspensões e géis de amido de amaranto: efeito da adição de sacarose e $\mathrm{NaCl}$ nas propriedades reológicas e térmicas. 2004. Dissertação (Mestrado em Engenharia de Alimentos), Universidade Estadual de Campinas. UNICAMP, Campinas, SP.

PERONI, F. H. G. Estrutura do grânulo de amido de banana e sua relação com as enzimas que atuam no metabolismo amido-sacarose. 2007. Tese de Doutorado - Faculdade de Ciências Farmacêuticas - Universidade de São Paulo, São Paulo.

POLESI, L. F. Propriedades físico-químicas, nutricionais e sensoriais de grãos e amido de arroz submetidos à radiação gama. 2014. Tese de Doutorado - Centro de Energia Nuclear, Universidade de São Paulo, Piracicaba.

RAKSHIT, S. K. Recent trends in cassava starch prodution and application. Tailândia. 2004. Disponível em: <http:// www.agfdt.de/loads/st00/raksit.pdf>

RAMASWAMY, H. S.; BASAK, S.; ABBATEMARCO, C.; SABLABI, S. S. Rheological properties of gelatinized starch solutions as influenced by thermal processing in an agitating retort. Journal of Food Engineering, v.25, p. 441-454, 1995.

RAO, M. A.; COOLEY, H. J. Applicability of flow models with yield for tomato concentrates. Journal of Food Process Engineering, v. 6, n. 3, p. 159-173, 1982.

RAO, M. A.; RIZVI, S. S. Engineering properties of foods, New York, Marcel Dekker, 1986.

RAO, M. A.; TATTIYAKUL, J. Granule size and rheological behavior of heated tapioca starch dispersions. Carbohydrate Polymers, v. 38, p. 123-132, 1999.

RICKARD, J. E.; ASAOKA, M.; BLANSHARD, J. M. V. The physicochemical properties of cassava starch. Tropical Science, v. 31, p. 189-207, 1991.

RILEY, C. K.; WHEATLEY, A. O.; ASEMOTA, H. N. Isolation and characterization of starches from eight Dioscorea alata cultivars grown in Jamaica. African Journal of Biotechnology, v. 5, n.1 7, p. 1528-1536, 2006. 
ROBIN, J. P.; MERCIER, C.; CHARBONNIERE, R.; GUILBOT, A. Litnerized starches gel filtartion and enzimatic studies of insoluble residues from prolonged acid treatment of potato starch. Cereal Chemistry, v.51, p.389-405, 1974.

ROCHA, S. T.; DEMIATE, M. I., FRANCO, L. C. M. Características estruturais e físico- químicas de amidos de mandioquinha-salsa (Arracacia xanthorrhiza). Ciência e Tecnologia de Alimentos, v. 28, n. 3, p. 620-628, 2008.

ROY, M. K.; GHOSH, S. K.; CHATTERJEE, S. R. Gamma - irradiation of rice grains. Journal of Food Science and Technology, v. 28, n. 6, p. 337-340, 1991.

SALGADO, S.M.; GUERRA, N.B.; ANDRADE, S.A.C.; LIVERA, A.V.S. Caracterização físico-química do grânulo do feijão caupí. Ciência e Tecnologia de Alimentos, v.25, n.3, p.525-530, 2005.

SANDHU, K. S.; SINGH, N.; LIM, S. T. A comparison of native and acid thinned normal and waxy corn starches: Physicochemical, thermal, morphological and pasting properties. Lebensmittel-Wissenschaft \& Techonologie, v.40, p.15271536, 2007.

SCHARAMM, G. A pratical approach to rheology and rheometry. $2^{a}$ edição, Karlsruhe, Alemanha, 2000.

SCHMITZ, C. S.; SIMAS, K. N., SANTOS, K.; JOÃO, J. J., AMBONI, R. D. M. C.; AMANTE, E. R. Cassava starch functional properties by etherification hydroxypropylation. International Journal of Food Science and Technology, v. 41, p. 681-687, 2006.

SELF, K. P.; WILKINS, T. J.; MORLEY, M. J.; BAILEY, C. Rheological and heat transfer characteristics of starch-water suspensions during cooking. Journal of Food Engineering, v. 11. p. 291-316, 1990.

SHARMA, S. K.; MULVANEY, S.J.; RIZVI, S. S. H. Food processing engineering theory and laboratory experiments. United States of America: Wiley-Interscience, p. 348, 2000.

SILVA, A. L. F.; ROZA, C. R. Uso da irradiação em alimentos: revisão. Boletim do Centro de Pesquisa de Processamento de Alimentos, Curitiba, v.28, n.1, p.40-56, 2010.

SILVA, C. C. D. Estudo das propriedades óticas, elétricas e térmicas da hidroxiapatita obtida por moagem de alta energia, seus compósitos e filmes espessos. 2003. Departamento de Química orgânica e inorgânica, Universidade Federal do Ceará, Fortaleza. 
SILVA, E. E.; DE-POLLI, H.; GUERRA, J. G . M.; AZEVEDO, P. H. S.; TEIXEIRA, M. G.; ESPINDOLA, J. A. A.; ALMEIDA, M. M. T. B. Consórcio de inhame (taro) ecrotalário em sistema orgânico de produção. Embrapa Agrobiologia, 2006.

SILVERSTEIN, R. M., BASSLER, G. C., MORRILL, T. C.; Spectrometric identification of organic compounds, v.5, 1991.

SINGH, J.; KAUR, L.; MCCARTHY, O. J. Factors influencing the physicochemical, morphological, thermal and rheological properties of some chemically modified starches for food applications-A review. Food Hydrocolloids, v. 21, p. 1-22, 2007.

SINGH, N.; SINGH, J.; KAUR, L.; SODHI, N. S.; GILL, B. S. Morphological, thermal and rheological properties of starches from different botanical sources. Food Chemistry, v. 81, n. 2, p. 219-231, 2003.

SINGH, R. P.; HELDMAN, D. R. Introduction to food engineering. Academic Press, San Diego, 1993.

SINGH, S. et al. Effects of gamma-irradiation on the morphological, structural, thermal and rheological properties of potato starches. Carbohydrate Polymers, v. 83, n. 4, p. 1521-1528, 2011.

SIRISOONTARALAK, P.; NOOMHORM, A. Changes to physicochemical properties and aroma of irradiated rice. Journal of Stored Products Research, v.42, n.3, p.264-276, 2006.

SKELLAND, A. H. P. Non-Newtonian Flow and Heat Transfer. Journal of Fluid Mechanics, v.32, 1967.

SMITH, A. M.; DENYER, K.; MARTIN, C. The synthesis of the starch granule. Annual Review of Plant Physiology and Plant Molecular Biology, v. 48, p. 6787, 1997.

SOARES, R. M. D. Caracterização parcial de amido em cultivares brasileiros de cevada (Hordeum vulgare L.). 2003. Dissertação (Mestrado em Ciências de Alimentos), Universidade Federal de Santa Catarina, Florianópolis, Santa Catarina.

SOUZA, A. C. Desenvolvimento de embalagem biodegradável ativa a base de fécula de mandioca e agentes antimicrobianos naturais. 2011. Tese (Doutorado em Engenharia Química) - Escola Politécnica, Universidade de São Paulo, São Paulo.

SOUZA, A. C.; DITCHFIELD, C.; TADINI, C. C. Biodegradable films based on biopolymers for food industries. In M. L. Passos, \& C. P. Ribeiro (Eds), Innovation 
in Food Engineering: New techniques and products, Boca Raton, FL: CRC Press, p. 511-537, 2010.

SOUZA, A. S. Efeitos da irradiação na composição e propriedades funcionais da soja. 2006. Tese (Doutorado em Alimentos e Nutrição) - Universidade Estadual de Campinas, Faculdade de Engenharia de Alimentos, Campinas.

SRIROTH, K.; SANTISOPASRI, V.; PETCHALANUWAT, C.; KUROTJANAWONG, K.; PIYACHOMKWAN, K.; OATES, C.G. Cassava starch granule structurefunction properties: influence of time and conditions at harvest on four cultivars of cassava starch. Carbohydrate Polymers, v.38, p. 161-170,1999.

STEFFE, J. F. Rheological Methods in Food Process Engineering. 2a Edição. Freeman Press, East Lansing, Michigan State, USA, p. 418, 1996.

SWINKELS, J. J. M. Composition and properties of commercial and native starches. Starch/Stärke, n. 37, p.1-5, 1985.

TESTER, R. F. Starch: The polysaccharide fractions. In: FRAZIER, P. J.; RICHMOND, P.; DONALD, A. M. Starch: Structure and Functionality. London: Royal Society of Chemistry, p. 163-171, 1997.

TESTER, R. F.; KARKALAS, J.; QI, X. Review. Starch-composition, fine structure and architecture. Journal of Cereal Science, v. 39, p. 151-165, 2004.

THARANATHAN, R. N., Food-derived carbohydrates: Structural complexity and functional diversity. Critical Reviews in Biotechnology, v.22, p. 65-84, 2002.

THEBAUDIN, J. Y.; LEFEBVRE, A. C.; DOUBLIER, J. L. Rheology of starch pastes from starches of different origins: applications to starch-based sauces. Lebensmittel-Wissenschaft und-Technologie, v. 31, p. 354-360, 1998.

URBAIN, W. M. Food Irradiation, Food Science and Technology Monographs, Academic Press Inc., p.246, 1986.

VAN SOEST, J. J. G.; ESSER, P. Influence of amylose-amylopectin ratio on properties of extruded starch plastics sheets. Journal of Macromolecular Science. Part A, v. 34, p. 1665-1689, 1997.

VEIGA-SANTOS, P. Elaboração, aditivação e caracterização de biofilmes à base de fécula de mandioca. 2004. Tese (Doutorado em Engenharia de Alimentos) - Faculdade de engenharia de Alimentos, Universidade Estadual de Campinas, Campinas.

VEIGA-SANTOS, P., OlIVEIRA, L. M.; CEREDA, M. P., ALVES, A. J.; SCAMPARINI, A. R. P. Mechanical properties, hydrophilicity and water activity of starch-gum films: Effect of additives and deacetylated xanthan gum. Food 
Hydrocolloids, v. 19, p. 341- 349, 2005.

VEIGA-SANTOS, P.; DITCHFIELD, C.; TADINI, C. C. Development and evaluation of a novel $\mathrm{pH}$ indicator biodegradable film based on cassava starch. Journal of Applied Polymer Science,v. 120, p. 1069-1079, 2011.

VIEIRA Jr., A. Alfa e beta-amilase no metabolismo do amido durante o amdurecimento da banana: clonagem, expressão e caracterização molecular. 2006. Tese de Doutorado - Faculdade de Ciências Farmacêuticas Universidade de São Paulo, São Paulo.

VIEIRA, F. Efeito do tratamento com calor e baixa umidade sobre características físicas e funcionais dos amidos de mandioquinha-salsa (Arracacia xanthorrhiza), de batata-doce (Ipomoe batatas) e de gengibre (Zinziber officinale). 2004. Dissertação (Mestrado em Ciência de Alimentos) Escola Superior de Agricultura Luiz de Queiroz, Piracicaba, 2004.

VILELA, E.R.; FERREIRA, M.G. Tecnologia de produção e industrialização do amido de mandioca. Informe Agropecuário. Belo Horizonte, v.13, n.145, p.6973, 1987.

VOSS, D. H. Relating colorimeter measure-ment of plant color to the Royal Horticultural Society colour chart. HortSci., v.27, p.1256-1260, 1992.

WANG, L. Z.; WHITE, P. J. Structure and physicochemical properties of starches form oats with different lipid content. Cereal Chemistry, v. 71, n. 5, p. 443-450, 1994a.

WANG, L. Z.; WHITE, P. J. Structure and properties of amylose, amilopectin and intermediate materials of oat starches. Cereal Chemistry, v. 71, p. 263-460, 1994b.

WANG, S.; YU, J.; ZHU, Q.; YU, J.; JIN, F. Granular structure and allomorph position in C-type Chinese yam starch granule revealed by SEM, 13C CP/MAS NMR and XRD. Food Hydrocolloids, v. 23, p. 426-433, 2009.

WANG, T.L.; BOGRACHEVA, T.Y.; HEDLEY, C.L. Starch: as simple as A, B, C. Journal of Experimental Botany, v.49, n.320, p.481-502, 1998.

WHISTER, R. L.; BEMILLER, J. N. Starch. Carbohydrate Chemistry for Food Scientists. Saint Paul: AACC, Eagan Press, p. 117-151,1997.

WIENDL, F. M. A salubridade dos alimentos irradiados. Boletim da Sociedade Brasileira de Ciência e Tecnologia de Alimentos, Campinas, v. 18, n. 1, p. 4856, 1984. 
WORCMAN-BARNINKA, D.; LANGRAF, M. Irradiação de carnes. Boletim da SBCTA, Campinas, v.1, n.37, p.22-27, 2003.

WURZBURG, O. B. Crosslinking starches. In: Wurzburg, O. B. Modified starches: properties and uses. Boca Raton: CRC Press, p. 41-53, 1986.

XU, Z.; RAPHAELIDES, S. N. Flow behavior of concentrated starch dispersions using a tube rheometer of novel design. Journal of Texture Studies, v. 29, p. 113, 1998.

YOON, H. S. et al. In vitro digestibility of gamma-irradiated corn starches. Carbohydrate Polymers, v. 81, n. 4, p. 961-963, 2010.

YU, L.; CHRISTIE, G. Measurement of starch thermal transitions using differential scanning calorimetry. Carbohydarte Polymers. V.46, p.176-184. 2001.

YU, Y.; WANG, J. Effect of gamma-ray irradiation on starch granule structure and physicochemical properties of rice. Food Research International, v. 40, n. 2, p. 297-303, 2007.

ZAMORA, A. Carbohydrates - Chemical Structure, 2010. Disponível em: $<$ http://www.scientificpsychic.com/fitness/carbohydrates2.html> .Acesso em: 29 jan. 2016.

ZANÃO, C. F. P. Características físico-químicas e sensoriais do arroz (Oryza sativa) irradiado e o efeito no desenvolvimento de Sitophilus oryzare $L$. 2007. Dissertação de Mestrado - Centro de Energia Nuclear, Universidade de São Paulo, Piracicaba.

ZEEMAN, S. C.; SMITH, S. M.; SMITH, A. M. Tansley review: the breakdown of starch in leaves. New Phytologist, v. 163, p. 247-261, 2004. 